\title{
FROM FIRST WORDS TO GRAMMAR IN CHILDREN WITH FOCAL BRAIN INJURY
}

\author{
Elizabeth Bates \\ University of California, San Diego \\ Donna Thal \\ San Diego State University \\ Doris Trauner \\ University of California, San Diego \\ Judi Fenson \\ Children's Hospital \& Research Center, San Diego \\ Dorothy Aram \\ Emerson College \\ Julie Eisele \\ Skidmore College \\ Ruth Nass \\ New York University Medical Center
}

In D. Thal \& J. Reilly (Eds.), Special issue on Origins of Language Disorders.

Developmental Neuropsychology, 1997, 13, 275-343.

This research was supported by NIH/NIDCD Program Project P50 DC01289-0351 "Origins of communicative disorders" to Elizabeth Bates, and by a grant from the John D. and Catherine T. MacArthur Foundation. We are grateful to Larry Juarez and Meiti Opie for assistance in manuscript preparation. 


\begin{abstract}
The effects of focal brain injury are investigated in the first stages of language development, during the passage from first words to grammar. Parent report and/or free speech data are reported for 53 infants and preschool children between 10 - 44 months of age. All children had suffered a single, unilateral brain injury to the left or right hemisphere, incurred before six months of age (usually in the pre- or perinatal period). This is the period in which we should expect to see maximal plasticity, but it is also the period in which the initial specializations of particular cortical regions ought to be most evident. In direct contradiction of hypotheses based on the adult aphasia literature, results from 10 - 17 months suggest that children with righthemisphere injuries are at greater risk for delays in word comprehension, and in the gestures that normally precede and accompany language onset. Although there were no differences between left- vs. right-hemisphere injury per se on expressive language, children whose lesions include the left temporal lobe did show significantly greater delays in expressive vocabulary and grammar throughout the period from 10 - 44 months. There were no specific deficits associated with left frontal damage, but there was a significant effect of frontal lobe injury to either hemisphere in the period from 16 - 31 months, when normal children usually show a burst in vocabulary and grammar. This bilateral effect of frontal damage is independent of motor impairment. Hence there are specific effects of lesion site in early language development, but they are not consistent with the lesion-syndrome correlations observed in adults with homologous injuries, nor with the literature on acquired lesions in older children. Results are used to argue against innate localization of linguistic representations, and in favor of an alternative view in which innate regional biases in style of information processing lead to familiar patterns of brain organization for language under normal conditions, while permitting alternative patterns to emerge in children with focal brain injury.
\end{abstract}




\section{FROM FIRST WORDS TO GRAMMAR IN CHILDREN WITH FOCAL BRAIN INJURY}

In 1861, Paul Broca described a case of nonfluent aphasia with preserved comprehension, associated with damage to a region of left frontal cortex that now bears Broca's name. By 1874, Carl Wernicke had described a very different form of aphasia, a severe comprehension deficit with preserved fluency and melodic line (albeit with clear impairment of word retrieval). This syndrome was associated with damage to the posterior portion of the left temporal lobe, a region now referred to as Wernicke's area. The reliability and significance of these two complementary lesion-syndrome mappings have been called into question many times (Freud 1891/1953; Goldstein, 1948; Head, 1963; Marie, 1906; Mohr et al., 1978), including recent studies using in vivo brain imaging which show that the classic lesion-syndrome correlations are violated at least $20 \%$ of the time (Basso, Capitani, Laiacona, \& Luzzatti, 1980; Bates, Appelbaum, \& Allard, 1991; Dronkers, Shapiro, Redfern, \& Knight, 1992; Willmes \& Poeck, 1993). Nevertheless, there is still broad consensus on four points.

(1) The left hemisphere is specialized for language in over 95\% of normal adults (Bryden, 1982; Damasio, 1992; Galaburda, 1994; Gazzaniga, 1994; Hellige, 1993).

(2) The perisylvian regions of the left hemisphere are particularly important for language (Damasio, 1989; Damasio \& Damasio, 1992; Geschwind, 1972; Rasmussen \& Milner, 1977), although they are not the only relevant areas (Ojemann, 1991).

(3) The contrasting syndromes described by Broca and Wernicke are robust findings across natural languages (Bates \& Wulfeck, 1989; Menn \& Obler, 1990).

(4) These syndromes are reliably albeit imperfectly correlated with anterior vs. posterior lesion sites along the Sylvian fissure (Damasio, 1992; Goodglass, 1993; Naeser, Helm-Estabrooks, Haas, Auerbach, \& Levine, 1984)

Given these findings in adults, it is not unreasonable to assume that the left hemisphere must be innately specialized for language, with privileged roles for the perisylvian areas that are implicated in the major forms of aphasia. On these grounds, one would expect to find forms of language impairment in small children with unilateral brain injury that are grossly analogous to the major categories of aphasia in adults, an expectation that can be framed in terms of three hypotheses. 
(1) The left-specialization hypothesis predicts more severe language impairments overall in children with injuries to the left hemisphere.

(2) The Broca hypothesis predicts more severe deficits in language production among children with damage to the anterior regions of the left hemisphere (in particular, the perisylvian area of the left frontal lobe).

(3) The Wernicke hypothesis predicts more severe deficits in language comprehension in children with damage to the posterior regions of the left hemisphere (in particular, the posterior portion of the left temporal lobe).

Although these adult-based hypotheses form a reasonable starting point for developmental research, they are largely unsupported by the literature on language development in children with focal brain injury (Alajouanine \& Lhermitte, 1965; Almli \& Finger, 1984; Annet, 1973; Aram, 1988, 1992; Aram, Ekelman, \& Whitaker, 1985, 1986; Aram, Meyers, \& Ekelman, 1990; Bishop, 1981, 1983, 1992; Day \& Ulatowska, 1979; Fletcher, 1993; Hammill \& Irwin, 1966; Hecaen, 1976, 1983; Hecaen, Pernin, \& Jeannerod, 1984; Isaacson, 1975; Janowsky \& Finlay, 1983; Kohn, 1980; Kohn \& Dennis, 1974; Marchman, Miller, \& Bates, 1991; Reed \& Reitan, 1969; Reilly, Bates, \& Marchman, in press; Riva \& Cazzaniga, 1986; Riva, Cazzaniga, Pantaleoni, Milani, \& Fedrizzi, 1986; Smith, 1984; Stiles \& Thal, 1993; Thal et al., 1991; Trauner, Chase, Walker, \& Wulfeck, 1993; Vargha-Khadem, Isaacs, Papaleloudi, Polkey \& Wilson, 1991; Vargha-Khadem, Isaacs, Van Der Werf, Robb, \& Wilson, 1992; Vargha-Khadem, O'Gorman, \& Watters, 1985; Vargha-Khadem \& Polkey, 1992; Woods, 1980; Woods \& Carey, 1979; Woods \& Teuber, 1978; Wulfeck, Trauner, \& Tallal, 1991; for another view, see St. James-Roberts, 1979).

The first and most important challenge lies in the fact that most children with early unilateral brain injury go on to achieve levels of language performance that are within the normal range. This does not mean that early brain damage has no effect on language outcomes. However, the impairments that are observed in children with this neurological history are more subtle and less persistent than the outcomes observed in adults with homologous injuries (for reviews, see Eisele \& Aram, 1995; Fletcher, 1993; Riva, Milani, Pantaleoni, Devoti, \& Zorzi, 1992; Satz, Strauss, \& Whitaker, 1990; Stiles, 1995; Stiles \& Thal, 1993; Vargha-Khadem \& Polkey, 1992), and many children show no impairments at all (Dall'Oglio, Bates, Volterra, DiCapua, \& Pezzini, in press; Feldman, Holland, Kemp, \& Janosky, 1992; Vargha-Khadem et al., 1991). Results vary from one study to another, depending on the measures used, the age range of interest, and the inclusionary and exclusionary criteria adopted in the study (e.g., age of 
lesion onset, etiology, presence/absence of children with seizures or seizure medication). In some studies, there are no significant differences of any kind between the focal-lesion population and normal controls. In other studies, children with focal brain injury score significantly lower as a group on a number of different language and cognitive measures, compared with controls matched for age, sex and social class (i.e., brain damage often does exact a cost). However, one conclusion is clear across all these studies: Children with a history of early focal brain injury rarely meet the criteria required for a diagnosis of aphasia.

The second finding has been the absence of a clear-cut difference between children with left- vs. right-hemisphere injury. To be sure, some studies do report differences in the predicted direction, especially for expressive language, and/or for tasks that involve subtle morphosyntactic contrasts (e.g., Aram et al., 1985, 1986, 1987, 1990; Dennis, 1980, 1988; Dennis \& Kohn, 1975; Dennis, Lovett, \& Wiegel-Crump, 1981; Dennis \& Whitaker, 1976, 1977; but see Bishop, 1983). However, these left-hemisphere findings are often complicated by other factors. For example, Aram and Eisele have suggested that damage to anterior subcortical structures may be the strongest predictor of residual language and cognitive deficits in both LHand RH-lesioned children. However, a small group of LH children with anterior subcortical damage do present with more language-specific deficits than RH children with comparable damage (Aram \& Eisele, 1994a\&b; Aram, Rose, Rekate, \& Whitaker, 1983; Eisele \& Aram, 1995; Eisele, Alexander, \& Aram, in preparation). Reilly, Marchman, \& Bates (in press) report a small but reliable LH disadvantage in production of complex syntax for children under age 5, but no effects of lesion site whatsoever in children after age 5-even though all the children in their study had the same etiology (i.e., lesion onset prior to 6 months of age). The issue is complicated even further by occasional findings in the opposite direction, i.e., a significant disadvantage for children with RH damage on some receptive language tasks (Eisele \& Aram, 1993, 1994; Thal et al., 1991; Trauner et al., 1993; Wulfeck, Trauner, \& Tallal, 1991).

The next finding is perhaps less surprising, once one has digested the ambiguous results obtained for LH vs. RH damage. That is, even in those cases where a left-right difference has been reported, there is little evidence in favor of site-specific effects within the left hemisphere (Eisele \& Aram, 1995; Riva \& Cazzaniga, 1986). Indeed, Thal et al. (1991) report effects that run directly counter to the Broca hypothesis, with more severe and protracted delays in early word production in children with left posterior damage. Putting this result together with the finding that comprehension deficits appear to be more likely in children with RH damage (a disconfirmation of the Wernicke hypothesis), Thal et al. conclude that it may be a mistake to expect the developing brain to yield brain-behavior correlations similar to those that are observed in the adult, because the processes involved in language acquisition are quite different 
from processes required for fluent and efficient language use in a mature adult native speaker ("The regions that mediate language learning are not necessarily the same regions that mediate maintenance and use of language in the adult"). A similar proposal has been offered by Petersen, Fiez, \& Corbetta (1992), who suggest that localization of function in adults may reflect the developmental status of a behavior (i.e., novice vs. expert, or controlled vs. automatic) instead of domain-specific content (see also Raichle, 1994).

Earlier reports on recovery of language in children with focal brain injury led some investigators to conclude that the two hemispheres are initially equipotential for language (Lashley, 1950, 1951; Lenneberg, 1967; for some related comments, see Caplan \& Hildebrandt, 1988; Kennard, 1936). On this view, the familiar pattern of left-hemisphere specialization does not emerge until some point after language has been acquired. Indeed, Lenneberg went so far as to suggest that the acquisition of language may be the cause rather than the effect of lateralization. Most modern investigators dispute this claim, because there is at least some evidence for early differences in lateralization, and for early left-hemisphere specialization for speech stimuli. Such evidence includes those studies that do show a disadvantage for children with LH damage (cited above), but it also includes neuroanatomical studies demonstrating structural differences between the left and right hemisphere at birth and/or in the first years of language learning, with special reference to perisylvian cortex (Geschwind \& Levitsky, 1968; Witelson \& Kigar, 1988), together with electrophysiological studies suggesting differential response of the left hemisphere to speech sounds in normal infants (Molfese, 1989, 1990; Molfese \& Segalowitz, 1988).

In our view, the best argument for early left-hemisphere specialization is a logical one, based on findings from adults. Simply put, there has to be something special about left perisylvian tissue that makes it particularly well suited for language learning and language use. If this were not the case, there would be no explanation for the huge bias toward left-hemisphere mediation observed in $95 \%$ of normal adults. But what is that "something"? How direct is the relationship between the initial predispositions of the left hemisphere, and the classic form of brain organization for language that is so often observed in adults?

In a recent book called Rethinking innateness: Development in a connectionist perspective (Elman et al., in press), the authors propose three different levels at which it would be fair to say that a given function is "innate", or at least, "innately predisposed". Let us consider each of these three options in turn, with reference to the role of the left hemisphere in early language learning. 
(1) Innate representations. Although strong proponents of nativism within linguistics and psycholinguistics are rarely explicit about the level at which innate ideas are implemented in the brain, the usual argument has been that children are born with innate knowledge about basic principles of language in general, and grammar in particular (Crain, 1992; Lightfoot, 1991; Pinker 1991, 1994a\&b). To be sure, this knowledge will be shaped by experience to some extent (perhaps in the form of "triggering" or "selecting" among predetermined options-PiatelliPalmarini, 1989), and some maturation may have to take place before the innate knowledge can be used (Borer \& Wexler, 1987; Spelke, Breinlinger, Macomber, \& Jacobson, 1992). However, most of these investigators have been clear in their belief that children are born with domainspecific representations laid out somewhere in the brain.

The most likely neural implementation for such innate knowledge would have to be in the form of fine-grained patterns of synaptic connectivity at the cortical level (i.e., cortical microcircuitry). To the best of our knowledge at the present time, this is how the brain stores its representations, whether they are innate or acquired. In this regard, Pinker (1994b) suggests that the "language instinct" is indeed based upon detailed microcircuitry, and that the same is probably true for many other cognitive processes:

"It is a certain wiring of the microcircuitry that is essential......If language, the quintessential higher cognitive process, is an instinct, maybe the rest of cognition is a bunch of instincts too-complex circuits designed by natural selection, each dedicated to solving a particular family of computational problems posed by the ways of life we adopted millions of years ago” (pp. 93, 97).

If this is the claim with regard to left-hemisphere specialization for language, then it would mean that the left hemisphere starts with representations that are not present in the right. To explain the fact that children who have lost these areas go on to achieve language abilities in the normal range, one would have to conclude that (a) partial representations were also available in the right, sufficient to support compensatory language learning, or (b) no representations are innately present in the right hemisphere, but that hemisphere can acquire representations "from scratch" that are adequate for language even though they are not optimal. In either case, it seems that these innate left-hemisphere representations are not necessary for normal language development to take place-which raises interesting questions about how they might have evolved in the first place.

In fact, evidence has been mounting against the notion of innate microcircuitry as a viable account of cortical development (i.e., against representational nativism). In a number of 
recent studies with vertebrate animals, investigators have changed the nature of the input received by a specific area of cortex, either by transplanting plugs of fetal cortex from one area to another (e.g., somatosensory to visual, or vice-versa-O'Leary, 1993; O'Leary \& Stanfield, 1989 ), by radically altering the nature of the input by deforming the sensory surface (Friedlander, Martin, \& Wassenhove-McCarthy, 1991; Killackey, Chiai, Bennett-Clarke, Eck, \& Rhoades, 1994), or by redirecting inputs from their intended target to an unexpected area (e.g., redirecting visual inputs to auditory cortex-Frost, 1982, 1990; Pallas \& Sur, 1993; Roe, Pallas, Hahm, \& Sur, 1990; Sur, Garraghty, \& Roe, 1988; Sur, Pallas, \& Roe, 1990; see also Molnar \& Blakemore, 1991). Surprisingly, under these aberrant conditions it is clear that fetal cortex takes on neuroanatomical and physiological properties that are appropriate for the information it receives ("When in Rome, do as the Romans do...."), and quite different from the properties that would have emerged if the default inputs had occurred. This suggests that cortex has far more representational plasticity than previously believed. Indeed, recent studies have shown that cortex retains representational plasticity into adulthood (e.g., radical "remapping" of somatosensory cortex after amputation, in humans and in infrahuman primates-Merzenich, Recanzoni, Jenkins, Allard, \& Nudo, 1988; Pons et al., 1991; Ramachandran, 1993; see also Greenough, Black, \& Wallace, 1993; Greenough, McDonald, Parnisari, \& Camel, 1986). Although one cannot entirely rule out the possibility that neurons are born "knowing" what kinds of representations they are destined to take on, the case for innate representations does not look very good right now. As Elman et al. note, this means we have to search for other ways that genes might operate to insure species-specific forms of brain organization.

(2) Innate architectures. Although it now seems unlikely that regions of cortex contain detailed, innate representations, this does not mean that "all cortex is created equal". Regions can vary along a number of structural and functional parameters that have important implications for the kinds of computations they are able to carry out, and (by extension) for the kinds of representations they are likely to take on. Elman et al. describe constraints at this level under "architectural innateness." To operationalize architectural constraints in real brains and in neural nets, they break things down further into three sublevels:

A. Basic computing units. In real brains, this sublevel refers to neuronal types, their firing thresholds, neurotransmitters, excitatory/inhibitory properties, etc. In neural networks, it refers to computing elements with their activation function, learning algorithm, temperature, momentum and learning rate, etc.

B. Local architecture. In real brains, this sublevel refers to regional factors like the number and thickness of layers, density of different cell types within layers, type of 
neural circuitry (e.g., with or without recurrence). In neural networks, it refers to factors like the number of layers, density of units within layers, presence/absence of recurrent feedback units, and so forth.

C. Global architecture. In real brains, this sublevel includes gross architectural facts like the characteristic sources of input (afferent pathways) and patterns of output (efferent pathways) that connect brain regions to the outside world and to one another. In many neural network models, the size of the system is so small that the distinction between local and global architecture is not useful. However, in so-called modular networks or expert networks, it is often useful to talk about distinct subnets and their interconnectivity.

If we assume that the brain is an enormous and highly differentiated neural network, with many parts of the system activated in parallel, then it is reasonable to assume that development is based in part on a process of competition among regions with somewhat different architectures (Changeux, Courrège, \& Danchin, 1973; Changeux \& Danchin, 1976; Churchland \& Sejnowski, 1992; Edelman, 1987; Killackey, 1990). Through this competitive process, regions of the brain attract those inputs that they handle particularly well, and they are recruited for those tasks that require a particular form of computation (not unlike the process by which tall and agile children are recruited to play basketball). In a bidirectional cycle of cause-and-effect, each region goes on to form representations that are particularly well suited for the tasks that they do best (through additive processes of synaptic growth and strengthening of existing connections, and through subtractive processes of synaptic pruning and cell loss-for a review, see Bates, Thal, \& Janowsky, 1992). As a result, the suitability of specific regions for specific tasks will increase over time, above and beyond the predispositions that permitted them to "win" in the first place. In this way, an initial architectural bias can result in regional specialization at the representational level.

There are now several simulations of brain development in artificial neural networks that provide support for the idea that representational specializations emerge through experience in systems that differ only in their initial computational properties. One example (Jacobs, Jordan, Nowlan, \& Hinton, 1991; Jacobs \& Kosslyn, 1994) involves the development of two distinct visual systems, one for object recognition and another for motion detection, out of two subnetworks that initially differed only in their mode of processing. In other words, one of the best-known examples of modularity in brain organization for higher cognitive functions (in this case, object recognition and spatial analysis) can be demonstrated in systems with relatively minimal innate predispositions (see also Hazeltine \& Ivry, 1994). 
As Freud (1891/1953) and Wernicke (1874) argued many years ago, innate constraints on input and output can also play a major role in brain organization for language. Specifically, perisylvian cortex may be destined to play a special role in language because of its proximity to the basic input and output systems of speech (i.e., primary auditory cortex; cortical and subcortical speech-motor output systems). If this is the case, then we might expect to find a different pattern of intrahemispheric specialization in visual-manual languages like American Sign Language - an idea that does have some support (Bellugi \& Hickok, 1995; Klima, Kritchevsky, \& Hickok, 1993; Poizner, Klima, \& Bellugi, 1987). Under this argument, it should also be possible for regions farther away from the privileged perisylvian zones to take over after localized brain injury, if (and only if) they have access to the relevant information. The fact that so many children with perisylvian injuries eventually develop normal or near-normal language provides prima facie support for a process of this kind (for clear evidence of "long distance" reorganization in infant monkeys with lesions to specific areas of visual cortex, see Webster, Bachevalier, \& Ungerleider, 1995).

Although the input-output argument can help to explain intrahemispheric organization for language, it does little to explain why the perisylvian areas of the left hemisphere play a more important role than the perisylvian areas of the right. Presumably, these two areas are receiving the same kind of information, from the speech signal and from the world to which that signal refers. To explain the asymmetry of human language processing, we need to invoke some combination of input-output constraints and innate differences between the left and right hemispheres in local architecture. Together, these initial biases may set in motion a gradual "modularization" process, built upon innate predispositions that are only indirectly related to the full form of brain organization for language observed in the adult (see also Karmiloff-Smith, 1992). An approach of this kind could explain why it is that the left hemisphere "wins" a primary role in mediation of language in $95 \%$ of normal adults. At the same time, it is compatible with the fact that children with focal brain injury can develop alternative forms of brain organization for language at surprisingly little cost if the default systems are damaged in some way. However, this still leaves a number of unanswered questions about timing, and temporal constraints on cortical plasticity—which brings us to the final point.

(3) Innate scheduling. Elman et al. underscore the role of timing in all aspects of development (cf. Gould, 1977), with particular reference to the role that genes play in turning systems on and off at different points in the life span. In addition to the computational biases described above, variations in timing can also play a role in the specialization of cortical regions for particular cognitive functions-what Elman et al. refer to as "chronotopic constraints" (see also Molnar \& Blakemore, 1991). For example, regions of cortex may be recruited into a 
particular task (and develop subsequent specializations for that task) simply because they are ready at the right time. Conversely, other areas of the brain may lose their ability to perform that task because they developed too late (i.e., after the job is filled). Differential rates of maturation have been invoked to explain the left-hemisphere bias for language under default conditions (Annett, 1973, 1985; Corballis \& Morgan, 1978; Courchesne, Townsend, \& Chase, in press; Kinsbourne \& Hiscock, 1983; Parmelee \& Sigman, 1983; Simonds \& Scheibel, 1989). For example, it has been suggested that the left hemisphere matures more slowly than the right in the first year of life, which could help to explain why the right hemisphere plays a more important role in visual-spatial functions that begin to develop at birth, while the left hemisphere takes a greater role in linguistic functions that start to develop many weeks or months after birth. The chronotopic argument may also be related to the subcortical findings reported by Aram, Rose, Rekate, \& Whitaker (1983; see also Eisele, Alexander, \& Aram, in preparation). That is, damage to certain subcortical structures may be more devastating in the early stages of language development (before cortical organization is established), compared with homologous subcortical injuries in the adult (after cortical organization for language is complete).

Genetic timing has also been invoked to explain critical-period effects in language learning (Johnson \& Newport, 1989; Krashen, 1973; Lenneberg, 1967; Locke, 1993). However, there are at least two versions of the critical-period hypothesis that need to be considered here, one that requires an extrinsic genetic signal and another that does not (Marchman, 1993; see also Oyama, 1992). On the "hard" maturational account, plasticity comes to an end because of some explicit and genetically determined change in learning capacity (e.g., a reduction in neurotrophic factors). In this case, the genetically timed stop signal is independent of the state of the system when the critical period comes to an end. On the "soft" maturational account, no extrinsic stop signal is required. Instead, reductions in plasticity are an end-product of learning itself, due to the process of progressive cortical specialization described above. In essence, the system "uses up" its learning capacity by dedicating circuits to particular kinds of tasks, until it reaches a point at which there are serious limitations on the degree to which the system can respond to insult.

An example of soft maturation comes from Marchman (1993), who simulated aspects of grammatical development in neural networks that were subjected to "lesions" (i.e., random elimination of $2 \%-44 \%$ of all connections) at different points across the course of learning. Although there were always decrements in performance immediately following the lesion, networks with small and/or early lesions were able to recover to normal levels. However, late lesions (if they were large enough) resulted in a permanent impairment of language learning. Furthermore, this impairment was more severe for some aspects of the task than it was for others (e.g., regular verb inflections were more impaired than irregular verbs). Notice that these 
findings mimic classical critical-period effects described for human language learning (e.g., Johnson \& Newport, 1989), but without any extrinsic ("hard") changes in the state of the system. Instead, the network responds to the demands of learning through specialization, changing its structure until it reaches a point of no return, i.e., a point at which the system can no longer start all over again to relearn the task without prejudice.

As Marchman points out, the respective hard and soft accounts of critical-period effects are not mutually exclusive. Both could contribute to the reductions in plasticity that are responsible for differences between children and adults in recovery from unilateral brain injury (see also Oyama, 1992). However, if the soft account is at least partially correct, it would help to explain why the end of the critical period for language in humans has proven so difficult to find, with estimates ranging from one year of age to adolescence (e.g., Johnson \& Newport, 1989; Krashen, 1973).

In the present study, we will examine the first stages of language development in children with early-onset focal brain injury, using the framework provided by Elman et al. to resolve apparent contradictions between plasticity and early specialization for language. We will focus on children with unilateral lesions to the left or right hemisphere, incurred prenatally or before six months of life. We will present results on early communication and language from 10 - 44 months of age, the period in which normally developing children make the transition from first words to grammar. This is the group which should (on the arguments provided above) yield the strongest evidence for plasticity, because these children acquire their lesions before language development has gotten underway (cf. Marchman, 1993). At the same time, this is also the period of development in which inherent regional specializations should be most apparent, because the child has not yet had the time or occasion to develop alternative forms of brain organization. That is, we will be looking at children with focal brain injury during their first encounters with the language problem, watching them seek the best solution to that problem that they can find with limited neural resources.

The present study is similar to an earlier paper from our laboratories (Thal et al., 1991) on children with the same etiology, with a number of critical differences. First, we have combined data for 18 of the 27 children studied by Thal et al. with 35 new subjects added since 1991, yielding a total of 53 children with focal brain injury who participate in at least one of the three substudies described below. Hence we now have a sample that is roughly twice the size of that used by Thal et al. Second, the Thal et al. paper focussed on two periods of development, which we will refer to as the Infant phase (10 - 17 months) and the Toddler phase (18 - 31 months). We will look again at the same two periods, with a similar methodology, but in addition we will look 
at free-speech data between 20 - 44 months. This means that the window of development under study now extends all the way from first words to the point where the fundamentals of grammar are normally in place. Third, Thal et al. looked exclusively at early vocabulary, in comprehension and production. We will look at early vocabulary in the present study as well, but we will also examine the development of gestures (from 10 - 17 months) and the emergence of grammar (from 18 - 44 months). Fourth, and most important for our purposes here, Thal et al. analyzed the relationship between language development and lesion site by looking at the presence/absence of damage to one of the four quadrants of the brain (i.e., left anterior, left posterior, right anterior, right posterior). In the present study, we will take a more detailed look at lesion site within each hemisphere, examining the effects of presence/absence of damage to each of the four cortical lobes (frontal, temporal, parietal, occipital), with particular emphasis on frontal and temporal lesions, where the classical language zones are located. For many of the subjects, we also have ancillary information on seizure history, and on motor and visual symptoms (i.e., hemiparesis; visual field cuts).

Summarizing briefly, Thal et al. reported few differences in early language as a result of left- vs. right-hemisphere injury, although there were some interesting and surprising trends. In their analyses of the infant phase, none of the right/left comparisons reached significance. In both lesion groups, there were more children at or below the 10th percentile for expressive vocabulary than one would expect by chance (the 10th percentile is used because this has been the definition of "late talkers" in previous studies within this age range). In other words, it is hard to get language production off the ground following damage to either hemisphere (see Marchman, Miller, \& Bates, 1991, for related results on babbling). Results for comprehension were somewhat different: In the RH group, there were significantly more children at risk for comprehension impairment than one would expect by chance (i.e., 4 out of 6 or $67 \%$ fell below the 10th-percentile mark); this was not true in the LH group, where 3 out of 10 or $30 \%$ of the sample were in the risk range $(\mathrm{p}<.10)$. This RH disadvantage in comprehension is surprising in light of the adult aphasia literature (i.e., against the Wernicke hypothesis), but it is compatible with other reports for young children (Eisele \& Aram, 1993, 1994; Trauner et al., 1993; Wulfeck et al., 1991).

In Thal et al.'s analyses of the toddler phase, the predicted left-right difference in word production was finally evident. However, there were no differences between children with and without left anterior damage (against the Broca hypothesis). Instead, significant delays in word production were found in children with injuries to left posterior cortex, compared to RH children and to LH children without posterior involvement. In addition, Thal et al. report that children with right-hemisphere injury and/or isolated left anterior lesions tended to produce a remarkably 
high number of "closed-class words" for their vocabulary size (e.g., prepositions, pronouns, articles, auxiliary and copular verbs, question words). This suggests that the ability to produce these "little words" may be greater if the posterior quadrant of the left hemisphere is intact.

Based on the theoretical framework described above, and on earlier findings by Thal et al., our expectations in the present study include the following.

(1) Site-specific effects. We have argued that there must be something special about the initial status of left perisylvian tissue, in order to explain the patterns of brain organization for language that are reliably observed in the adult. And yet, results to date have not revealed clear effects of lesion site in children with focal brain injury. Many studies have found no effects at all, while others report effects that do not map onto the adult literature (i.e., the leftspecialization hypothesis, the Broca hypothesis, and the Wernicke hypothesis). In the present study, we will ask the same questions again with a finer-grained coding for lesion site. We will frame our questions in a series of planned comparisons based on the adult literature (i.e., left/right comparisons, and presence/absence of left frontal and/or left temporal injury), and then go back to search for patterns that do not follow the adult model.

(2) Phase-specific effects. We are alerted to the possibility that effects of lesion site may change across the course of development, for at least three reasons. First, the processes required for successful language learning are not necessarily the same processes required for efficient language use after learning is complete. Hence regions that are important in one phase of development may be less important in another (see also Petersen, Fiez, \& Corbetta, 1992; Raichle, 1994). Second, learning to gesture, learning to comprehend and learning to produce speech may each call upon different learning mechanisms, which are (in turn) different from the mechanisms that are required for gesture, comprehension and production in the adult. Third, regional biases that are evident at the beginning of language learning may disappear over time, not only because the challenges of learning have changed, but because alternative forms of brain organization have emerged to solve each learning problem. In other words, brain-behavior mapping is a moving target across the first years of life.

By putting together site-specific and phase-specific findings for infants with focal brain injury, we hope to learn more about innate regional variations in style of computation that lead to brain organization for language in adults under normal conditions. 


\section{GENERAL METHOD}

\section{Subjects}

A total of 53 infants and toddlers with unilateral focal brain injury participated in the study, 36 with lesions to the left hemisphere and 17 with lesions to the right (see Footnote 1). For 27 of these children, data are available at only one time point; another 20 contributed data at two time points, while 6 children are represented in all three studies (see Footnote 2). Total sample sizes across studies are 26 for Study 1 (language and gesture from 10 - 17 months), 29 for Study 2 (vocabulary and grammar from 17 - 31 months), and 30 for Study 3 (mean length of utterance between 20 - 44 months). A breakdown of individual subjects is provided in Table 1, indicating the substudies in which each child participates, and whether that child contributed data to the previous report by Thal et al.

Children were selected from ongoing studies of language, cognition and focal brain injury, at three different research sites (Language Research Center at UCSD and Children's Hospital in San Diego; Cornell University Medical Center in New York City, and the Rainbow Babies and Children's Hospital in Cleveland). In all cases, lesion onset occurred prenatally or within first 6 months of life. In most cases, neurological data are consistent with pre- or perinatal stroke, although it is often difficult to diagnose the etiology or the age of lesion onset with precision. The presenting symptoms that lead to such a diagnosis include motor weakness on one side, and/or evidence of neonatal seizures. Identification of lesion site was based on CT and/or MRI. Since subjects were obtained from different sites, those measures cannot be expected to be identical. However, in all cases there was sufficient information in the scan to derive information on the presence or absence of damage to each of the four lobes in the involved hemisphere. For a subset of these cases, the original scans on which a diagnosis of unilateral brain injury was based were not available for inspection. In those cases, codings of side and site were based on explicit notations in the radiological report (cases in which lobe information was absent were excluded from the study). All the remaining scans were read by a pediatric neurologist who was blind to the language status of each subject.

Table 1 presents information on gender, lesion side (LH vs. RH), intrahemispheric lesion site (frontal, temporal, parietal, occipital), and (where available) presence/absence of subcortical involvement, seizure history, hemiparesis and/or visual field cuts. In 44 cases there was evidence of subcortical involvement (including subcortical structures and/or deep white matter), while for 7 cases the scan suggested subcortical sparing; for the remaining 2 cases, evidence for subcortical involvement was unavailable or inconclusive. 26 of the 53 children were known to 
have some form of hemiparesis, 11 children had no motor involvement, while information on motor involvement was not available for 16 cases. There was evidence of a hemianopia (i.e., visual field cut) in 5 cases, while 19 children had no evidence of visual involvement; field cut information was not available for the remaining 29 cases. Preliminary analyses showed that the major neurological variables were not confounded with age or gender, and the lesion site variables were (with one exception) independent of seizure history, hemiparesis and/or visual field cuts (see Table 1 for details). The single exception is a significant relationship between presence/absence of frontal injury and evidence for a visual field cut, with fewer children in the frontal category showing visual problems ( $\mathrm{p}<.04$ by a chi-square likelihood ratio). This is not surprising, since we would expect injuries with a more anterior distribution to spare visual functions. It is interesting to note, however, that there was no significant relationship between visual symptoms and presence/absence of occipital damage. There was also no relationship between evidence for hemiparesis and presence/absence of frontal damage.

Among the 30 cases that were known to have temporal involvement (in the left or the right hemisphere), there were 15 cases in which it was possible to judge whether the lesion compromised Wernicke's area (defined to include the posterior perisylvian region of the temporal lobe, near the parietal/occipital juncture). Of these 15 cases, 10 were judged to involve damage to Wernicke's area, while the same area appeared to be spared in another 5 cases. Among the 23 cases that were known to have frontal involvement (in the left or right hemisphere), there were 15 cases in which it was possible to determine whether Broca's area was involved (defined as the third convolution of the frontal lobe, near the Sylvian fissure). Of these 15 cases, 9 lesions were judged to involve Broca's area while 6 lesions appeared to spare this region. In all the analyses described below, effects of temporal or frontal damage (especially left temporal damage) become numerically stronger if they are recalculated to reflect presence/absence of damage to Broca's area, or presence/absence of damage to Wernicke's area. However, the effects are also statistically weaker because of reductions in sample size. Because these numbers are relatively small, and because there was not sufficient information to support a clear decision in many cases, tests of the Broca hypothesis and the Wernicke hypothesis will be based on presence/absence of damage to the frontal or temporal lobes, respectively.

Children were excluded from the study if there was any evidence of multiple lesions, trauma or tumor, or if lesions were a product of disorders that might produce more diffuse brain damage. The latter include congenital viral infection, consistent problems during pregnancy, maternal drug or alcohol ingestion during pregnancy, bacterial meningitis, encephalitis, severe anoxia, and chronic lesions such as tumor or arteriovenous malformation. Children were also screened for visual and auditory sensory impairment. Children with severe or uncontrollable 
seizures were not included in this sample, although 9 of the 53 children did have a positive history of seizure activity (30 cases had no documented seizures; information on past seizure history was not available for 14 cases). In all cases, vision was 20/50 or better with correction and hearing was present at 25 decibels at two or more pure tone frequencies. The resulting sample represents a range of social class and educational levels, although the sample mean is skewed toward middle-class families with at least 12 years of formal education.

In previous studies, we have used a five-point rating scale originally developed by Vargha-Khadem to assess lesion size. In the study by Thal et al., there was no linear effect of lesion size using this measure. We also applied the Vargha-Khadem measure in the present study, but found no significant effects of lesion size in any of the analyses that follow. In the interests of brevity, these null results will not be discussed further.

Although our sample size is small by the standards of traditional epidemiological studies, it represents the combined efforts of three different research laboratories, across an eight-year period, using the same stringent inclusionary and exclusionary criteria. As a result, we believe that this is the largest and most homogeneous group of children with early focal brain injury that has been described in this critical age range.

\section{Materials \& Procedure}

Studies 1 and 2 are based on parental report data from the MacArthur Communicative Development Inventories (for details, see Fenson et al. 1991; Fenson, Dale, Reznick, Bates, \& Thal, 1994). This instrument was developed over a 20 -year period in laboratories across the United States, and it provides normative information (including separate percentile scores for girls and boys) based on a cross-sectional study of 1,803 English-speaking children between 8 and 30 months of age (excluding children with evidence of mental retardation or significant medical problems, ascertained by a family history questionnaire, and any child with significant exposure to a language other than English). The norming sample represents a broad range of social class and educational groups, although it is (like our focal-lesion sample) skewed toward middle-class families with 12 or more years of formal education.

A variety of studies have demonstrated the reliability and validity of this instrument (Dale 1990, 1991; Dale, Bates, Reznick, \& Morisset 1989; for reviews, see Fenson et al., 1991, 1994), enough to give us considerable confidence in the generality of these results. For example, the vocabulary checklists correlate positively and significantly with laboratory observations of vocabulary (from standard tests and free speech), with coefficients ranging from +.40 to +.80 , depending on the study. The grammar measures obtained in Part II of the Toddler Scale (see 
Method, below) are also strongly correlated with laboratory measures of grammar. For example, Dale has shown that the grammatical complexity scale correlates with a laboratory measure of Mean Length of Utterance at +.88 at 20 months of age, and +.76 at 24 months of age. Details for the respective Infant and Toddler scales are presented below.

Study 3 is restricted to a report of Mean Length of Utterance in Morphemes, based on freespeech samples that were video-recorded in the laboratory, across three standardized situations (book-reading, having a snack, free play on the floor). A minimum of 50 utterances were required for transcription and analysis; for children who were still producing little or no speech in the free-speech sample, a default score of 1.00 was assigned (indicating a mean utterance length of only one morpheme). This was done to avoid biasing the sample by including only those children with productive language (which might give a spuriously high estimate of language abilities in children with focal brain injury). Transcriptions were made according to the CHAT coding system of the Child Language Data Exchange System (MacWhinney, 1991). Mean Length of Utterance in Morphemes was calculated according to criteria recommended by Miller and Chapman (1981), which are in turn based on the criteria recommended by Brown (1973). Mean length of utterance scores were then transformed into age-based percentile scores, based on norms provided by Miller and Chapman for healthy, middle-class children across the age span covered in the present study.

\section{Data Analysis}

Ideally, one would want to test for the effects of specific lesion sites by looking at children whose damage is restricted entirely to that site. Unfortunately, this ideal strategy is not realistic when one is dealing with rare accidents of nature. The injuries suffered by these children usually involve more than one lobe within the damaged hemisphere, and more than one neurological risk factor (see Table 1). For example, there were 19 cases of lesions restricted to a single lobe, 29 cases with injuries involving two or more lobes, and 5 cases of purely subcortical damage. Furthermore, some lesion sites are more common than others (due to the nature of the middle cerebral artery strokes that are responsible for many cases of early focal brain injury). The incidence of specific lesion sites breaks down as follows (from most to least frequent): $69.7 \%$ of all cases have parietal involvement, $56.5 \%$ have lesions involving the temporal lobe, $43.4 \%$ have frontal involvement, $34 \%$ have injuries that include the occipital lobe, and $9.4 \%$ have deep subcortical injuries that spare all four lobes (including their associated white matter). Chi-square tests showed that there was no significant relationship between side of injury and probability of damage to any of these sites. In the results that follow, we will treat specific neurological variables as risk factors, partitioning the same data in various ways-for example, 
presence/absence of a positive seizure history, presence/absence of evidence for hemiparesis, and presence/absence of damage to a particular lobe (e.g., presence/absence of left temporal damage; presence/absence of left frontal damage).

Since the same children are contributing to each of these analyses (grouped in different ways), these cannot be viewed as independent tests. Protection against spurious effects can only come from the strength of the hypotheses under test, and from the order in which tests are conducted. In each of the three substudies reported below, relationships between neurological predictors and behavioral outcomes are assessed in a specified order, starting with planned comparisons based on the adult literature. In each of these analyses, the focal-lesion sample is grouped by presence/absence of a risk factor (e.g., presence/absence of left-hemisphere damage, of left temporal damage, and so forth), so that that one subgroup serves as the hypothetical "risk group" while the remaining cases in the sample serve as controls.

First, differences between children with left- vs. right-hemisphere lesions are assessed with a one-tailed t-test (assuming that LH children should perform significantly worse on each variable, i.e., the left-specialization hypothesis). Second, comparisons are conducted with children regrouped to reflect presence/absence of left temporal damage, and (where sample size permits) presence/absence of left frontal damage. Group comparisons that reach significance in these planned comparisons will be regarded as "strong evidence". The same data will also be examined from a nonparametric perspective, looking at the number of children within each subgroup who fall at or below the 10th percentile (defined as the "risk range"). We may find, for example, that more children with LH damage fall in the risk range on a particular measure than we would expect by chance on a binomial test, while the same is not true for children with RH damage. Conceptually, this is similar to the approach taken in several previous studies of early unilateral brain injury (e.g., Aram et al., 1985; Dennis \& Kohn, 1975; Riva \& Cazzaniga, 1986), where children in each neurological group were compared with a separate set of normal controls. In the absence of a significant between-group comparison (e.g., a significant difference between LH vs. RH), significant findings using this binomial approach will be regarded as "weak evidence".

After these planned comparisons, the data for each study are explored in a number of ways, including (1) control analyses comparing children with and without left parietal injury (to determine whether any findings based on the "classical language lobes" are artifacts of lesion site or middle cerebral artery etiology), (2) regroupings based on presence/absence of damage to the frontal lobes or the temporal lobes (independent of side), and (3) regroupings looking at the "mirror image" of our left-hemisphere tests (i.e., presence/absence of right temporal and right 
frontal damage). In addition, differences associated with seizure history, hemiparesis, visual field cuts and subcortical involvement are assessed where there are enough cases to warrant statistical analysis.

Our interpretation of results for each of these studies depends crucially on background information about the mean age at which early language milestones are attained in normal children, and on the range of variation that can be observed in children without focal brain injury. Therefore, we will begin each study with a brief synopsis of normal development for each of the variables in question, as background for the focal lesion findings that follow.

\section{STUDY 1: FIRST WORDS AND GESTURE}

Background. For children who are developing on a normal schedule, systematic evidence for word comprehension usually appears between 8 - 10 months of age, although there is enormous variation. For example, Fenson et al. (1994) report that 10-month-olds in their norming sample already have a mean receptive vocabulary of 36 words, but the range extends from zero to more than 150 items. Vocabulary production develops much more slowly, with the first words appearing between 10 - 12 months, and there is much less variation at the beginning. For example, the mean at 12 months in the Fenson et al. sample is 10 words, with a range from zero to just over 50. However, many children move sharply ahead of their age mates after this point, so that the mean at 16 months is 64 words, with a range from zero to more than 200 .

There is also ample evidence for a marked dissociation between comprehension and production in this age range (Bates, Dale, \& Thal, 1995; Benedict, 1979). Indeed, some normally developing children are reported to have receptive vocabularies of 200 words or more, even though they still produce little or no meaningful speech. One of the questions that we can ask in the present study (following Thal et al., 1991) is whether such dissociations are correlated with lesions to particular areas of the left or right hemisphere. In the present study, the relationship between comprehension and production is operationalized with a ratio of expressive to receptive vocabulary (i.e., the proportion of words reported in language comprehension that are also produced by the child-see Footnote 3$)$.

This is also the age range in which children begin to produce communicative gestures, including universal gestures like giving, showing, pointing, as well as cultural conventions like waving good-bye. At the same time, they also start to produce conventional gestures associated with familiar objects, inside and outside of a communicative situation (e.g., putting telephone receivers to the ear, stirring with spoons, putting a teddy bear to bed). Studies with normally developing children and with several clinical populations suggest that these gestural categories 
are all correlated with the onset of first words (Acredolo \& Goodwyn, 1988, 1990; Bates, Benigni, Bretherton, Camaioni, \& Volterra, 1979; Bates, O'Connell, \& Shore, 1987; Bates \& Thal, 1991; Brownell, 1988; Shore, O'Connell, Beeghly, Bretherton, \& Bates, 1990), although the correlation between gesture and comprehension tends to be higher in this age range than the correlation between gesture and production (Bates, Thal, Whitesell, Fenson, \& Oakes, 1989; Fenson et al., 1994). In adults with focal brain injury, impairments in the ability to imitate familiar gestures and/or produce them on command (sometimes called "ideomotor apraxia") are associated with damage to the left hemisphere (Duffy \& Duffy, 1981; Goodglass, 1993; see also Bates, Bretherton, Shore, \& McNew, 1983; Milner, 1994). To date, little is known about the relationship between early gesture and lesion type in children with focal brain injury (but see Aram \& Eisele (1985) and Marchman, Miller, \& Bates (1991) for preliminary evidence that early gestural development may be at risk in this population).

Subjects. 26 infants with focal brain injury participated in this study, 16 left and 10 right, with a mean age of 13.8 months (s.d. $=1.9$, range $=10-17$ ). The sample includes 7 children whose infant data were included in Thal et al. (1991). Of the children with LH damage, 8 had lesions that included left temporal cortex, and 2 of these also had damage to left frontal cortex. Of the children with RH involvement, 4 had lesions that included right temporal cortex and the same 4 had lesions involving the right frontal lobe. There were no frontal cases without accompanying temporal damage in this sample, in either the LH or the RH group. For details, see Table 1.

Method. Data for this study were based on the CDI:Words and Gestures Scale (formerly called the CDI:Infants). This instrument comes in two parts. Part I is a checklist of 396 words that are among the first to appear in the vocabularies of young English-speaking children. Next to each word, the parent is asked to indicate if the child (a) understands that word, and (b) understands and produces that word (see Footnote 3). The checklist is divided into 19 semantic categories: sound effects (e.g., "moo", "vroom"), animal names, vehicle names, toys, food items, articles of clothing, body parts, furniture, household objects, outside things and places to go, people (including proper nouns), routines and games (e.g., "peekaboo"), verbs, words for time, adjectives, pronouns, question words, prepositions, and quantifiers. All forms are presented in their "citation form" (e.g., verbs are listed as stems). Part II is a checklist of 63 communicative and/or symbolic gestures that also develop in this age range. Data from Part II were not available for six of the children, leaving a total sample size of 20 for all gestural analyses.

We will provide information about mean raw scores for comprehension, production and gesture. However, because the children vary in age, all neurological analyses are based on 
percentile scores (separately normed by age and gender). In addition, we will analyze results for the percent of comprehension vocabulary that is realized in production, a proportion score that takes age-based variance in vocabulary totals into account.

\section{Results.}

Correlations among measures: Pearson product-moment correlations were calculated among the four key measures in this study (comprehension, production and gesture percentile scores; percent of word comprehension that is also produced), across all 26 children in the focallesion sample. Results are consistent in direction (though not always in magnitude) with several correlational studies of normal controls (Bates et al. 1989; Bates, Bretherton, \& Snyder, 1988; Fenson et al., 1994; Thal, Bates, Goodman \& Jahn-Samilo, this volume). The relation between comprehension and production fails to reach significance with a sample of 26 (+.18, n.s.). This means that the focal-lesion sample displays the same dissociation between lexical comprehension and production that is so often observed for normally developing infants in this age range. Gesture is strongly related to comprehension $(+.71, \mathrm{p}<.001)$, but its relation to production falls below significance $(+.35, \mathrm{p}<.10)$, another finding that is often reported for normally developing infants. The production/comprehension ratios are positively and significantly correlated with total production $(+.73, \mathrm{p}<.001)$, but uncorrelated with total comprehension (-.25, n.s.), and gesture (-.01, n.s.). Despite the high correlation between the ratio scores and total production, a longitudinal study with normal controls has shown that this ratio is a significant predictor of language ability six months later even after variance from raw production and comprehension scores is removed (Thal et al., this volume). So it appears that this proportion score can yield unique information of relevance for the neurological analyses below. We turn now to separate results for each of the four measures.

Word comprehension. Children in this sample were reported to understand an average of 93 words (s.d. $=67.6$, range $=20-232$ ). The mean percentile score for the sample as a whole was 32.7 (s.d. = 29.3), with a range from 4 to 94 . In other words, our focal-lesion sample spans the full range of variation observed in the CDI norming sample of 659 infants. However, of the 26 children in the present study, 8 children or $31 \%$ of the sample score at or below the bottom 10th percentile in word comprehension for their age. A binomial test indicates that this is more than we would expect by chance $(\mathrm{p}<.002)$.

A planned one-tailed t-test comparing percentile scores for children with left- vs. righthemisphere damage did not reach significance. In fact, results were not even in the direction one would predict based on the adult literature. Children in the LH group actually scored higher in 
word comprehension (mean $=36$ ) than children in the RH group (mean = 28), against the Wernicke hypothesis but in the same direction reported in some developmental studies (Eisele \& Aram, 1994; Thal et al., 1991; Trauner et al., 1993). These results are displayed in Figure 1a.

Insert Figure 1a here

This tendency emerges more clearly when we take a nonparametric look at the same data. Within the LH group, 3 out of 16 children or $18 \%$ of the sample fell at or below the 10th percentile on word comprehension. A binomial test revealed that this is no more than we would expect by chance if the LH sample had been drawn randomly from the normal population. However, within the RH group, 5 out of 10 children or $50 \%$ of the sample were at or below the 10th percentile, far more than we would expect by chance $(p<.004)$. These differences are illustrated in Figure 1b. This is the same result reported by Thal et al. for a smaller sample of children with focal brain injury (including 7 of the 26 children in the present study). However, a likelihood ratio comparing the number of LH vs. RH children who did or did not fall below the bottom 10th percentile failed to reach significance $(\mathrm{p}<.10)$. So this is only weak evidence for an $\mathrm{RH}$ disadvantage in comprehension.

\section{Insert Figure $1 \mathrm{~b}$ here}

As planned, we also conducted a one-tailed t-test comparing comprehension percentile scores for children with and without left temporal damage-a direct test of the Wernicke hypothesis. There was no significant difference $(p<.18)$, and, in any case, results were in the opposite direction from what we would expect based on the adult literature: a mean comprehension score of 27 for children without left temporal damage, compared with a mean of 46 for children whose lesions extended into left temporal cortex (see Figure 1c). A nonparametric look at the same data indicates that 8 of the 18 children without left temporal damage (i.e., 44\%) fall at or below the 10th percentile, significant by a binomial test $(\mathrm{p}<.001)$, but none of the eight children with left temporal damage fall within this range (i.e., $0 \%$, a finding that directly contradicts the Wernicke hypothesis. A likelihood ratio comparing children with and without left temporal damage who fell above or below the 10th percentile was 
significant $(\mathrm{p}<.007)$, which means that children with damage to the left temporal lobe are actually less likely to suffer from comprehension delays than children whose lesions spare this area!

Insert Figure 1c here

There were only two children with lesions involving the left frontal lobe, too few to justify a separate statistical analysis. However, it is interesting to note that the mean comprehension percentile score for the two children with left frontal involvement was 65.5, compared with a mean of 30 for children without this kind of lesion. If we put this finding together with the lefttemporal analysis above, it seems that damage to the classical language zones within the left hemisphere has little impact on the early development of word comprehension. If anything, right-hemisphere damage is a greater risk factor in early comprehension, while children with left frontal and/or temporal lesions are well within the normal range.

To explore the possibility that particular sites within the right hemisphere may be involved in this effect, we looked separately at data for the $10 \mathrm{RH}$ children, comparing those with and without damage involving the right temporal lobe. For the six $\mathrm{RH}$ children with sparing of the temporal lobe, the mean comprehension score was 30; for the four RH children with temporal lobe involvement, the mean score was 25. Although this is in the direction we might predict (based on the idea that the homologue of Wernicke's area is important in early comprehension), the difference is not reliable by a one-tailed t-test. The same children with right temporal involvement also had right frontal involvement, and there were no isolated right-frontal cases, so we cannot ask about separate contributions of right temporal vs. frontal areas in this sample. Because 9 out of 10 RH cases had some parietal involvement, it was not possible to conduct a control analysis separating out effects of parietal damage from other sites. An analysis comparing children with and without right occipital damage failed to reach significance.

Finally, we used two-tailed t-tests to look separately at the effects of presence/absence of a seizure history, hemiparesis and/or subcortical involvement (sample sizes for each comparison vary depending on availability of information-see Table 1). None of these effects reached significance. There were too few children in this sample with documented visual field cuts to support a separate analysis of this neurological variable. 
To summarize so far, we have an apparent disconfirmation of the Wernicke hypothesis: Children with LH damage are not at significant risk for comprehension deficits. Even more important, none of the children with damage to the left temporal lobe (the presumed site of Wernicke's area) were significantly delayed in word comprehension. In fact, there is weak support in these data for the idea that the right hemisphere is more important for early word comprehension (in line with three other development studies-Eisele \& Aram, 1994; Thal et al., 1991; Trauner et al., 1993). However, we could not find evidence implicating particular sites within the right hemisphere.

Word production. The mean number of words produced by children in this sample was 9.3 (s.d. $=13.7$, range $=0-61$ ). This corresponds to a mean percentile score of 27.2 (s.d. $=$ 23.9), with a range from 4 - 90- just as impressive as the range observed for comprehension. However, 9 of the 26 children or $35 \%$ of the sample scored at or below the bottom 10th percentile, significantly more than we would expect by chance on a binomial test $(\mathrm{p}<.0001)$.

A planned one-tailed t-test comparing production percentile scores for $\mathrm{LH}$ vs. $\mathrm{RH}$ children failed to reach significance-not surprising, since the mean scores for the two groups were identical $(\mathrm{LH}$ mean $=27$; $\mathrm{RH}$ mean $=27$ ). These data are graphed in Figure 1a, to facilitate comparison with word comprehension (above) and with the other measures that follow below. In the LH sample, 6 of 16 cases or $37.5 \%$ fell at or below the 10th percentile, compared with 3 of 10 cases or $30 \%$ of the RH sample. Binomial tests indicate that there are more LH children in the risk range than we would expect by chance $(\mathrm{p}<.006)$, but the corresponding statistic fails to reach significance in the RH group. This is a difference in the predicted direction, but it is confounded by the fact that the RH group is smaller. A likelihood ratio comparing LH vs. RH children who do or do not fall at or below the 10th percentile failed to reach significance. Although these left/right differences are not significant, they are included in Figure 1b to facilitate comparison across measures.

We also conducted a planned comparison of children with and without left temporal damage $(-\mathrm{LT}$, mean $=29 ;+\mathrm{LT}$, mean $=23)$, and found no significant difference by a one-tailed t-test (see Figure 1c). Within the -LT group, 6 out of 18 or $33 \%$ of the sample fell at or below the 10th percentile, significantly more than we would expect by chance $(p<.02)$. Within the +LT group, 3 out of 8 cases or $37.5 \%$ of the sample fell in the same risk range, missing significance by a binomial test $(\mathrm{p}<.08)$. A likelihood ratio comparing presence/absence of left temporal damage in children under and over the 10th percentile failed to reach significance. In other words, we have little evidence here for a specific left temporal effect on production of first words. 
Because there are only two children in this sample with left frontal involvement, we cannot justify statistical analyses looking at presence/absence of this risk factor. Examination of mean percentile scores suggests that children with lesions extending into the left frontal lobe may be somewhat worse off $(-\mathrm{LF}$ mean $=28 ;+\mathrm{LF}$ mean $=17)$. However, these two children also had left temporal involvement, so there is no evidence here to support the idea of a special role for left anterior cortex in this stage of word production (i.e., no support for the Broca hypothesis).

We also took an exploratory look at sites within the right hemisphere. Children with lesions involving the right temporal zone were somewhat worse off in word production (mean = 20.5), compared with those whose right temporal lobe is spared (mean $=31$ ), but a 2-tailed t-test showed that the difference is not reliable. Since temporal and frontal damage always coincide in this RH sample, the results provide no information supporting the idea that right-hemisphere homologues to the classical language zones play an important role in production of first words. And because all but one of the $10 \mathrm{RH}$ cases had parietal involvement, we cannot determine whether right parietal injuries play any special role. A comparison of children with and without right occipital damage failed to reach significance.

Similar to our findings for word comprehension (above), a series of separate t-tests was conducted to look for possible effects of seizure history, hemiparesis or subcortical involvement. None of these effects were significant. There were (as noted) too few cases with visual field cuts to permit analysis.

To summarize, children with focal brain injury as a group are markedly delayed in the onset of word production ( $\mathrm{LH}$ and $\mathrm{RH}$ ), although some children perform very well despite their injuries. In direct contradiction of hypotheses based on the adult literature (the left-specialization hypothesis and the Broca hypothesis), we have little evidence here to suggest that lefthemisphere sites are particularly important for the production of first words. However, as we shall see below, site-specific evidence will emerge when production is viewed in a different way, i.e., as that percentage of comprehension vocabulary that children are able to produce.

Gesture. Children in this sample produced an average of 28 gestures out of the 63 total on the CDI scale (s.d. $=10.5$, range $=5$ to 45 ). The corresponding mean percentile score was 31.4 (s.d. $=22.8$ ), with a range from $4-88$. Once again, this is a very wide range for a sample this small. Of the 20 children for whom gesture data are available, 5 children (i.e., $25 \%$ of the sample) fell at or below the 10th percentile. This is not significantly more than we would expect by chance, although it is in the expected direction $(\mathrm{p}<.09)$. 
Based on the adult literature, we would expect more left-hemisphere involvement in the production of communicative and symbolic gestures (Duffy \& Duffy, 1981; Goodglass, 1993; Milner, 1994). We therefore conducted a planned comparison of gesture percentile scores for LH vs. RH children, predicting a disadvantage in the LH sample. T-tests results were robust and reliable-but in precisely the opposite direction $(\mathrm{t}=2.38, \mathrm{p}<.03,2$-tailed $)$ ! For the $11 \mathrm{LH}$ children for whom gesture data are available, the mean score was $41 ; 1$ of the 11 children (9\% of the sample) fell at or below the 10th percentile, no more than we would expect by chance on a binomial test. For the $9 \mathrm{RH}$ children for whom we have gesture scores, the mean was 19; 4 out of 9 or $44 \%$ of the sample are at or below the 10th percentile, which is (despite the small sample size) more than we would expect by chance $(\mathrm{p}<.02)$. However, a likelihood ratio comparing left/right damage with performance above/below the 10th percentile failed to reach significance $(\mathrm{p}<.07)$. Parametric data for individual children are presented in Figure 1a, together with the group means for the respective LH vs. RH groups. Nonparametric data are illustrated in Figure $1 b$.

Following the plan of analysis outlined earlier, we also compared gesture scores for children with and without left temporal damage. Results missed significance by a two-tailed test $(\mathrm{t}=-2.09, \mathrm{p}<.067)$, and we are not entitled to use a one-tailed test because these results are not in the predicted direction $(-\mathrm{LT}$ mean $=25 ;+\mathrm{LT}$ mean $=47)$. This analysis is simply a weak reconfirmation of the surprising finding reported above, i.e., an association of gestural delays with right-hemisphere damage. Results are graphed in Figure 1c, to facilitate comparison across measures.

Taking a nonparametric look at the same contrasts, we find that 5 of the 14 children whose lesions spare left temporal cortex (including all the RH children) fall at or below the 10th percentile. This corresponds to $36 \%$ of the sample, and is significantly more than we would expect by chance on a binomial test $(\mathrm{p}<.02)$. Of the 6 children whose lesions do involve left temporal cortex, none fell at or below the 10th percentile for gesture, which definitely suggests that left temporal cortex is not crucial for symbolic or communicative gesture in this age range. A chi-square likelihood ratio comparing children with and without left temporal damage who fall above or below the 10th percentile was reliable $(\mathrm{p}<.04)$.

Mean scores for children with and without lesions involving left frontal cortex also suggest a relative sparing of gesture, although the numbers are too small for a statistical comparison. The two children with left frontal involvement had a gestural mean of 59, compared with a mean of 28 for the rest of the sample. At the very least, it appears that left frontal damage does not make things worse in the gestural domain. 
To explore the possibility that sites within the right hemisphere may be particularly important for gesture, we looked at the data in several ways. First, we compared results for children with and without right temporal damage. Results confirm that performance is indeed significantly worse for the +Right Temporal group (mean $=12.5, \mathrm{n}=4$ ) compared with the -Right Temporal group (mean $=36.12, \mathrm{n}=16$ ), a difference that reaches significance by a 2 tailed test $(\mathrm{t}=3.62, \mathrm{p}<.002)$. Because the right temporal cases all had frontal damage as well, this result does not discriminate between right temporal and right frontal damage. If the data are regrouped to reflect presence/absence of right parietal damage, results are slightly weaker (+Right Parietal $=21.3, \mathrm{n}=9 ;-$ Right Parietal $=38.1, \mathrm{n}=11)$, and fail to reach significance by a 2 -tailed test $(\mathrm{p}<.086)$. Finally, because gesture does involve the visual modality, it seemed appropriate to compare children with and without right occipital damage $(+$ Right Occipital $=$ 11.2, $\mathrm{n}=5$; -Right Occipital $=38.13, \mathrm{n}=15)$. This difference was reliable by a 2 -tailed test $(\mathrm{t}=$ $4.22, \mathrm{p}<.001)$. It is worth noting that there is no trace of an occipital effect in the LH sample; in fact, there is a trend in the opposite direction from what one would predict if injuries to visual cortex in either hemisphere caused delays in gestural development (+Left Occipital $=55.5, \mathrm{n}=4$; -Left Occipital $=25, \mathrm{n}=16 ; \mathrm{t}=-2.44, \mathrm{p}<.07,2$-tailed). Similar to our findings for comprehension, we must conclude that RH children have a significant disadvantage in early gestural development (indeed, a stronger disadvantage than we found for word comprehension). There is little evidence for site-specific effects within the right hemisphere, although right occipital damage may be a risk factor.

Finally, we looked at presence/absence of seizure history, hemiparesis and/or subcortical involvement on gesture percentile scores, and obtained no significant effects. There were too few children with visual field cuts to permit statistical analysis.

To summarize, we have found an apparent disadvantage for gesture in children with RH damage, in direct contradiction of expectations based on the adult literature. However, one aspect of this finding is compatible with studies of early gesture in normally developing children. As we noted earlier, the correlation between gesture and word comprehension is invariably higher in this age range than the correlation between gesture and word production in normal children (Fenson et al., 1994). We have already seen that comprehension deficits are somewhat more likely in children with RH damage, and now we have seen that gestural deficits are also more likely with injuries to the right hemisphere. This raises the intriguing possibility that early gesture and word comprehension may have a common neurological base, with the right hemisphere playing a role that is not evident later in life. We will return to this idea in the final discussion. 
Proportion of receptive vocabulary that is produced. It is usually the case in this age range that children comprehend far more words than they are able to say. In the CDI norming sample (based on 659 children), the average percent of receptive vocabulary that children can also produce is $15 \%$ (s.d. $=17 \%$ ), although the range goes all the way from zero to $100 \%$ (see Footnote 3). This ratio is moderately correlated with age across the large norming sample $(\mathrm{r}=$ $+.40, \mathrm{p}<.001$ ). In the focal-lesion sample, the mean was $11 \%$ (s.d. $=12 \%$, range $=0-45 \%$ ), and these ratios were not significantly related to age, although there was a trend in that direction $(\mathrm{r}=+.26, \mathrm{p}<.10)$.

A planned comparison of $\mathrm{LH}$ and $\mathrm{RH}$ children on these percentage scores was not significant, although there was a tendency for LH children to produce a smaller proportion of their receptive vocabulary (9\%) compared with RH children (14\%). Results are graphed in Figure 1d.

In contrast, the planned comparison of children with left temporal involvement and children with left temporal sparing did reach significance $(\mathrm{t}=2.12, \mathrm{p}<.022,1$-tailed $)$. This reflects a mean score of $6 \%$ for children with left temporal involvement, vs. $13 \%$ for children whose lesions spare that area. Results are graphed in Figure 1d, to facilitate comparison of this significant left-temporal contrast with the nonsignificant left/right contrast described above. The two children who also had left frontal involvement were at an even greater disadvantage, producing only $3 \%$ of their receptive vocabularies (vs. $12 \%$ for the rest of the sample). Recall, however, that these children have large left-hemisphere lesions involving both the temporal and the frontal zones, so this does not give us clear information about the role of left anterior cortex.

This finding does appear to offer some support for the idea that left temporal cortex plays a special role in the development of expressive language. However, such temporal injuries are usually caused by middle cerebral artery strokes that involve other brain regions. For example, 6 of the 8 children in this sample with left temporal damage also had damage to the left parietal lobe; conversely, six of the 12 children with left parietal damage had injuries that include left temporal cortex (see Table 1). Although we did not find a gross association between lesion size and delays in language, the possibility remains that risks associated with left temporal damage may be an epiphenomenon of damage to adjacent areas. To control for this possibility, we repeated the same paired comparison using presence/absence of left parietal damage as a grouping factor. A t-test revealed no evidence for specific effects of left parietal injury $(t=0.59$, $\mathrm{p}<.56$ ). This control analysis bolsters our confidence that the process of turning comprehension into speech is delayed in children with damage involving the left temporal lobe. 
Following these comparisons, we took an exploratory look at children with damage to specific sites within the right hemisphere. Scores were slightly higher for the eight RH children without frontal/temporal involvement (16\%) than they were for four RH children with damage to both these regions (12\%), but the difference was not reliable. Regroupings based on presence/absence of right parietal or right occipital damage also yielded null results.

Finally, we found no evidence of a difference in performance as a function of seizure history, hemiparesis and/or subcortical involvement. We could not conduct analyses on presence/absence of visual field cuts due to limitations on sample size.

To summarize, even though there are no site-specific effects on percentile scores for total word production, we do find a difference when production is analyzed as a proportion of receptive vocabulary. Specifically, children with left temporal damage produce a smaller percentage of the words they know, a tendency that is even greater when lesions include both the temporal and frontal zones. This is the only strong evidence we have obtained in Study 1 for some version of the left-specialization hypothesis. However, the left temporal finding runs against the Wernicke hypothesis in its original form (i.e., the prediction that left temporal injuries will affect comprehension while left frontal injuries affect production). We will return to this point in the summary and conclusion.

\section{STUDY 2: VOCABULARY AND EARLY GRAMMAR}

Background. In normally developing children, language development undergoes a dramatic change from 16 to 30 months of age. Most children display a marked acceleration in vocabulary development during this period, a nonlinear increase that is sometimes referred to as the "vocabulary burst". This acceleration usually begins by 18 months of age (e.g., Dromi, 1987), although there are enormous individual differences in onset and rate of growth (Bates et al., 1988; Nelson, 1973). For example, Fenson et al. report a mean vocabulary of 312 words at 24 months, with a range from under 50 words to more than 500. It is during this period of development that Thal et al. observed particularly marked delays in word production among children with left posterior injuries.

This is also the period in which most normal children make the transition from first words to grammar. First word combinations typically appear between 18 - 20 months, with a marked increase in the use of grammatical inflections and function words between 24 - 30 months of age. Recent studies suggest that the onset of grammar is tightly linked to vocabulary growth in the normal population (Bates et al., 1994; Fenson et al., 1994). For example, the transition from single words to word combinations is better predicted by vocabulary size than age (i.e., most 
children start to produce sentences when their vocabularies exceed 50 words). The tight relationship between vocabulary growth and grammar continues after this point, with studies reporting correlations ranging from +.76 to +.88 for grammatical complexity and vocabulary size between 20 and 28 months of age (see also Bates et al., 1988). This strong association contrasts markedly with the dissociations between comprehension and production that are so often observed in early language development. At this point, very little is known about the emergence of grammar or its relation to vocabulary size in children with focal brain injury, although preliminary observations by Eisele \& Aram (1995) suggest that both domains are at risk in the focal-lesion population (cf. Feldman et al., 1992).

Another measure that will be examined in the present study is the proportion of total vocabulary comprising grammatical function words (also known as "closed-class" words). This is a particularly interesting and controversial measure in the literature on early child language. At first glance, one might expect the early appearance of function words to index early emergence of productive control over grammar. However, studies show that this is not the case for English-speaking children in the first stages of language acquisition (Bloom et al., 1991; Bloom, Lightbown, \& Hood, 1975; Peters, 1983). For example, in a longitudinal study by Bates et al. (1988), percent use of closed-class words at 20 months was significantly and negatively correlated with the very same measure at 28 months. Bates et al. (1994) have shown that this age-related change in the meaning of "closed-class style" actually reflects a transition in vocabulary size. For children with vocabularies under 400 words, "closed-class style" is completely unrelated to current or later grammar. For children with vocabularies over 400 words, the very same measure is an excellent index of current and later grammatical abilities. To explain these peculiar findings, Bates et al. suggest that early use of function words actually reflects a tendency for some children to produce rote and formulaic structures that have not yet been broken down into their constituent elements; for this reason, children who start with telegraphic speech have actually conducted a more detailed analysis of their input (i.e., they have decided which elements they can afford to leave out).

Early use of closed-class words may be related to a continuum of individual differences that have been described for normally developing children in the 18 - 24-month age range (Bloom, 1970, 1973; Nelson, 1973, 1981), with children at one extreme who avoid grammatical function words, restricting themselves to "telegraphic speech" (e.g., "Mommy sock"—Bloom, 1970), while children at the other extreme tend to specialize in well-practiced routines and/or in the reproduction of acoustic details that they do not fully understand (a tendency that has been called "rote", "expressive" or "pronominal style"—Bloom, Lightbown, \& Hood, 1975). Bates, Dale \& Thal (1995) have speculated that individual differences in auditory memory may be 
responsible for this pattern of variation. In this regard, it is interesting to note that Thal et al. (1991) found that children with right-hemisphere damage had higher ratios of closed-class elements in their speech, suggesting that this style is associated with greater reliance on lefthemisphere processes.

Subjects. Data on vocabulary and grammar were analyzed for 29 toddlers with focal brain injury, with a mean age of 26.5 months (s.d. $=3.2$, range $=19-31$ ). Vocabulary data for 8 of these children were reported in the study by Thal et al.; 15 children also contributed data to Study 1 (above). There were 17 cases with left-hemisphere damage and 12 with righthemisphere damage. Of the $17 \mathrm{LH}$ cases, 10 had damage involving the left temporal lobe, and 5 had injuries involving the frontal lobe. Of these five left frontal cases, four also had left temporal damage, which means that it will not be possible to disentange the effects of left frontal injury from left temporal lobe effects (similar to the problem faced in Study 1). Of the $10 \mathrm{RH}$ cases, 9 had lesions involving the right temporal lobe, and six of these also had damage to the frontal lobe. For details, see Table 1.

Materials. Parents of all the children in the study completed the CDI:Words and Sentences Scale (previously known as the CDI:Toddlers). This scale is also composed of two sections. Part I is a checklist of 680 words (including the 396 words from the Infant list). In contrast with the Infant form, the Toddler form only asks about word production (previous research in our laboratories has shown that most parents of normally developing children are unable to track word comprehension after 16 months of age). The Toddler list is divided into 22 semantic categories. In addition to the 19 categories from the Infant checklist, the Toddler list also contains separate sections for "helping verbs" (auxiliaries and modals) and conjunctions, and the Infant category "outside things and places to go" is divided into two separate sections, "outside things" and "places".

Part II of the Toddler Scale looks at early grammar, from several different points of view (for a detailed discussion, see Dale 1991; Fenson et al., 1994; Marchman \& Bates, 1994). It begins with a single question regarding the onset of word combinations, where parents are asked to check "not yet", "sometimes" or "often". If the child is reportedly producing any word combinations at all, parents are asked to continue to a series of questions about the nature of word combinations and grammatical forms. These include a checklist of verbs and nouns in regular and irregular inflected forms, a section in which parents are asked to write in the three longest utterances that their child has produced in the last few weeks, and a separate section on grammatical complexity. The complexity section is made up of 37 sentence pairs, each reflecting a minimal contrast in grammatical complexity (e.g., "Kitty sleeping" vs. "Kitty is 
sleeping"). Parents are asked to indicate which alternative within each pair "sounds most like the way that your child is talking right now". The minimal contrasts tapped by this subscale include presence/absence of copulae, auxiliaries, modals, possessives, plurals, tense markers, prepositions and articles in obligatory contexts. It also includes a few items in which both items are grammatically correct but vary in complexity (e.g., "Lookit me!" vs. "Lookit me dancing!"). Scores can vary from 0 (parents always check the simpler alternative) to 37 (parents always check the more complex alternative). As noted earlier, this scale is highly correlated with laboratory measures of Mean Length of Utterance. Finally, parents are asked to provide examples of the three longest utterances they have heard their child produce in the past two weeks. These were scored manually, according to procedures of the Child Language Data Exchange System (MacWhinney 1991) for calculation of mean length of utterance in morphemes. We will refer to this measure as M3L. Preliminary analyses have shown that M3L and the complexity scale are highly correlated. To avoid redundant analyses that would capitalize on chance, we will restrict ourselves here to an analysis of M3L, because that measure bears a more transparent relationship to the MLU scores used in Study 3. Both vocabulary and M3L scores are expressed as percentiles, based on the MacArthur CDI norms. Finally, percentile scores were also assigned for the ratio of function words to total vocabulary, based on data from the same large norming study.

\section{Results:}

Correlations among measures. Pearson product-moment correlations were calculated among three key measures (vocabulary percentiles, M3L percentiles, and percentiles for closedclass proportion scores), across all 30 children in the present study. In line with findings for normal controls (Fenson et al., 1994), there was a very strong correlation between M3L and vocabulary $(+.77, \mathrm{p}<.0001)$, providing very little evidence for a dissociation between grammatical and lexical development in this age range. However, the closed-class proportion scores were unrelated to the other two measures (+.07 for vocabulary and closed-class scores, n.s.; +.27 for M3L and closed-class scores, n.s.).

Word production. Mean vocabulary size in the focal-lesion sample was 251 words (s.d. = 217 , range $=2$ to 670 ). This corresponds to a mean percentile score (based on age and gender) of 27.5 (s.d. $=28$, range $=4-96$ ). Once again, it is interesting that our sample of 29 covers the same large range in vocabulary development observed in normal controls. However, 11 of the 29 children or $38 \%$ of the sample obtained scores at or below the lowest 10th percentile, significantly more than we would expect by chance on a binomial test $(\mathrm{p}<.00001)$. 
The mean vocabulary percentile score for LH children was 25 , compared with a mean score of 31 for RH children (see Figure 2a). This difference was not reliable by a planned onetailed t-test. Within the LH group, 7 of 17 cases of $41 \%$ of the sample fell at or below the 10th percentile, more than we would expect by chance if these children were drawn from the normal population $(\mathrm{p}<.002)$. However, 4 of 12 children with RH damage (or $33 \%$ of that sample) were also at or below the 10th percentile, which approaches significance in a binomial test $(\mathrm{p}<.06)$. A likelihood ratio comparing LH vs. RH on performance above/below the 10th percentile failed to reach significance. The nonparametric data are illustrated in Figure $2 b$.

Insert Figures $2 \mathrm{a}$ and $2 \mathrm{~b}$ here

A second planned comparison involved children with left temporal lesions $(\mathrm{N}=10$, mean percentile $=17)$, vs. children whose lesions spared left temporal cortex $(\mathrm{N}=19$, mean percentile $=33$ ). This difference was significant by a one-tailed $\mathrm{t}$-test $(\mathrm{t}=1.75, \mathrm{p}<.05,1$-tailed $)$, which means that children with left temporal lesions are at greater risk for delays in vocabulary development during the crucial period from 19 to 31 months, when normally developing children pass through the vocabulary burst. Results for this left temporal analysis are plotted in Figure 2a, to facilitate comparison with the nonsignificant left/right comparison.

A nonparametric look at the same data showed that 6 out of 19 cases $(32 \%)$ of children without left temporal involvement were at or below the 10th percentile, significant in a binomial test $(\mathrm{p}<.02)$. Among the children whose lesions do involve the left temporal zone, 5 out of 10 $(50 \%)$ were in the bottom 10 th, highly reliable in a binomial test $(\mathrm{p}<.0033)$. A likelihood ratio comparing children with/without left temporal involvement who were or were not in the bottom 10th failed to reach significance. The nonparametric data are presented in Figure $2 \mathrm{~b}$, to facilitate comparison with the left/right analysis.

In this particular sample, we have only one case of isolated left frontal damage. However, we do have four cases in which the lesion involves both left temporal and left frontal zones, so that we can at least look to see whether left frontal and left temporal damage have an additive effect. Among the 5 children with left frontal involvement, the mean vocabulary percentile score was 11 , compared with a mean of 31 for the rest of the sample (i.e., all RH children and all LH with frontal sparing). This difference is significant by a one-tailed t-test $(t=2.36, \mathrm{p}<.032,1$ tailed). When we restrict ourselves only to children with a left-hemisphere lesion, the difference between those with and without frontal involvement is also significant $(t=2.00, p<.035,1$ - 
tailed; $-\mathrm{LF}$ mean $=30,+\mathrm{LF}$ mean $=11$ ). However, when we look only at those children who have left temporal involvement $(\mathrm{N}=10)$, the four with frontal extension are not significantly worse than the six without $(\mathrm{t}=0.67, \mathrm{p}<.53$; -Frontal mean $=20,+$ Frontal mean $=13.2)$. Hence this is best viewed as weak evidence for the Broca hypothesis, due to the confound between frontal and temporal involvement (more on this below).

To control for the possibility that our left temporal and frontal effects are epiphenomena of lesion size, we regrouped the children to reflect presence/absence of left parietal damage. Of the 10 children in this sample with left temporal damage, 8 have injuries that also involve the left parietal zone; conversely, of the 13 children with left parietal damage, 8 have injuries extending into the temporal lobe. Hence, even though the overlap between lesion sites is substantial, there are enough dissociated cases to permit separate analyses. A t-test comparing vocabulary percentile scores for children with and without left parietal damage did not reach significance $(\mathrm{t}$ $=-0.16, \mathrm{p}<.88 ;-$ Left Parietal mean $=28.2,+$ Left Parietal mean $=26.5)$. This control analysis provides further support for the idea that the "classical language lobes" play a specific role in the early stages of expressive language.

Having determined that there are weak but reliable effects implicating the left temporal and (perhaps) frontal zones, we went on to take an exploratory look at the role of homologous areas within the right hemisphere. Results were rather surprising. Out of $12 \mathrm{RH}$ children, the mean percentile score for expressive vocabulary was 39 for three children with sparing of the temporal zone, compared with a mean of 29 for nine children with temporal involvement. This difference failed to reach significance by a 2 -tailed t-test $(\mathrm{p}<.75)$. Out of the same $12 \mathrm{RH}$ children, the mean score was 49.5 for six without frontal involvement, compared with a low of 13 for six whose lesions do involve right frontal cortex. This difference did approach significance by a two-tailed test $(\mathrm{t}=2.23, \mathrm{p}<.07,2$-tailed). Although these are only trends, it would appear that right frontal injuries are associated with delays in expressive vocabulary that are just as severe as those that we see with left frontal damage.

This pattern led to the hypothesis that any form of frontal damage (left or right) may result in expressive language delays from 19 - 31 months. To explore this possibility further, we carried out a direct comparison of children with and without injuries involving the frontal lobe, without regard to side of lesion. Since this was not a planned comparison, we used a two-tailed test, but still found a robust and reliable difference $(\mathrm{t}=3.03, \mathrm{p}<.006,2$-tailed $)$, reflecting a mean percentile score of 37 in eighteen children with frontal sparing, vs. a mean of 12 in eleven children with frontal involvement. This finding is illustrated in Figure 2c. Figure 2d illustrates the same information broken down by side of lesion. By contrast, when we conducted a similar 
analysis comparing ten children without temporal involvement $($ mean $=36)$ and nineteen children with temporal injuries (mean $=23)$, the difference was not reliable $(\mathrm{t}=1.15, \mathrm{p}<.27$, n.s.). In other words, frontal involvement is a significant risk factor for expressive vocabulary, for both left- and right-hemisphere cases. Temporal involvement does not show the same degree of bilateral risk. To facilitate comparison with the significant bilateral effects for frontal involvement, the side by temporal breakdown is illustrated in Figure 2e.

Insert Figures $2 \mathrm{c}, 2 \mathrm{~d}$ and $2 \mathrm{e}$ here

Finally, we also looked for differences associated with subcortical involvement, seizure history, hemiparesis, and/or visual field cuts. None of the comparisons were reliable.

To summarize, left-hemisphere injury per se does not appear to be a significant risk factor for expressive vocabulary. A significant number of children are at risk (i.e., at or below the 10th percentile) in both the LH and RH groups. There was, however, a small but reliable effect of injuries involving the left temporal zone, a difference that is magnified if the lesion also involves left frontal cortex. Similar effects are not found when children are regrouped according to presence/absence of left parietal injury. All of these results are in the direction we would predict, based on the adult aphasia literature. However, there was also a surprising "mirror image" of these perisylvian findings in the right-hemisphere group. In particular, it seems that injuries to either side of frontal cortex can result in marked delays in expressive vocabulary, at least during this phase of development. Results are in the same direction for temporal cortex (i.e., temporal injuries on the right also result in lower scores), but they are not reliable.

Mean length of the three longest utterances (M3L). For children in the focal-lesion sample, the three longest utterances in morphemes averaged 3.55 in length (s.d. $=2.74$, range $=$ 1 - 12.33). This corresponds to a mean percentile score of 23.7 (s.d. $=26.4$, range $=4$ - 88). The range is just as impressive as we have seen so far for lexical development and grammar. However, 16 of the 29 children or $55 \%$ of the sample fell at or below the lowest 10 th percentile, far more than we would expect by chance $(p<.00001)$.

A planned comparison of LH vs. RH children on the M3L measure failed to reach significance $(\mathrm{t}=-0.45$, n.s.; $\mathrm{LH}$ mean $=22$; RH mean $=26)$. This difference (or absence of a difference) is presented in Figure 2a (alongside the effects and noneffects of lesion site on vocabulary). Within the LH group, 11 out of 17 cases or $65 \%$ of the sample fell at or below the 
10th percentile, highly reliable by a binomial test $(\mathrm{p}<.00001)$. However, it was also true that 5 out of 12 cases or $42 \%$ of the RH sample fell at or below the 10th percentile, another reliable finding by a binomial test ( $\mathrm{p}$.009). A likelihood ratio comparing LH vs. RH on number of children above or below the 10th percentile failed to reach significance. The nonparametric data are presented in Figure $2 b$, to facilitate comparison of results for vocabulary and grammar.

We then conducted a planned comparison of children with and without left temporal involvement, and obtained a reliable difference $(\mathrm{t}=2.47, \mathrm{p}<.02,1$-tailed $)$. This reflects a mean M3L percentile score of 30 for children with sparing of the left temporal zone, compared with a mean of 11 for children with left temporal involvement. Data are illustrated in Figure 2c, where grammar and vocabulary can be compared.

A nonparametric look at the same data showed that 7 of the 10 children with left temporal involvement (or 70\%) were at or below the 10th percentile for this measure of grammar, a reliable result by a binomial test $(\mathrm{p}<.00001)$. However, 6 of the 19 children without left temporal involvement (or 32\%) were in the same risk range, a smaller proportion but still a reliable finding $(\mathrm{p}<.02)$. So there are clearly children at risk in both groups, even though the numbers are greater with left temporal injury. A likelihood ratio comparing the two groups on numbers above and below the 10th percentile mark failed to reach significance. The nonparametric data are presented in Figure 2d, where vocabulary and grammar are compared.

The data were regrouped to see whether left frontal involvement increases the magnitude of effects. Among the 24 children without left frontal injuries, the mean percentile score was 27; for the 5 children who do have left frontal involvement, the mean grammar score was 7.5. This group difference is reliable $(\mathrm{t}=3.18, \mathrm{p}<.004)$. If we restrict our attention entirely to children with left-hemisphere damage, the corresponding mean percentile scores are 28 without left frontal involvement vs. 8 for children with left frontal injury, an effect that is reliable by a onetailed test (based on the Broca hypothesis $-\mathrm{t}=2.05, \mathrm{p}<.04,1$-tailed). Hence it does appear that delays associated with left temporal injury are exacerbated if the children also have lesions extending into frontal cortex. Since we have only one case of isolated left frontal damage in this group, we cannot say anything more about the relative contribution of temporal vs. frontal cortex.

We conducted another control analysis grouping children according to presence/absence of left parietal injury. Results of a t-test based on this grouping did not reach significance $(\mathrm{t}=0.49$, $\mathrm{p}<.63$ ), and the means for the two respective groups are very close (+Left Parietal $=21 ;-$ Left 
Parietal = 26). It therefore appears that the left temporal and frontal effects reported above are relatively specific, and are not by-products of lesion size within the left hemisphere.

We also took an exploratory look at results for homologous sites in the right hemisphere, and obtained results quite similar to those reported above for expressive vocabulary. The differences associated with presence/absence of temporal damage were not large: a mean of 35 in RH children without temporal involvement, vs. 23 in children with temporal lesions, a nonsignificant difference $(\mathrm{t}=0.64$, n.s.). By contrast, mean scores were 39 for six $\mathrm{RH}$ children without frontal involvement, compared with a mean of only 13 in six RH children with frontal damage, a reliable difference $(\mathrm{t}=2.52, \mathrm{p}<.04,2$-tailed $)$.

Once again, this pattern led us to hypothesize that frontal injuries may create delays in expressive language regardless of side. A t-test comparing children with and without frontal lesions was reliable by a 2-tailed test $(\mathrm{t}=2.76, \mathrm{p}<.011,2$-tailed $)$. This reflects a -Frontal mean of 32 and a + Frontal mean of 11, illustrated in Figure 2c (see also Figure 2d where the respective left frontal and right frontal effects are plotted separately). By contrast, a comparison based on presence/absence of temporal lesions (regardless of side) failed to reach significance by a 2tailed test ( $\mathrm{t}=1.66, \mathrm{p}<.12,2$-tailed), although the difference was in the same direction and similar in magnitude $(-$ Temporal mean $=37$; +Temporal mean $=17$ ). Although this side by temporal breakdown is not reliable, it is presented in Figure 2e to facilitate comparison with the bilateral frontal effect.

Finally, there were no significant differences on the M3L measure as a function of seizure history, hemiparesis, visual field cuts or presence/absence of subcortical damage. It is also worth noting that the mean for children without evidence of motor involvement was 16.75, compared with a mean of 32 for children with some kind of hemiparesis. Although this difference is not reliable, it can be used to argue that gross motor involvement per se is not a significant risk factor for early grammar, and cannot be responsible for the left temporal effect or the bilateral frontal effects described above.

To summarize, these findings for early grammar parallel the findings reported above for vocabulary development from 19 - 31 months. Although there are no significant differences associated with left- vs. right-hemisphere injury, children with damage to the left temporal lobe are at a significant disadvantage. No such disadvantage is seen when children are regrouped to reflect presence/absence of left parietal damage. The left temporal disadvantage is even greater if left temporal lesions are accompanied by left frontal involvement. However, these frontal effects appear to be bilateral. That is, significant delays in the emergence of grammar are 
observed with damage to the frontal region, with equivalent delays for left frontal and right frontal cases.

Proportion of vocabulary comprising grammatical function words. As noted earlier this measure is not related to productive control over grammar during the first stages of combinatorial speech. Instead, it has been argued that a (proportionally) high ratio of grammatical function words indicates a tendency for children to produce rote formulae and unanalyzed acoustic details that they still do not understand.

In the present study, the average ratio of function words to total vocabulary was $12.7 \%$ ( s.d. $=20.6 \%$, range $=1.8$ to $100 \%$ ). This enormous range reflects nothing more than the volatility of percentile scores when denominators are very small. For example, a child with only two words ("No!" and "Up!") would obtain a function word percentage score of $100 \%$. For this reason, Bates et al. (1994) recommend use of percentile scoring based on total vocabulary size instead of raw percentages, and they note that these percentile scores should only be assigned to children whose vocabularies are greater than 70 words. Before that point, percentile scoring is subject to floor effects. Following these recommendations, percentile scores for function words as a percent of total vocabulary were available for only 16 of the 29 children in the sample For these children, the average percentile score was 56.4 (s.d. $=33.6$, range $=4$ - 96). Three of these 16 children ( $18 \%$ of the sample) had percentile scores at or below the 10 th percentile, and another two (12\%) had percentile scores at or above the 90th percentile. Neither of these figures are greater than we would expect by chance, which means that we do not have an abnormal number of children at either extreme of the hypothesized continuum from telegraphic speech to formulaic style.

Although we do not have an abnormal number of cases at the extreme ends of the distribution on these closed-class percentile scores, we do have effects of lesion side. Based on the adult literature, we might expect less use of grammatical function words in children with LH damage. In fact, the mean percentile score (controlling for total vocabulary size) was 33 for the LH group, vs. 75 for the RH group, a significant difference by a one-tailed t-test $(\mathrm{t}=-3.21, \mathrm{p}<$ $.004,1$-tailed). Results are presented in Figure $2 \mathrm{f}$.

Insert Figure $2 \mathrm{f}$ here 
Although this is the direction we would predict if $\mathrm{LH}$ children were at a significant disadvantage in the early use of function words, this particular result actually looks less like a left-hemisphere disadvantage, and more like a right-hemisphere advantage (with a mean of 75). In fact, a likelihood ratio comparing LH vs. RH children who are above or below the median was reliable (i.e., 2 above and 6 below in the LH group, 7 above and 1 below in the RH group, p < $.01)$.

No further analyses of lesion type were conducted on this measure, because the sample size within specific lesion sites is too small to warrant statistical analyses (recall that the overall sample for the closed-class style analysis is only 16). It is worth noting, however, that the 3 children with left temporal involvement had relatively low closed-class scores $($ mean $=29)$, compared with a mean of 60 for the rest of the sample. For the three children in this subsample who had left frontal involvement, the mean closed-class score was 40, compared with 57 for the rest of the sample. Hence there is a trend in the direction of less closed-class style with left temporal (but not left frontal) damage.

To summarize, we do find a significant difference between $\mathrm{LH}$ and $\mathrm{RH}$ children on function words as a proportion of expressive vocabulary. In this period of development, a high score on this measure has been interpreted to reflect rote, unanalyzed reproduction of acoustic details that the child does not yet understand. This interpretation is supported in the present study by the fact that utterance length (M3L) is only weakly correlated with function word percentile scores. In fact, our results do not look like a selective disadvantage for LH children (which we would expect if this were a form of developmental agrammatism). Rather, it appears to reflect a selective advantage for RH children, i.e., a marked tendency for children in the RH group to engage in rote or formulaic speech. We will offer some possible explanations for this finding in the final discussion.

\section{STUDY 3: GRAMMAR IN FREE SPEECH}

Background. As we have already noted, there is a dramatic surge in the use of inflections and function words between 24 - 30 months. By 3 years of age, most normal children can engage in intelligible conversations with adults from outside the family, using a wide range of grammatical constructions. By 4 years of age, it is usually safe to conclude that all of the basic principles of grammar have been mastered, in all of the world's languages that have been studied to date (MacWhinney \& Bates, 1989; Slobin, 1985). Hence the period between 18 and 48 months represents a critical time in grammatical development, where we are most likely to observe delays that might be associated with regional specializations for language learning. 
There are literally hundreds of measures that can be and have been applied to free-speech development during this period (MacWhinney, 1991). However, Mean Length of Utterance in Morphemes (MLU) is the most widely used measure, particularly in studies of children acquiring English. Although this measure has severe limitations after 4 years of age, it is an excellent index during the period in which most grammatical forms are mastered, correlating highly with more detailed and labor-intensive measures (e.g., indices of morphological productivity, sentence complexity and/or propositional complexity_for a discussion, see Bates et al., 1988, Chap 12). According to Miller and Chapman (1981), the average MLU in morphemes at 20 months is less than 1.50 (referred to by Brown, 1973, as Early Stage I), and there is usually little or no productive control over grammatical morphemes. By 44 months of age, the average MLU has reached 4.0 (referred to by Brown as Stage IV), and all the basic structures of English appear to be intact (including the complex system of modal verbs, and difficult syntactic structures like the passive). This is the period covered by our third and final study.

Subjects. Free-speech data were available for 30 children, with a mean age of 30.5 months (s.d. $=6.2$, range $=20-44$ ). Eleven of these 30 children had participated in the study by Thal et al., nine were included in Study 1 above, and fourteen were in Study 2 (see Table 1 for details). The total sample includes 24 children with LH damage and only 6 with RH damage. Because the left/right imbalance is particularly large in this substudy, analyses based on side of lesion must be interpreted with caution. For additional details, see Table 1.

Procedure. See General Methods.

Results. Children in the focal-lesion sample had a mean utterance length of 1.98 (s.d. = .94 , range $=1.00-4.38$ ). Although the mean age of our sample was 30.5 months, these MLU scores correspond to a mean language age of 26.9 months (s.d. $=7.6$, range $=19-45.6$ ). In other words, the children with focal brain injury as a group are approximately four months behind their normal age mates. Expressed in terms of z-scores, the mean for our sample is -0.88 (i.e., almost one standard deviation below the mean for normally developing children), but the range is once again very broad (s.d. $=1.48$, range $=-3.17$ to +2.15 ). A z-score of -1.28 or less would correspond to a percentile score of 10 or less, which would be comparable to the risk range we adopted in the last two studies. By this metric, 16 of the 30 children or $52 \%$ of the sample were at or below the 10th percentile, far more than we would expect by chance $(\mathrm{p}<.00001)$. By contrast, only 3 out of 30 children fell at or above the 90th percentile-exactly what we would expect if children were drawn by chance from the normal population. 
A planned comparison of children with left- vs. right-hemisphere injury failed to reach significance $(\mathrm{t}=-0.83$, n.s.), although the respective group means are in the predicted direction $(\mathrm{LH}$ mean $=-0.99$; RH mean $=-0.44)$. These results are presented in Figure 3a, together with results for individual children in each group. Within the LH group, 15 out of 24 or $62 \%$ of the sample scored at or below the 10th percentile (with z scores less than -1.28). This is far more than we would expect by chance if these children were drawn from the normal population ( $\mathrm{p}<$ .00001). Within the RH group, only one child out of 6 (or 17\%) fell in the same risk range, a chance finding on a binomial test. A likelihood ratio comparing $\mathrm{LH}$ and $\mathrm{RH}$ children who are above or below the 10 th percentile was significant $(\mathrm{p}<.04)$. Nonparametric results are presented in Figure $3 b$.

Insert Figures $3 a$ and $3 b$ here

Another planned comparison of children with and without left temporal involvement did reach significance $(\mathrm{t}=3.96, \mathrm{p}<.0005,1$-tailed). This reflects a mean MLU z-score of -0.15 for children without left temporal involvement, compared with a mean of -1.84 for children with left temporal injuries. These data are presented in Figure 3a, where they can be compared with the nonsignificant results for LH vs. RH.

From a nonparametric perspective, 5 of the 17 children without left temporal injuries or $31 \%$ of the sample fell at or below the 10th percentile, reliable by a binomial test $(\mathrm{p}<.05)$. By comparison, 11 of the 13 children with left temporal injuries or $85 \%$ of the sample fell in the same risk range, far more than we would expect by chance $(p<.00001)$. A likelihood ratio comparing children with and without left temporal injury who were above or below the 10th percentile was reliable $(\mathrm{p}<.002)$. The nonparametric data are presented in Figure $3 \mathrm{~b}$, next to results for the $\mathrm{LH} / \mathrm{RH}$ comparison.

In this study (unlike the previous two), we do have enough children with left frontal involvement but no involvement of the left temporal lobe to warrant separate analyses. A planned comparison of children with and without left frontal injuries did not reach significance $(\mathrm{t}=0.66$, n.s.), although mean scores were in the predicted direction (-LFrontal $=-0.72$; + LFrontal $=-1.08)$. These data are graphed in Figure $3 \mathrm{a}$, to facilitate comparison with the LH/RH and -Left Temporal/+Left Temporal findings discussed above. 
Taking a nonparametric look at the same data, we find that 7 out of 16 children or $44 \%$ of those without left frontal involvement are at or below the 10th percentile, substantially more than we would expect by chance $(\mathrm{p}<.001)$. This compares with 9 out of 14 or $64 \%$ of children with left frontal injuries, also highly reliable on a binomial test $(\mathrm{p}<.00001)$. In other words, a high proportion of these children are at risk, whether or not they have injuries to left frontal cortex. A likelihood ratio comparing children with and without left frontal damage who were above or below the 10th percentile failed to reach significance.

Based on our findings in Study 2, we carried out an exploratory comparison of children with and without frontal damage, regardless of side, and found no significant effects by a 2-tailed test $(\mathrm{t}=0.98, \mathrm{p}<.34,2$-tailed; -Frontal mean $=-0.57 ;+$ Frontal mean $=-1.12)$. We then conducted a complementary analysis comparing children with and without temporal damage, again regardless of side. In this case, the finding was reliable by a two-tailed test $(\mathrm{t}=2.88, \mathrm{p}<$ .008 ; - Temporal mean $=-0.13 ;+$ Temporal mean $=-1.54$ ).

To learn more about the specificity of our left temporal effects, children were regrouped to reflect presence/absence of left parietal damage. Among the 13 children with left temporal injuries, 9 also had damage to the parietal zone; conversely, among the 14 children with left parietal damage, 9 had injuries extending into left temporal cortex. Hence there is considerable overlap between these two lesion types, but enough separation to warrant separate analyses. In contrast with our findings in Studies 1 and 2, a t-test comparing MLU z-scores for children with and without left parietal damage did reach significance (mean $+\mathrm{LP}=-1.61$; mean $-\mathrm{LP}=-.24, \mathrm{t}=$ $2.89, \mathrm{p}<.01)$. Hence the effects of left temporal and left parietal damage appear to be confounded. To pull apart these confounds, we conducted two separate analyses of covariance. In the first analysis, we looked at MLU z-scores as a function of presence/absence of left temporal damage, controlling for presence/absence of left parietal injury. The effect of the left parietal covariate was reliable $(\mathrm{F}(1,29)=9.38, \mathrm{p}<.01)$, but so was the effect of left temporal damage after left parietal effects are controlled $(\mathrm{F}(1,29)=6.29, \mathrm{p}<.002)$. In the converse analysis, the effect of the left temporal covariate was reliable $(\mathrm{F}(1,29)=14.07, \mathrm{p}<.001)$, but the effect of left parietal injury was not reliable when left temporal contributions are controlled $(\mathrm{F}(1,29)=1.60$, n.s.). Hence we may conclude that left temporal injuries represent a significant and unique risk factor for grammatical development in this age range.

Because there are only six children with RH damage in this particular sample, a statistical search for specific sites of risk within the right hemisphere was not warranted. However, the raw data are largely compatible with our findings for grammar in Study 2. For the $3 \mathrm{RH}$ children with right frontal sparing, the mean MLU z-score was +.45 , while the mean for RH children with 
right frontal involvement was -1.32 . This is in the same direction that we reported in Study 2, suggesting that bilateral frontal effects may still be operating, although they have begun to ebb. For the 3 RH children with right temporal sparing, the mean score was -.66, compared with a score of -.21 for the $3 \mathrm{RH}$ children with right temporal involvement. This is in the opposite direction from what we might predict if there was an RH "mirror image" of our left temporal effects.

Finally, we looked for possible effects of presence/absence of seizure history, hemiparesis and visual field cuts, and found no significant differences. Because there were only two children in this sample without some kind of subcortical involvement, no statistical analyses were conducted on this factor.

To summarize, these data provide only weak support for a left-hemisphere disadvantage in mean length of utterance during the period from 19 - 44 months (i.e., the effect was not significant on a parametric test, although a likelihood ratio showed that more LH children fall at or below the 10th percentile). There was much stronger support for a site-specific disadvantage for children with injuries to the left temporal lobe, in line with our findings for Studies 1 and 2. By contrast, there was no evidence for a specific left frontal contribution (against the Broca hypothesis), and only a trend toward the kind of bilateral frontal effect that emerged in Study 2.

\section{SUMMARY AND CONCLUSION}

We began this paper by pointing out a paradox: Most cases of adult aphasia are associated with injuries to the left hemisphere, and yet infants who have suffered massive injuries to the same left-hemisphere sites usually go on to achieve language abilities within the normal range. Why are these left-hemisphere sites so important for adults if they are not necessary for normal language acquisition? The results presented here point toward a possible solution. In line with the taxonomy of innate constraints provided by Elman et al. (in press), and with a number of earlier proposals on the origins of lateralization (e.g., Annett, 1985; Bradshaw \& Nettleton, 1981; Bryden, 1982), we propose that the human capacity for language is not localized at birth. Instead, it emerges indirectly out of innate variations in the way that information is processed in different regions of the brain, an example of what Elman et al. (in press) call "architectural nativism." New information about the existence and nature of these regional variations in architecture can be inferred from the site-specific and phase-specific effects of early focal brain injury that are observed during the passage from first words to grammar. 
As a point of departure in the search for site-specific effects in children, we derived three straightforward predictions from the adult aphasia literature.

(1) The left-specialization hypothesis predicts more severe language impairments overall in children with injuries to the left hemisphere.

(2) The Broca hypothesis predicts more severe deficits in language production among children with damage to the anterior regions of the left hemisphere (in particular, the perisylvian area of the left frontal lobe).

(3) The Wernicke hypothesis predicts more severe deficits in language comprehension in children with damage to the posterior regions of the left hemisphere (in particular, the posterior portion of the left temporal lobe).

The developmental literature to date provides surprisingly little support for any of these hypotheses, and the same is true for the present study. In contrast with a number of previous studies, we did find clear positive evidence for site-specific effects during particular periods in development. However, these effects do not map onto the adult aphasia literature in a straightforward fashion, and they vary depending on the kind of language problem that the child is trying to solve at each point in time.

Table 2 provides a summary of neurological findings for each of the three studies presented here. Robust findings are indicated by a double arrow, which means that a particular neurological risk factor is associated with a significant between-group difference (comparing children with that risk factor to the rest of the focal-lesion sample). Weak findings are indicated by a single arrow, indicating that children with that risk factor are more likely to fall in the "risk range" than we would expect by chance, even though between-group comparisons did not reach significance.

insert Table 2 about here

Starting with the emergence of first words and gesture from 10 - 17 months, we found only modest evidence in favor of an early left-hemisphere specialization for language (Hypothesis 1). In fact, some of our findings run in the opposite direction, suggesting that the right hemisphere may play a unique and important role in the first stages of language comprehension and gestural communication. Right-hemisphere lesions were associated with a 
robust disadvantage in gestural development-precisely the opposite of what we would expect based on the adult literature on communicative and pantomimic gesture (Duffy \& Duffy, 1981; Goodglass, 1993). Right-hemisphere lesions were also associated with a weak disadvantage for word comprehension (i.e., more children with RH damage fell at or below the 10th percentile than we would expect by chance, something that was not true for the LH sample). Furthermore, none of the children with left temporal injuries were in the risk range for word comprehension, solid evidence against the Wernicke hypothesis (Hypothesis 3).

We did find a weak disadvantage for word production in the LH group (i.e., more of these children were at or below the 10th percentile than we would expect by chance), but the left/right comparison was not reliable (against Hypothesis 1). However, the Broca hypothesis (Hypothesis 2) did not fare very well. There was a robust disadvantage for the left temporal group on a measure that reflects the proportion of comprehended words that the child is able to produce for himself. In fact, as we have just noted, the left temporal group does very well in word comprehension. Their problem seems to involve the process by which a normal receptive vocabulary is converted into speech, and may be related to the sharp dissociations between comprehension and production that are so often reported in the normal population (e.g., Bates et al., 1988).

Study 2 focussed on the passage from first words to grammar from 19 - 30 months, a particularly dramatic period of development in normal children. Here we found a number of additional surprises.

First, we found no evidence for a dissociation between grammar and vocabulary in this population. This finding is in line with reports for normal children (Fenson et al., 1994) and for several other clinical groups (e.g., Williams Syndrome-Singer, Bellugi, Bates, Jones, \& Rossen, this volume). In fact, one might argue that the absence of a grammar/vocabulary dissociation is tautological, i.e. that the correlations observed in the normal population mean that it would be impossible to find a dissociation in any clinical group. However, the paper by Singer et al. in this volume does report significant dissociations in the Down Syndrome population, with grammar falling far behind the levels we would expect for normal children at the same vocabulary level. If grammar and vocabulary were governed by separate brain regions, then we might have expected to find at least a few dissociated cases in our focal-lesion sample. Instead, we found no evidence for a dissociation between grammar and the lexicon in this period of development, and no evidence for differential effects of lesion side or site on these two domains. 
Second, the results of Study 2 provide a further disconfirmation of Hypotheses 1 - 3. One of the biggest surprises in this data set was an effect of frontal lobe injury on progress in vocabulary and grammar that appears to be independent of lesion side (i.e., it was equally strong for LH and RH children). One might speculate that this bilateral frontal effect reflects nothing more than gross motor impairment, slowing children down in a period that is normally marked by rapid acceleration of vocabulary and first word combinations. However, we found no relationship between frontal damage and presence/absence of hemiparesis in this sample of children (see General Method, and Table 1).

Assuming for the moment that the bilateral frontal effect is not a by-product of gross motor impairment, are there any other explanations? There are at least three possibilities, and they are not mutually exclusive. First, even though gross motor impairments are apparently not responsible for the bilateral frontal effect, there could be motor impairments specific to the motor speech system. A second and closely related possibility is that children with frontal damage are more likely to sustain damage to anterior subcortical systems (in particular, the basal ganglia), structures that may be particularly important in this phase of development. Unfortunately, we do not have detailed information on subcortical structures for this sample of children, but this remains a viable hypothesis for future research (Aram \& Eisele, 1994; Aram, Rose, Rekate, \& Whitaker, 1983; Eisele, Alexander, \& Aram, in preparation). A third possibility is that children with frontal injuries are impaired in planning and sequencing (i.e., the so-called "executive functions"- Diamond, 1988; Milner, Petrides, \& Smith, 1985; Shimamura, Janowsky, \& Squire, 1990; Welsh \& Pennington, 1988). Regardless of the explanation for this bilateral frontal effect, we should underscore that the result is only reliable in this particular phase of language development, albeit a very important and dramatic phase for normally developing children. The result is important primarily because it suggests that Broca's area and associated regions in left frontal cortex have not yet assumed the special role that they are known to play in adult language processing.

Study 2 does provide limited evidence for left-hemisphere specialization in early expressive vocabulary and grammar (in favor of Hypothesis 1), but this unilateral finding is almost entirely due to lesions involving the left temporal lobe (against Hypotheses 2 and 3). Children with lesions involving the left temporal lobe were significantly delayed in both vocabulary and grammar, a continuation of the left temporal delays observed from $10-17$ months in the percentage of receptive vocabulary that children are able to realize in speech. Although there was a trend toward a mirror image effect on the right side, the RH temporal effect was not reliable. Hence the effect of temporal lobe damage appears to be asymmetrical, unlike the frontal lobe effects discussed above. Control analyses comparing children with and without 
left parietal injury did not reach significance, bolstering our confidence that the left temporal effects are real, and quite specific.

Study 2 also replicated an interesting trend reported earlier by Thal et al.: Children with RH damage produce a higher proportion of grammatical function words than children with LH damage, controlling for total vocabulary size. As we noted earlier, this measure looks (at first glance) like an index of emerging grammar. However, studies of normally developing children have confirmed that the early use of function words (termed "closed-class style") is either unrelated or negatively related to progress in grammar several months later (Bates et al., 1988). The same measure was also unrelated to concurrent vocabulary and grammar in the present study. So what does this peculiar measure mean? In a review of the literature on stylistic differences in early language, Bates et al. (1995) propose that closed-class style (also called "pronominal style"-Bloom et al., 1975) may occur in children who can perceive, store and reproduce passages of speech that they still do not understand. They suggest that this propensity may reflect variations in auditory short-term memory, and/or an acute capacity for perceptual detail. If it is the case that children with RH damage are forced to rely more on left-hemisphere processes, and if it is the case that the left hemisphere plays a critical role in the extraction and reproduction of perceptual detail (more on this below), then we may have an explanation for the prevalance of "closed-class style" in the RH population-an explanation with interesting implications for the occurrence of this style in normal children.

The bilateral frontal effects observed in Study 2 did not reach significance in Study 3 (which looks at free speech, with an age range extending from 19 through 44 months of age), although results are in the same direction. However, the left temporal effect on expressive language observed in Studies 1 and 2 is still operating in Study 3. If anything, the disadvantage associated with left temporal involvement is even greater in this phase of development, with this particular measure of language ability (i.e., mean length of utterance in morphemes, or MLU). The same finding could not be seen in a simple left-right comparison, and we also found no effects of left parietal injury when left temporal involvement is controlled. These results provide further evidence that the left temporal lobe is central to the emergence of left-hemisphere specialization for language.

In a separate study of grammar and discourse in 30 children with early focal brain injury (including 10 children from the present study), Reilly, Bates \& Marchman (in press) report a lefthemisphere disadvantage in grammar between 3 - 6 years of age, a disadvantage that is due almost entirely to children with left temporal involvement. Interestingly, they found no sign whatsoever of this left temporal effect after age 6, on grammar or on any other measure of 
language in a story-telling task. When data were collapsed across the range from 3 - 12 years of age, no side or site of lesion effects of any kind were detectable in their data, for lexical, grammatical and/or discourse measures. Children with focal brain injury were (as a group) significantly lower on a host of language measures, compared with normal controls, although their performance was well within the normal range in all but a few cases. For this reason, Reilly et al. conclude that early focal brain injury does exact a price; the alternative forms of brain organization for language that these children have developed work very well in most cases, but they are not optimal. However, the Reilly et al. findings agree with many other studies of language in the focal-lesion population, with very limited evidence for site-specific effects after 5-7 years of age.

These are all cross-sectional findings (although a few children appear in consecutive studies), and they must be replicated in a longitudinal design before we can draw strong conclusions about development and recovery over time. However, the picture that emerges when results from all these studies are combined is one in which site-specific effects come and go over time, depending on the task at hand. Eventually all these children find a solution to the problems of language acquisition, a solution that is workable even if it is not optimal (see Webster et al. for similar findings in lesion studies with primate infants and adults). Putting our data together with those of Reilly et al., we propose that these solutions are relatively stable by 57 years of age, when the fundamental principles of oral language are well established in the normal population. Before this point, we do find interesting site-specific effects, with particular emphasis on (a) right-hemisphere mediation of some processes that are usually handled in the left hemisphere among adults, (b) bilateral frontal effects during the most dramatic period of vocabulary expansion and early grammar, with (c) left temporal effects on expressive (but not receptive) language that are visible across the period from 10 - 60 months of age. After age 6 , these site-specific effects are difficult to detect in children with pre- or perinatal brain injury, suggesting that a substantial degree of inter- and/or intrahemispheric reorganization has taken place (Rasmussen \& Milner, 1977; Webster et al., 1995).

We must stress that our conclusions pertain only to children with early (pre-linguistic) lesion onset, the group for whom it is reasonable to assume maximal plasticity with minimal commitment. It is not clear when the capacity for reorganization disappears, although there are good reasons to believe that later lesions have a more severe and perhaps irreversible effect (Hecaen, 1976, 1983; Marchman, 1983). We also want to underscore the fact that brain damage does exact a price, even in cases of early lesion onset. Thus (for example), the children studied by Reilly et al. are significantly behind their agemates on a host of language measures, even though they are still well within the normal range. The capacity of the human brain to reorganize 
and redistribute language functions is not total. But it is certainly impressive, raising problems for any theory that presupposes innate localization of linguistic knowledge.

Although it will no doubt prove difficult to find a unifying account of all these findings, we have proposed that they reflect regional differences in architecture and (perhaps) in timing, biases that are only indirectly related to the functional and representational specializations that are evident in adult language processing (specializations that can be set up in other places if the child has no other choice). This framework could explain the apparent paradox between the adult aphasia literature and decades of research on language recovery in children with homologous injuries. Can we be more specific about the nature of these putative biases? A full account will require the collaborative efforts of behavioral scientists and developmental neurobiologists, delineating the computational properties of specific regions in infant cortex and their functional consequences. However, we can offer a few speculations and a possible place to start.

Following a proposal by Stiles and Thal (1993), we suggest that left and right temporal cortex differ at birth in their capacity to support perceptual detail (enhanced on the left) and perceptual integration (enhanced on the right). The site-specific effects that we see in early language development reflect the differential importance of detail and integration at various stages in the learning process. Although it was once believed that the right hemisphere is innately specialized for visual-spatial analysis, most researchers now agree that the two hemispheres contribute equally to the analysis of visual displays-but they do so in markedly different ways. For example, a number of recent studies have shown that lesions to the right hemisphere lead to problems in the integration of elements in a perceptual array, while lesions to the left hemisphere create problems in the analysis of perceptual details in the same array (e.g. Robertson \& Lamb, 1991). Asked to reproduce a triangle made up of many small squares, adult patients with left-hemisphere damage tend to reproduce the global figure (i.e., the triangle) while ignoring information at the local level. Adult patients with right-hemisphere damage display the opposite profile, reproducing local detail (i.e., a host of small squares) but failing to integrate these features into a coherent whole. Stiles and Thal report that children with focal brain injury behave very much like their adult counterparts on the local-global task, suggesting that the differential contribution of left- and right-hemisphere processes on this task may be a developmental constant. Interestingly, this double dissociation is most evident in patients with temporal involvement (on the left or on the right-Stiles, personal communication, September 1994). 
We suggest that a relatively simple bias in style of computation may underlie the left temporal effects observed in visual perception by Robertson \& Lamb (in adults) and Stiles and Thal (in children), and the left temporal effects on language observed in the present study. In the first stages of word comprehension and (perhaps) recognition and reproduction of familiar gestures, the ability to integrate information within and across modalities may be particularly helpful and important. After all, learning the meaning of the word "elephant" for the very first time is quite different from the passive and automatic processes that underlie word recognition in the adult. Unlike the adult, the child can and must integrate information from many different sources and modalities to make sense of this new word (e.g., the sight of the elephant, accompanying sounds and smells, the context of the zoo and memories of being there before, parental gestures and facial expressions as the word is spoken). Perhaps for this reason, integrative processes in the right hemisphere may predominate in word comprehension from 10 17 months, placing children with right-hemisphere injuries at a special (but temporary) disadvantage.

The learning process changes markedly when children have to convert the same sound patterns into motor output. At this point, perceptual detail may be of paramount importance (i.e., it is one thing to recognize the word "elephant", but quite another thing to pull out each phonetic detail and construct a motor template). If it is the case that left temporal cortex plays a critical role in the extraction, storage and reproduction of perceptual detail (visual and/or acoustic), then children with left temporal injuries will be at a greater disadvantage in this phase of learning (see also Galaburda \& Livingstone, 1993, Galaburda, Menard, \& Rosen, 1994; Tallal, Sainburg, \& Jernigan, 1991). However, once the requisite patterns are finally constructed and set into welllearned routines, the left temporal disadvantage may be much less evident.

\section{Some Caveats}

Although we believe that these results raise some important questions for future research, we close by underscoring some limitations of the present study.

First, the population of children with early unilateral brain injuries is quite small. Indeed, it has taken us eight years in three large cities to accumulate the data reported here, which means (among other things) that there is also considerable variability in the quality of the CT and MRI scans that were used to derive lesion information. All of these findings need to be replicated with separate samples of children, and with state-of-the-art techniques for three-dimensional lesion reconstruction. 
Second, in contrast with adult aphasics, whose acquired lesions are usually diagnosed soon after the incident occurred, the onset time and etiology of the lesions in our children are often unknown. In addition, the distribution of left- vs. right-hemisphere lesions is highly skewed, and within each group, there is considerable overlap in lesion location. Hence some of our more interesting findings regarding the role of left temporal structures must be qualified by the fact that the left temporal lobe is also one of the most probable sites of injury, with obvious consequences for sample size and statistical power (although it is comforting that parallel analyses involving presence/absence of left parietal injury did not show the same pattern, since parietal sites are even more common than temporal ones). To replicate the left temporal effect, and to explore some of the unexpected findings uncovered here (e.g., the RH effects in Study 1 and the bilateral frontal effects in Study 2), it would be useful to investigate a larger and more balanced population of children with focal brain injury, with special emphasis on the separate contributions of temporal and frontal damage.

Third, the results that we have reported here are cross-sectional in nature. Before we can conclude with conviction that the site-specific effects observed in Studies 1 - 3 resolve by 5 - 7 years of age, we need to follow the same, longitudinal sample of children across this hypothesized transition point.

Fourth, we must remember that development involves change at many levels, including changes in brain structure. For example, there are some cases in which a small lesion that is apparent on an early scan seems to have disappeared when the same child is studied many years later. Perhaps the early scan was "wrong" and the later scan was "right", but it is also possible that tissue changes have taken place as a consequence of that early lesion. In fact, very little is known about the functional and structural changes that occur as a result of early focal brain injury. Possibilities include compensatory sprouting in other regions, retention of exuberant neurons, axons and synapses that might have been eliminated in the absence of early injury, and "reprogramming" of areas that would have behaved quite differently if the lesion had never occurred. There are also occasional changes in a more negative direction, e.g. children with early focal brain injury who go on to develop neurological problems (including seizures) that were not evident in the period of development that we have studied here. For this reason, the null effects of lesion size, seizure history and/or motor involvement that we have reported here for children in the 10 - 44-month age range may underestimate the long-term contribution of these factors. These facts underscore the need for larger samples, and for long-term longitudinal studies. 
What are the practical solutions to these problems? One possibility would be to redefine and expand our definition of focal brain injury. For example, we could obtain a larger sample of children with frontal injuries (unilateral or bilateral) if we were to include cases of tumor or trauma. However, that would also guarantee an increase in the heterogeneity of the sample, due to the introduction of complications that we do not face in the present study (i.e., diffuse damage from closed-head injury, side effects of radiation or chemotherapy). In our view, the best solution to the problem of sample size lies in large-scale collaborations across clinical and research sites, permitting researchers to standardize their diagnostic criteria and pool data on robust and reliable neurological and behavioral measures. Some preliminary efforts in that direction are already underway.

At the very least, results of the present study confirm that detailed neuroanatomical and neurophysiological studies of children with focal brain injury could yield extremely important information about the developmental processes that lead to brain organization for language in adults. If the correlations between lesion localization and behavioral outcome observed in children were identical to those that are observed in adults, then developmental studies would have little to add (beyond a confirmation of strong claims about the innate bases of language). Conversely, if there were no correlations whatsoever between lesion type and behavioral outcome, then further developmental studies would not take us very far (beyond a confirmation of strong claims about brain plasticity). Our results suggest that both of these extreme views are wrong. We have a great deal to learn about the neural bases of language development, and research on children with early focal brain injury is one promising line of inquiry. 


\section{FOOTNOTES}

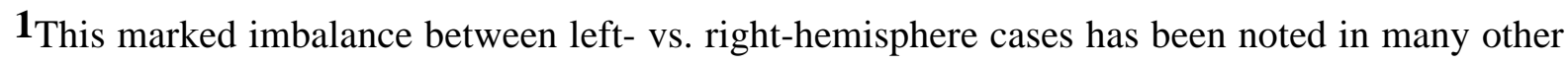
studies of pre- and perinatal brain injury, and may reflect asymmetries in blood flow that are particularly marked during fetal development (Altman \& Volpe, 1987).

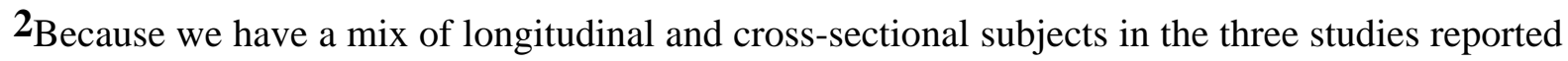
here, it would be important to determine whether the lesion-symptom correlations that we observe at each stage are produced by the same children, or by different children with the same neurological characteristics. In particular, our results could be skewed artificially if a few very slow children happened to be among the longitudinal subjects who contribute to more than one study. To determine whether this is the case, we divided the sample into longitudinal and nonlongitudinal subjects (with "longitudinal" defined to refer to participation in more than one of the three studies), and ran a series of preliminary one-way analyses of variance comparing these two groups on all of our primary dependent variables, at each age level. There were no significant differences between longitudinal and cross-sectional subjects in these comparisons, justifying our conclusion to group these cases together within each study.

3 On the MacArthur Infant Scale, there is a single-word checklist with separate columns for "understands" and "understands and says". The list does not allow for a category representing "says but does not understand." According to Fenson et al. (1993), parents of normally developing children who participated in earlier studies with predecessors of the CDI were unable to distinguish between saying with and without understanding; most parents assume that a child who says a word has some understanding of its meaning. Therefore, to avoid ambiguity, the third option was eliminated in the final form of the scale. This means, of course, that there is no direct mechanism for detecting "rote" or parrot-like production in the absence of understanding. Indirect estimates of "comprehension-free" production have been made in regression designs, partialling out comprehension totals from analyses looking at the correlates of production (see Fenson et al., 1994, for some examples). For present purposes, the main point is that a simple ratio of words produced to words comprehended can be interpreted as the percentage of those words that children understand which they can also produce. 


\section{REFERENCES}

Acredolo, L.P., \& Goodwyn, S.W. (1988). Symbolic gesturing in normal infants. Child Development, 59, 450-456.

Acredolo, L.P., \& Goodwyn, S.W. (1990). Sign language among hearing infants: The spontaneous development of symbolic gestures. In V. Volterra \& C. Erting (Eds.), From gesture to language in hearing and deaf children (pp. 68-78). Berlin: Springer-Verlag.

Alajouanine, T., \& Lhermitte, F. (1965). Acquired aphasia in children. Brain, 88, 553-562.

Allen, M. (1983). Models of hemispheric specialization. Psychological Bulletin, 93, 73-104.

Almli, C., \& Finger, S. (1984). Early brain damage. New York: Academic Press.

Altman, D., \& Volpe, J. (1987). Cerebral blood flow in the newborn infant: Measurement and role in the pathogenesis of periventricular and intraventricular hemorrhage. Advances in Pediatrics, 34, 111-38.

Annett, M. (1973). Laterality of childhood hemiplegia and the growth of speech and intelligence. Cortex, 9, 4-33.

Annett, M. (1985). Left, right, hand and brain: The right shift theory. Hillsdale, N.J.: Erlbaum.

Aram, D.M. (1988). Language sequelae of unilateral brain lesions in children. In F. Plum (Ed.), Language, communication, and the brain (pp. 171-197). New York: Raven Press.

Aram, D. (1992). Brain injury and language impairment in childhood. In P. Fletcher \& D. Hall (Eds.), Specific speech and language disorders in children. London: Whurr Publishers

Aram, D.M., \& Eisele, J.A. (1994a). Limits to a left-hemisphere explanation for specific language impairment. Journal of Speech and Hearing Research, 37(4), 824-830.

Aram, D.M., \& Eisele, J.A. (1994b). Intellectual stability in children with unilateral brain lesions. Neuropsychologia, 32(1), 85-95.

Aram, D., Ekelman, B., Rose, D., \& Whitaker, H. (1985). Verbal and cognitive sequelae following unilateral lesions acquired in early childhood. Journal of Clinical \& Experimental Neuropsychology, 7, 55-78. 
Aram. D., Ekelman, B., \& Whitaker, H. (1986). Spoken syntax in children with acquired unilateral hemisphere lesions. Brain and Language, 27, 75-100.

Aram, D., Ekelman, B., \& Whitaker, H. (1987). Lexical retrieval in left- and right-brainlesioned children. Brain and Language, 28, 61-87.

Aram, D. M., Meyers, S. C., \& Ekelman, B. L. (1990). Fluency of conversational speech in children with unilateral brain lesions. Brain and Language, 38(1), 105-121.

Aram, D.M., Rose, D.F., Rekate, H.L., \& Whitaker, H.A. (1983). Acquired capsular/striatal aphasia in childhood. Archives of Neurology, 40(10), 614-617.

Basso, A., Capitani, E., Laiacona, M., \& Luzzatti, C. (1980). Factors influencing type and severity of aphasia. Cortex, 16, 631-636.

Bates, E., Appelbaum, M., \& Allard, L. (1991). Statistical constraints on the use of single cases in neuropsychological research. Brain and Language, 40, 295-329.

Bates, E., Benigni, L., Bretherton, I., Camaioni, L., \& Volterra, V. (1979). The emergence of symbols: Cognition and communication in infancy. New York: Academic Press.

Bates, E., Bretherton, I., \& Snyder, L. (1988). From first words to grammar: Individual differences and dissociable mechanisms. New York: Cambridge University Press.

Bates, E., Bretherton, I., Shore, C., \& McNew, S. (1983). Names, gestures and objects: Symbolization in infancy and aphasia. In K. Nelson, (Ed.), Children's language. Vol. $I V$. Hillsdale, NJ: Erlbaum.

Bates, E., Dale, P.S., \& Thal, D. (1995). Individual differences and their implications for theories of language development. In Paul Fletcher \& Brian MacWhinney (Eds.), Handbook of child language. Oxford: Basil Blackwell.

Bates, E., Marchman, V., Thal, D., Fenson, L., Dale, P., Reznick, J.S., Reilly, J., \& Hartung, J. (1994). Developmental and stylistic variation in the composition of early vocabulary. Journal of Child Language, 21:1, 85-124.

Bates, E., O'Connell, B., \& Shore, C. (1987). Language and communication in infancy. In J. Osofsky (Ed.), Handbook of infant development (2nd ed.). New York: Wiley \& Sons. 
Bates, E., \& Thal, D. (1991). Associations and dissociations in child language development. In J. Miller (Ed.), Research on child language disorders: A decade of progress. Austin, TX: Pro-Ed.

Bates, E., Thal, D., \& Janowsky, J. (1992). Early language development and its neural correlates. In I. Rapin and S. Segalowitz (Eds.), Handbook of neuropsychology, Vol. 7: Child neuropsychology (pp. 69-110). Amsterdam: Elsevier.

Bates, E., Thal, D., Whitesell, K., Fenson, L., \& Oakes, L. (1989). Integrating language and gesture in infancy. Developmental Psychology, 25(6), 1004-1019.

Bates, E., \& Wulfeck, B. (1989). Comparative aphasiology: A cross-linguistic approach to language breakdown. Aphasiology, 3, 111-142 and 161-168.

Bellugi, U., \& Hickok, G. (1995). Clues to the neurobiology of language. In R.Broadwell (Ed.), Neuroscience, memory and language. Decade of the Brain Series, Vol. 1. Washington, DC: Library of Congress.

Benedict, H. (1979). Early lexical development: Comprehension and production. Journal of Child Language, 6, 183-200.

Best, C. (1988). The emergence of cerebral asymmetries in early human development: a literature review and a neuroembryological model. In D. Molfese and S. Segalowitz (Eds.), Brain lateralization in Children. New York: Guilford Press, 5-34.

Bishop, D.V.M. (1981). Plasticity and specificity of language localization in the developing brain. Developmental Medicine and Child Neurology, 23, 251.

Bishop, D.V.M. (1983). Linguistic impairment after left hemidecortication for infantile hemiplegia? A reappraisal. Quarterly Journal of Experimental Psychology, 35A, 199207.

Bishop, D.V.M. (1992). The biological basis of specific language impairment. In P. Fletcher \& D. Hall (Eds.), Specific speech and language disorders in children. London: Whurr Publishers.

Bloom, L. (1970). Language development: Form and function in emerging grammars. Cambridge, MA: MIT Press. 
Bloom, L. (1973). One word at a time: The use of single-word utterances before syntax. The Hague: Mouton.

Bloom, L., Joanne Bitetti Capatides et al. (Eds.) (1991). Language development from two to three. Cambridge; New York: Cambridge University Press.

Bloom, L., Lightbown, L., \& Hood, L. (1975). Structure and variation in child language. Monographs for the Society for Research in Child Development, 40, Serial \#160.

Borer, H., \& Wexler, K. (1987). The maturation of syntax. In T. Roeper \& E. Williams (Eds.), Parameter setting (pp. 123-172). Dordrecht, Holland: Reidel.

Bradshaw, J., \& Nettleton, N. (1981). The nature of hemispheric specialization in man. Behavioral and Brain Sciences, 4, 51-91.

Brown, R. (1973). A first language: The early stages. Cambridge, MA: Harvard University Press.

Brownell, C. (1988). Combinatorial skills: Converging developments over the second year. Child Development, 59, 675-685.

Bryden, M. (1982). Laterality: Functional asymmetry in the intact brain. New York: Academic Press.

Caplan, D., \& Hildebrandt, N. (1988). Disorders of syntactic comprehension. Cambridge, MA: MIT Press.

Changeux, J.P., Courrège, P., \& Danchin, A. (1973). A theory of the epigenesis of neural networks by selective stabilization of synapses. Proceedings of the National Academy of Sciences USA, 70, 2974-2978.

Changeux, J., \& Danchin, A. (1976). Selective stabilization of developing synapses as a mechanism for the specification of neuronal networks. Nature, 264, 705-712.

Churchland, P.S., \& Sejnowski, T.J. (1992). The computational brain. Cambridge, MA/London: MIT Press.

Corballis, M., \& Morgan, M. (1978). On the biological basis of human laterality: I. Evidence for a maturational left-right gradient. Behavioral and Brain Sciences, 1, 261-269. 
Courchesne, A., Townsend J., \& Chase, C. (in press). Neurodevelopmental principles guide research on developmental psychopathologies. In D. Cicchetti and D. Cohen (Eds.), A manual of developmental psychology. Cambridge University Press.

Crain, S. (1992). Language acquisition in the absence of experience. Behavioral and Brain Sciences, 14, 597-611.

Dale, P.S. (1991). The validity of a parent report measure of vocabulary and syntax at 24 months. Journal of Speech and Hearing Sciences, 34, 565-571.

Dale, P.S. Bates, E., Reznick, S., \& Morisset, C. (1989). The validity of a parent report instrument of child language at 20 months. Journal of Child Language, 16, 239-249.

Dall'Oglio, A., Bates., E., Volterra, V., DiCapua, M., \& Pezzini, G. (1994). Early cognition, communication and language in children with focal brain injury. Developmental Medicine and Child Neurology.

Damasio, A., \& Damasio, H. (1992). Brain and language. Scientific American, 267, 88-95.

Damasio, A. (1989). Time-locked multiregional retroactivation: A systems-level proposal for the neural substrates of recall and recognition. Cognition, 33, 25-62.

Day, P. S., \& Ulatowska, H. K. (1979). Perceptual, cognitive, and linguistic development after early hemispherectomy: Two case studies. Brain and Language, 7, 17-33.

Dennis, M. (1980). Capacity and strategy for syntactic comprehension after left or right hemidecortication. Brain and Language, 10, 287-317.

Dennis, M. (1988). Language and the young damaged brain. Washington, DC: American Psychological Association.

Dennis, M., \& Kohn, B. (1975). Comprehension of syntax in infantile hemiplegics after cerebral hemidecortication. Brain and Language, 2, 472-482.

Dennis, M., Lovett, M., \& Wiegel-Crump, C. (1981). Written language acquisition after left or right hemidecortication in infancy. Brain and Language, 12, 54-91.

Dennis, M., \& Whitaker, H. A. (1976). Language acquisition following hemidecortication: Linguistic superiority of the left over the right hemisphere. Brain and Language, 3, 404433. 
Dennis, M., \& Whitaker, H. (1977). Hemispheric equipotentiality and language acquisition. In S. J. Segalowitz \& F. A. Gruber (Eds.), Language development and neurological theory (pp. 93-106). New York: Academic Press. .

Diamond, A. (1988). Abilities and neural mechanisms underlying AB performance. Child Development, 59(2), 523-7.

Dromi, E. (1987). Early lexical development. New York: Cambridge University Press.

Dronkers, N.F., Shapiro, J.K., Redfern, B., \& Knight, R.T. (1992, February). The third left frontal convolution and aphasia: On beyond Broca. Paper presented at the Twentieth Annual Meeting of the International Neuropsychological Society, San Diego, CA.

Duffy, R., \& Duffy, J. (1981). Three studies of deficits in pantomimic expression and pantomime recognition in aphasia. Journal of Speech and Hearing Research, 46, 70 - 86.

Edelman, G. (1987). Neural darwinism: The theory of neuronal group selection. New York: Basic Books.

Elman, J., Bates, E., Johnson, M., Karmiloff-Smith, A., Parisi, D., \& Plunkett, K. (in press). Rethinking innateness: development in a connectionist perspective. Cambridge, MA: MIT/Bradford Books.

Eisele, J.A., Alexander, M.P., \& Aram, D.M. (in preparation). Anterior capsulostriatal lesions predict residual language and cognitive deficits in children.

Eisele, J.A., \& Aram, D. (1993). Differential effects of early hemisphere damage on lexical comprehension and production. Aphasiology, 7:5, 513-523.

Eisele, J.A., \& Aram, D. (1994). Comprehension and imitation of syntax following early hemisphere damage. Brain and Language, 46, 212-231.

Eisele, J.A., \& Aram, D. (1995). Lexical and grammatical development in children with early hemisphere damage: A cross-sectional view from birth to adolescence. In Paul Fletcher \& Brian MacWhinney (Eds.), Handbook of child language (pp. 664-690). Oxford: Basil Blackwell.

Feldman, H., Holland, A., Kemp, S., \& Janosky, J. (1992). Language development after unilateral brain injury. Brain and Language, 42, 89-102. 
Fenson, L., Dale, P., Reznick, J.S., Thal, D., Bates, E., Hartung, J., Pethick, S., \& Reilly, J. (1993). The MacArthur Communicative Development Inventories: User's guide and technical manual. San Diego: Singular Publishing Group.

Fenson, L., Dale, P.A., Reznick, J.S., Bates, E., \& Thal, D. (1994). Variability in early communicative development. Monographs of the Society for Research in Child Development, Serial No. 242, Vol. 59, No. 5.

Fletcher, J. M. (1993). Afterword: Behavior-brain relationships in children. In S. H. Broman \& J. Grafman (Eds.), Atypical cognitive deficits in developmental disorders: Implications for brain function (pp. 297-326). Hillsdale, NJ: Lawrence Erlbaum.

Freud, A. (1953). On aphasia: A critical study. New York: International Universities Press. (Original work published in 1891).

Friedlander, M.J., Martin, K.A.C., \& Wassenhove-McCarthy, D. (1991). Effects of monocular visual deprivation on geniculocortical innervation of area 18 in cat. The Journal of Neuroscience, 11, 3268-3288.

Frost, D.O. (1982). Anomalous visual connections to somatosensory and auditory systems following brain lesions in early life. Developmental Brain Research, 3(4), 627-635.

Frost, D.O. (1990). Sensory processing by novel, experimentally induced cross-modal circuits. Annals of the New York Academy of Sciences, 608, 92-109; discussion 109-12.

Galaburda, A.M. (1994). Language areas, lateralization and the innateness of language. Discussions in Neuroscience, 10, 1/2, 118-124.

Galaburda, A.M., \& Livingstone, M. (1993). Evidence for a magnocellular defect in neurodevelopmental dyslexia. Annals of the New York Academy of Sciences, 682, 70-82.

Galaburda, A.M., Menard, M.T., \& Rosen, G.D. (1994). Evidence for aberrant auditory anatomy in developmental dyslexia. Proceedings of the National Academy of Sciences, USA, 91, 8010-8013.

Gazzaniga, M. (1994). Language and the cerebral hemispheres. Discussions in Neuroscience, $10,1 / 2,136-149$.

Geschwind, N. (1972). Language and the brain. Scientific American, 226(4), 76-83. 
Geschwind, N., \& Levitsky, W. (1968). Human brain: left-right asymmetries in temporal speech region. Science, 161, 186-187.

Goldstein, K. (1948). Language and language disturbances . New York: Grune \& Stratton.

Goodglass, H. (1993). Understanding aphasia. San Diego: Academic Press

Gould, S. J. (1977). Ontogeny and phylogeny. Cambridge, MA: Harvard University Press.

Greenough, W.T., Black, J.E., \& Wallace, C.S. (1993). Experience and brain development. In M. Johnson (Ed.), Brain development and cognition: A Reader (pp. 290-322). Oxford: Blackwell.

Greenough, W.T., McDonald, J.W., Parnisari, R.M., \& Camel, J.E. (1986). Environmental conditions modulate degeneration and new dendrite growth in cerebellum of senescent rats. Brain Research, 380, 136-143.

Hammill, D., \& Irwin, O. C. (1966). I.Q. differences of right and left spastic hemiplegic children. Perceptual and Motor Skills, 22, 193-194.

Hazeltine, E. and Ivry, R. (1994, March). A connectionist model of sequential and laterality effects. Paper presented at the First Annual Meeting of the Cognitive Neuroscience Society, San Francisco.

Head, H. (1963). Aphasia and kindred disorders of speech. New York \& London: Hafner Publishing Company.

Hecaen, H. (1976). Acquired aphasia in children and the ontogenesis of hemispheric functional specialization. Brain and Language, 3, 114-134.

Hecaen, H. (1983). Acquired aphasia in children: Revisited. Neuropsychologia, 21, 581-587.

Hecaen, H., Perenin, M., \& Jeannerod, H. (1984). The effects of cortical lesions in children: language and visual functions. In C. Almli \& S. Finger (Eds.), Behavioral biology of early damage, Vol. 1. New York: Academic Press.

Hellige, J. (1993). Hemispheric asymmetry. Cambridge, MA.: Harvard University Press.

Isaacson, R. L. (1975). The myth of recovery from early brain damage. In N. G. Ellis (Ed.), Aberrant development in infancy (pp. 1-26). New York: Wiley. 
Jacobs, R., Jordan, M., Nowlan, S., \& Hinton, G. (1991). Adaptive mixtures of local experts. Neural Computation, 3, 79-87.

Jacobs, R., \& Kosslyn, S. (1994). Encoding shape and spatial relations:The role of receptive field size in coordinating complementary representations. Cognitive Science, 18(6), 361-386.

Janowsky, J., \& Finlay, B. (1986). The outcome of perinatal brain damage: The role of normal neuron loss and axon retraction. Developmental Medicine, 28, 375-389.

Johnson, J., \& Newport, E. (1989). Critical-period effects in second language learning. Cognitive Psychology, 21, 60-99.

Karmiloff-Smith, A. (1992). Beyond modularity: A developmental perspective on cognitive science. Cambridge, MA: MIT Press.

Kennard, M. (1936). Age and other factors in motor recovery from precentral lesions in monkeys. American Journal of Physiology, 115, 138-146.

Killackey, H.L., Chiaia, N.L., Bennett-Clarke, C.A., Eck, M., \& Rhoades, R. (1994). Peripheral influences on the size and organization of somatotopic representations in the fetal rat cortex. Journal of Neuroscience, 14, 1496-1506.

Killackey, H.P. (1990). Neocortical expansion: An attempt toward relating phylogeny and ontogeny. Journal of Cognitive Neuroscience, 2, 1-17.

Kimura, D. (1982). The neural basis of language qua gesture. In H. Whitaker \& H. Whitaker (Eds.), Studies in neurolinguistics, Vol. 2. New York: Academic Press.

Kinsbourne, M., \& Hiscock, M. (1983). The normal and deviant development of functional lateralization of the brain. In M. Haith \& J. Campos (Eds.), Handbook of child psychology (Vol. II, 4th ed.) New York: Wiley.

Klima, E., S., Kritchevsky, M., \& Hickok, G. (1993). The neural substrate for sign language. Symposium at the 31st Annual Meeting of the Academy of Aphasia, Tucson, AZ.

Kohn, B. (1980). Right-hemisphere speech representation and comprehension of syntax after left cerebral injury. Brain and Language, 9, 350-361.

Kohn, B., \& Dennis, M. (1974). Selective impairments of visuospatial abilities in infantile hemiplegics after right cerebral hemidecortication. Neuropsychologia, 12, 505-512. 
Krashen, S. (1973). Lateralization, language learning, and the critical period: Some new evidence. Language Learning, 23(1), 63-74.

Lashley, K.S. (1950). In search of the engram. In Symposia of the Society for Experimental Biology, No. 4 Physiological mechanisms and animal behaviour. New York: Academic Press.

Lashley, K. S. (1951). Central mechanisms in behavior. New York: Wiley.

Lenneberg, E. H. (1967). Biological foundations of language. New York: Wiley.

Lightfoot, D. (1991). The child's trigger experience: Degree-0 learnability. Behavioral and Brain Sciences, 14:2, 364.

Locke, J. (1993). The child's path to spoken language. Cambridge, MA: Harvard University Press.

MacWhinney, B. (1991). The CHILDES Project: tools for analyzing talk. Hillsdale, New Jersey: Lawrence Erlbaum.

MacWhinney, B., \& Bates, E. (Eds.). (1989 The cross-linguistic study of sentence processing. New York: Cambridge University Press, 1989.

Marchman, V. (1993). Constraints on plasticity in a connectionist model of the English past tense. Journal of Cognitive Neuroscience, 5:2, 215-234.

Marchman, V., \& Bates, E. (1994). Continuity in lexical and morphological development: A test of the critical mass hypothesis. Journal of Child Language, 21:2, 339-366.

Marchman, V. A., Miller, R., \& Bates, E. A. (1991). Babble and first words in children with focal brain injury. Applied Psycholinguistics, 12(1), 1-22.

Marie, P. (1906). Revision de la question de l'aphasie: La troisime circonvolution frontale gauche ne joue aucun role special dans la fonction du language. Semaine Medicale, 26, 241.

Menn, L., \& Obler, L.K. (Eds.). (1990). Agrammatic aphasia: Cross-language narrative sourcebook. Amsterdam/Philadelphia: John Benjamins. 
Merzenich, M., Recanzone, G., Jenkins, W., Allard, T., \& Nudo, R. (1988). Cortical representational plasticity. In P. Rakic \& W. Singer (Eds.), Neurobiology of neocortex (pp. 41-67). New York: Wiley.

Milberg, W., \& Albert, M. (1991). The speed of constituent mental operations and its relationship to neuronal representation: An hypothesis. In R.G. Lister \& H.J. Weingartner (Eds.), Perspectives on cognitive neuroscience. New York: Oxford University Press.

Miller, J.F., \& Chapman, R. (1981). The relation between age and mean length of utterances in morphemes. Journal of Speech and Hearing Research, 24, 154-161.

Milner, B. (1994). Carotid-amytal studies of speech representation and gesture control. Discussions in Neuroscience, 10, 1/2,. 109-117.

Milner, B., Petrides, M., \& Smith, M. (1985). Frontal lobes and the temporal organization of behavior. Human Neurobiology, 4, 137-142.

Mohr, J., Pesssin, M., Finkelstein, S., Funkenstein, H., Duncan, G., \& Davis, K. (1978). Broca aphasia: Pathologic and clinical. Neurology, 28, 311-324.

Molfese, D. (1989). Electrophysiological correlates of word meanings in 14-month-old human infants. Developmental Neuropsychology, 5, 70-103.

Molfese, D. (1990). Auditory evoked responses recorded from 16-month-old human infants to words they did and did not know. Brain and Language, 38, 345-363.

Molfese, D.L., \& Segalowitz, S.J. (1988). Brain lateralization in children: Developmental implications. New York: Guilford Press.

Molnar, Z., \& Blakemore C. (1991). Lack of regional specificity for connections formed between thalamus and cortex in coculture. Nature, 351 (6326), 475-7.

Naeser, M., Helm-Estabrooks, N., Haas, G., Auerbach, S., \& Levine, H. (1984). Relationship between lesion extent in "Wernicke's area" on computed tomographic scan and predicting recovery of comprehension in Wernicke's aphasia. Archives of Neurology, 44(1), 73-82.

Nelson, K. (1973). Structure and strategy in learning to talk. Monographs of the Society for Research in Child Development, 38, (1 \& 2, Serial \#149). 
Nelson, K. (1981). Individual differences in language development: Implications for development and language. Developmental Psychology, 17, 170-187.

Ojemann, G.A. (1991). Cortical organization of language. Journal of Neuroscience, 11:8, 22812287.

O'Leary, D.D. (1993). Do cortical areas emerge from a protocortex? In M. Johnson (Ed.), Brain development and cognition: A reader (pp.323-337). Oxford: Blackwell Publishers.

O'Leary, D.D., \& Stanfield, B.B. (1989). Selective elimination of extended by developing cortical neurons is dependent on regional locale: Experiments utilizing fetal cortical transplants. Journal of Neuroscience, 9(7), 2230-2246.

Oyama, S. (1993). The problem of change. In M. Johnson (Ed.), Brain development and cognition: A reader (pp.19-30). Oxford: Blackwell Publishers.

Pallas, S.L., \& Sur, M. (1993). Visual projections induced into the auditory pathway of ferrets: II. Corticocortical connections of primary auditory cortex. Journal of Comparative Neurology, 337(2), 317-33.

Parmelee, A., \& Sigman, M. (1983). Perinatal brain development and behavior. In M. Haith \& J. Campos (Eds.), Handbook of child psychology (Vol. II, 4th ed.). New York: Wiley.

Peters, A. (1983). The units of language acquisition. Cambridge: Cambridge University Press.

Petersen, S., Fiez, J., \& Corbetta, M. (1992). Neuroimaging. In E. Kandel \& L. Squire (Eds.), Special issue on cognitive neuroscience. Current Opinion in Neurobiology, 2:2, 217 222.

Piatelli-Palmarini, M. (1989). Evolution, selection and cognition: From "learning" to parameter setting in biology and the study of language. Cognition, 31:1, 1-44.

Pinker, S. (1991). Rules of language. Science, 253, 530-535.

Pinker, S. (1994). The language instinct: How the mind creates language. New York: William Morrow.

Pinker, S. (1994). On language. Journal of Cognitive Neuroscience, 6:1,84-91. 
Poizner, H., Klima, E., \& Bellugi, U. (1987). What the hands reveal about the brain. Cambridge, MA.: MIT/Bradford Books.

Pons, T.P., Garraghty, P.E., Ommaya, A.K., Kaas, J.H. Taub, E., \& Mishkin M. (1991). Massive cortical reorganization after sensory deafferentation in adult macaques [see comments]. Science, 252(5014), 1857-60.

Raichle, M. (1994). Positron emission tomography studies of verbal response selection. Discussions in Neuroscience, 10, 1/2, 130 - 135.

Ramachandran, V.S. (1993). Behavioral and magnetoencephalographic correlates of plasticity in the adult human brain. Proceedings of the National Academy of Sciences, 90, 1041310420.

Rasmussen, T., \& Milner, B. (1977). The role of early left brain injury in determining lateralization of cerebral speech functions. Annals of the New York Academy of Sciences, 299, 355-369.

Reed, J. C., \& Reitan, R. M. (1969). Verbal and performance differences among brain-injured children with lateralized motor deficits. Perceptual and Motor Skills, 29(3), 747-52.

Reilly, J., Bates, E., \& Marchman, V. (in press). Narrative discourse in children with early focal brain injury. M. Dennis (Ed.), Special issue, Discourse in children with anomalous brain development or acquired brain injury. Brain and Language.

Riva, D., \& Cazzaniga, L. (1986). Late effects of unilateral brain lesions before and after the first year of life. Neuropsychologia, 24, 423-428.

Riva, D., Cazzaniga, L., Pantaleoni, C., Milani, N., \& Fedrizzi, E. (1986). Acute hemiplegia in childhood: The neuropsychological prognosis. Journal of Pediatric Neurosciences, 2(4), 239-250.

Riva, D., Milani, N., Pantaleoni, C., Devoti, M., \& Zorzi, C. (1992). Gli esiti a distanza delle lesioni cerebrali emisferiche congenite ed adquisite. In A. Benton, H. Levin, G. Moretti, \& D. Riva (Eds.), Neuropsicologia in età evolutiva (pp. 185-197). Milano: FrancoAngeli.

Robertson, L. C., \& Lamb, M. R. (1991). Neuropsychological contributions to theories of part/whole organization. Cognitive Psychology, 23, 299-330. 
Roe, A.W., Pallas, S.L., Hahm, J.O., \& Sur, M. (1990). A map of visual space induced in primary auditory cortex. Science, 250 (4982), 818-20.

Satz, P., Strauss, E., \& Whitaker, H. (1990). The ontogeny of hemispheric specialization: Some old hypotheses revisited. Brain and Language, 38(4), 596-614.

Shimamura, A., Janowsky, J., \& Squire, L. (1990). Memory for the temporal order of events in patients with frontal lobe lesions and amnesic patients. Neuropsychologia, 28:8, 803813.

Shore, C., O’Connell, B., Beeghly, M., Bretherton, I., \& Bates, E. (1990). Vocal and gestural symbols: Similarities and differences from 13 to 28 months. In V. Volterra \& C.J. Erting (Eds.), From gesture to language in hearing and deaf children (pp. 79-91). New York: Springer-Verlag.

Simonds, R.J., \& Scheibel, A.B. (1989). The postnatal development of the motor speech area: A preliminary study. Brain and Language, 37, 42-58.

Singer, N., Bellugi, U., Bates, E., Rossen, M., \& Jones, W. (in press). Emerging language in two genetically based neurodevelopmental disorders. In D. Thal \& J. Reilly, (Eds.). Special issue on Origins of Communication Disorders. Developmental Neuropsychology.

Slobin, D. (Ed.). (1985). The crosslinguistic study of language acquisition (Vols. 1 \& 2). Hillsdale, NJ: Erlbaum.

Smith, A. (1984). Early and long-term recovery from brain damage in children and adults: Evolution of concepts of localization, plasticity, and recovery. In C. R. Almli \& S. Finger (Eds.), Early brain damage (pp. 299-324). New York: Academic Press.

Spelke, E., Breinlinger, K., Macomber, J., \& Jacobson, K. (1992). Origins of knowledge. Psychological Review, 99:4, 605-632.

St. James-Roberts, I. (1979). Neurological plasticity, recovery from brain insult, and child development. In H. W. Reese (Ed.), Advances in Child Development and Behavior. New York: Academic Press, 253-319..

Stiles, J. (1995). Plasticity and development: Evidence from children with early focal brain injury. In B. Julesz \& I. Kovacs (Eds.), Maturational windows and cortical plasticity in 
human development: Is there reason for an optimistic view? (pp. 217-237). Reading, MA: Addison-Wesley Publishing.

Stiles, J., \& Thal, D. (1993). Linguistic and spatial cognitive development following early focal brain injury: Patterns of deficit and recovery. In M. Johnson (Ed.), Brain development and cognition: A reader (pp.643-664). Oxford: Blackwell Publishers.

Sur, M., Garraghty, P.E., \& Roe, A.W. (1988). Experimentally induced visual projections into auditory thalamus and cortex. Science, 242, 1437-1441.

Sur, M., Pallas, S.L., and Roe, A.W. (1990). Cross-modal plasticity in cortical development: differentiation and specification of sensory neocortex. Trends in Neuroscience, 13, 227233.

Thal, D., Goodman, J., Bates, E., Jahn, J., \& Fenson, L. (in press). Early identification of risk for language delay. Developmental Neuropsychology.

Tallal, P., Sainburg, R.L., \& Jernigan, T. (1991). The neuropathology of developmental dysphasia: Behavioral, morphological, and physiological evidence for a pervasive temporal processing disorder. Reading and Writing, 3, 363-377.

Thal, D. J., Marchman, V. A., Stiles, J., Aram, D., Trauner, D., Nass, R., \& Bates, E. (1991). Early lexical development in children with focal brain injury. Brain and Language, 40(4), 491-527.

Trauner D., Chase, C., Walker, P., \& Wulfeck, B. (1993). Neurologic profiles of infants and children after perinatal stroke. Pediatric Neurology, 9(5), 383-386.

Vargha-Khadem, F, Isaacs, E.B., Papaleloudi, H., Polkey, C.E., \& Wilson, J. (1991). Development of language in 6 hemispherectomized patients. Brain, 114, 473-495.

Vargha-Khadem, F., Isaacs, E., Van der Werf, S., Robb, S., \& Wilson, J. (1992). Development of intelligence and memory in children with hemiplegic cerebral palsy: The deleterious consequences of early seizures. Brain, 115, 315-329.

Vargha-Khadem, F., O'Gorman, A., \& Watters, G. (1985). Aphasia and handedness in relation to hemispheric side, age at injury and severity of cerebral lesion during childhood. Brain, 108, 677 - 696. 
Vargha-Khadem, F., \& Polkey, C.E. (1992). A review of cognitive outcome after hemidecortication in humans. In F.D. Rose \& D.A. Johnson (Eds.), Recovery from brain damage: Advances in experimental medicine and biology: Vol. 325. Reflections and Directions (pp. 137-151). New York: Plenum Press.

Webster, M.J., Bachevalier, J., \& Ungerleider, L.G. (1995). Development and plasticity of visual memory circuits. In B. Julesz \& I. Kovacs (Eds.), Maturational windows and adult cortical plasticity. Proceedings of the Santa Fe Institute Studies in the Sciences of Complexity, Vol. 25. Reading, MA: Addison-Wesley.

Welsh, M.C., \& Pennington, B.F. (1988). Assessing frontal lobe functioning in children: Views from developmental psychology. Developmental Neuropsychology, 4, 199-230.

Wernicke, C. (1874). The symptom complex of aphasia: A psychological study on an anatomic basis. The Boston Colloquium for the Philosophy of Science: Proceedings of the the Colloquium 1966-68. Vol. IV.

Willmes, K., \& Poeck, K. (1993). To what extent can aphasic syndromes be localized? Brain, 116, 1527-1540.

Witelson, S., \& Kigar, D. (1988). Asymmetry in brain function follows asymmetry in anatomical form: Gross, microscopic, postmortem, and imaging studies. In F. Boller \& J. Grafman (Eds.), Handbook of neuropsychology (Vol. 1, pp. 111-142). Amsterdam: Elsevier.

Woods, B. (1980). The restricted effects of right-hemisphere lesions after age one: Wechsler test data. Neuropsychologia, 18(1), 65-70.

Woods, B., \& Carey, S. (1979). Language deficits after apparent clinical recovery from childhood aphasia. Annals of Neurology, 6, 405-409.

Woods, B., \& Teuber, H. (1978). Changing patterns of childhood aphasia. Annals of Neurology, 3, 272-280.

Wulfeck, B., Trauner, D., \& Tallal, P. (1991). Neurologic, cognitive and linguistic features of infants after focal brain injury. Pediatric Neurology, 7:4, 266-269. 
Table 1: Neurological information for individual subjects

\begin{tabular}{|c|c|c|c|c|c|c|c|c|}
\hline & & \multicolumn{6}{|c|}{ Neurological Variables } & Studies $^{2}$ \\
\hline $\begin{array}{l}\text { Subject } \\
\text { ID \# }\end{array}$ & Gender & Side & $\begin{array}{c}\text { Lobes } \\
\text { Involved } 1\end{array}$ & Subcortical & Hemiparesis & Hemivisual & $\begin{array}{l}\text { Siezure } \\
\text { History }\end{array}$ & \\
\hline 1. & $\mathrm{M}$ & $\mathrm{R}$ & $\mathrm{T}, \mathrm{P}, \mathrm{O}$ & $\mathrm{Y}$ & $\mathrm{n} / \mathrm{a}$ & $\mathrm{n} / \mathrm{a}$ & $\mathrm{n} / \mathrm{a}$ & 0,2 \\
\hline 2. & $\mathrm{M}$ & $\mathrm{L}$ & $\mathrm{F}$ & $\mathrm{Y}$ & $\mathrm{N}$ & $\mathrm{N}$ & $\mathrm{N}$ & 0,3 \\
\hline 3. & $\mathrm{~F}$ & $\mathrm{R}$ & $\mathrm{T}, \mathrm{P}, \mathrm{O}$ & $\mathrm{Y}$ & $\mathrm{Y}$ & $\mathrm{n} / \mathrm{a}$ & $\mathrm{N}$ & 2 \\
\hline 4. & $\mathrm{M}$ & $\mathrm{L}$ & $\mathrm{P}$ & $\mathrm{Y}$ & $\mathrm{n} / \mathrm{a}$ & $\mathrm{n} / \mathrm{a}$ & $\mathrm{N}$ & $1,2,3$ \\
\hline 5. & $\mathrm{M}$ & $\mathrm{R}$ & $\mathrm{P}$ & $\mathrm{Y}$ & $\mathrm{N}$ & $\mathrm{N}$ & $\mathrm{N}$ & $1,2,3$ \\
\hline 6. & $\mathrm{M}$ & $\mathrm{L}$ & $\mathrm{F}, \mathrm{T}, \mathrm{P}, \mathrm{O}$ & $\mathrm{Y}$ & $\mathrm{Y}$ & $\mathrm{N}$ & $\mathrm{N}$ & 2,3 \\
\hline 7. & $\mathrm{M}$ & $\mathrm{L}$ & $\mathrm{P}$ & $\mathrm{Y}$ & $\mathrm{Y}$ & $\mathrm{N}$ & $\mathrm{N}$ & 0,3 \\
\hline 8. & $\mathrm{M}$ & $\mathrm{L}$ & $\mathrm{P}$ & $\mathrm{n} / \mathrm{a}$ & $\mathrm{n} / \mathrm{a}$ & $\mathrm{n} / \mathrm{a}$ & $\mathrm{n} / \mathrm{a}$ & $0,1,3$ \\
\hline 9. & $\mathrm{M}$ & $\mathrm{R}$ & $\mathrm{F}, \mathrm{T}, \mathrm{P}, \mathrm{O}$ & $\mathrm{Y}$ & $\mathrm{Y}$ & $\mathrm{N}$ & $\mathrm{Y}$ & $0,1,2,3$ \\
\hline 10. & $\mathrm{M}$ & $\mathrm{R}$ & $\mathrm{F}$ & $\mathrm{Y}$ & $\mathrm{Y}$ & $\mathrm{N}$ & $\mathrm{N}$ & 0,3 \\
\hline 11. & $\mathrm{M}$ & $\mathrm{R}$ & $\mathrm{F}, \mathrm{T}, \mathrm{P}$ & $\mathrm{Y}$ & $\mathrm{n} / \mathrm{a}$ & $\mathrm{n} / \mathrm{a}$ & $\mathrm{n} / \mathrm{a}$ & 2 \\
\hline 12. & $\mathrm{M}$ & $\mathrm{L}$ & - & $\mathrm{Y}$ & $\mathrm{Y}$ & $\mathrm{n} / \mathrm{a}$ & $\mathrm{N}$ & 3 \\
\hline 13. & $\mathrm{~F}$ & $\mathrm{~L}$ & $\mathrm{~F}, \mathrm{~T}, \mathrm{P}, \mathrm{O}$ & $\mathrm{Y}$ & $\mathrm{Y}$ & $\mathrm{N}$ & $\mathrm{N}$ & 1 \\
\hline 14. & $\mathrm{M}$ & $\mathrm{L}$ & $\mathrm{P}, \mathrm{O}$ & $\mathrm{Y}$ & $\mathrm{N}$ & $\mathrm{N}$ & $\mathrm{N}$ & $1,2,3$ \\
\hline 15. & $\mathrm{M}$ & $\mathrm{L}$ & $\mathrm{F}, \mathrm{T}$ & $\mathrm{Y}$ & $\mathrm{N}$ & $\mathrm{N}$ & $\mathrm{N}$ & 3,4 \\
\hline 16. & $\mathrm{M}$ & $\mathrm{L}$ & $\mathrm{F}, \mathrm{T}, \mathrm{P}, \mathrm{O}$ & $\mathrm{Y}$ & $\mathrm{N}$ & $\mathrm{Y}$ & $\mathrm{N}$ & 2,3 \\
\hline 17. & $\mathrm{M}$ & $\mathrm{L}$ & $\mathrm{T}, \mathrm{P}$ & $Y$ & $\mathrm{~N}$ & $Y$ & $\mathrm{~N}$ & $1,2,3$ \\
\hline 18. & $\mathrm{M}$ & $\mathrm{L}$ & $\mathrm{T}, \mathrm{O}$ & $\mathrm{Y}$ & $\mathrm{N}$ & $\mathrm{N}$ & $\mathrm{N}$ & 1 \\
\hline 19. & $\mathrm{M}$ & $\mathrm{L}$ & T,P & $\mathrm{Y}$ & $\mathrm{n} / \mathrm{a}$ & $\mathrm{n} / \mathrm{a}$ & $\mathrm{n} / \mathrm{a}$ & 0,2 \\
\hline 20. & $\mathrm{M}$ & $\mathrm{L}$ & $F$ & $Y$ & $\mathrm{Y}$ & $\mathrm{N}$ & $\mathrm{N}$ & 3 \\
\hline 21. & $\mathrm{M}$ & $\mathrm{R}$ & $\mathrm{F}, \mathrm{T}, \mathrm{P}, \mathrm{O}$ & $\mathrm{Y}$ & $\mathrm{Y}$ & $\mathrm{N}$ & $\mathrm{N}$ & 1,2 \\
\hline 22. & $\mathrm{M}$ & $\mathrm{L}$ & $\mathrm{T}, \mathrm{P}, \mathrm{O}$ & $\mathrm{Y}$ & $\mathrm{n} / \mathrm{a}$ & $\mathrm{n} / \mathrm{a}$ & $\mathrm{n} / \mathrm{a}$ & 1,2 \\
\hline 23. & $\mathrm{M}$ & $\mathrm{L}$ & $\mathrm{T}$ & $\mathrm{Y}$ & $\mathrm{Y}$ & $\mathrm{Y}$ & $\mathrm{N}$ & 3 \\
\hline 24. & $\mathrm{~F}$ & $\mathrm{~L}$ & $\mathrm{P}$ & $\mathrm{N}$ & $\mathrm{n} / \mathrm{a}$ & $\mathrm{n} / \mathrm{a}$ & $\mathrm{n} / \mathrm{a}$ & $0,1,2$ \\
\hline 25. & $\mathrm{M}$ & $\mathrm{R}$ & $\mathrm{P}, \mathrm{O}$ & $\mathrm{Y}$ & $\mathrm{Y}$ & $\mathrm{n} / \mathrm{a}$ & $\mathrm{Y}$ & 1 \\
\hline 26. & $\mathrm{M}$ & $\mathrm{L}$ & $\mathrm{T}, \mathrm{P}, \mathrm{O}$ & $\mathrm{n} / \mathrm{a}$ & $\mathrm{Y}$ & $\mathrm{n} / \mathrm{a}$ & $Y$ & $0,1,3$ \\
\hline 27. & $\mathrm{M}$ & $\mathrm{R}$ & $\mathrm{F}, \mathrm{T}$ & $\mathrm{Y}$ & $\mathrm{n} / \mathrm{a}$ & $\mathrm{n} / \mathrm{a}$ & $\mathrm{Y}$ & 2,3 \\
\hline 28. & $\mathrm{~F}$ & $\mathrm{~L}$ & $\mathrm{~T}, \mathrm{P}, \mathrm{O}$ & $Y$ & $\mathrm{n} / \mathrm{a}$ & $\mathrm{n} / \mathrm{a}$ & $\mathrm{n} / \mathrm{a}$ & 0,2 \\
\hline
\end{tabular}

${ }^{1} \mathrm{~F}=$ Frontal; $\mathrm{T}=$ Temporal $\mathrm{P}=$ Parietal $\mathrm{O}=$ Occipital

2 Study $0=$ Thal et.al., 1991. 


\begin{tabular}{|c|c|c|c|c|c|c|c|c|}
\hline \multirow[b]{2}{*}{$\begin{array}{c}\text { Subject } \\
\text { ID \# }\end{array}$} & \multirow[b]{2}{*}{ Gender } & \multicolumn{6}{|c|}{ Neurological Variables } & \multirow[t]{2}{*}{ Studies $^{2}$} \\
\hline & & Side & $\begin{array}{c}\text { Lobes } \\
\text { Involved } 1\end{array}$ & Subcortical & Hemiparesis & Hemivisual & $\begin{array}{l}\text { Siezure } \\
\text { History }\end{array}$ & \\
\hline 29. & $\mathrm{M}$ & $\mathrm{R}$ & $\mathrm{F}, \mathrm{T}, \mathrm{P}, \mathrm{O}$ & $\mathrm{N}$ & $\mathrm{Y}$ & $\mathrm{N}$ & $\mathrm{N}$ & 1 \\
\hline 30. & $\mathrm{M}$ & $\mathrm{L}$ & $\mathrm{F}, \mathrm{T}, \mathrm{P}$ & $\mathrm{Y}$ & $\mathrm{Y}$ & $\mathrm{N}$ & $\mathrm{N}$ & 0,3 \\
\hline 31. & $\mathrm{M}$ & $\mathrm{L}$ & $\mathrm{F}, \mathrm{T}, \mathrm{P}$ & $\mathrm{N}$ & $\mathrm{Y}$ & $\mathrm{Y}$ & $\mathrm{N}$ & 0,3 \\
\hline 32. & $\mathrm{~F}$ & $\mathrm{~L}$ & $\mathrm{~F}, \mathrm{~T}, \mathrm{P}, \mathrm{O}$ & $\mathrm{Y}$ & $\mathrm{Y}$ & $\mathrm{n} / \mathrm{a}$ & $\mathrm{N}$ & 2,3 \\
\hline 33. & $\mathrm{M}$ & $\mathrm{L}$ & $\mathrm{F}, \mathrm{T}, \mathrm{P}$ & $\mathrm{Y}$ & $\mathrm{N}$ & $\mathrm{N}$ & $\mathrm{N}$ & 0,3 \\
\hline 34. & $\mathrm{~F}$ & $\mathrm{R}$ & $\mathrm{T}, \mathrm{P}$ & $\mathrm{Y}$ & $\mathrm{Y}$ & $\mathrm{N}$ & $\mathrm{N}$ & 2,3 \\
\hline 35. & $\mathrm{~F}$ & $\mathrm{~L}$ & - & $\mathrm{Y}$ & $\mathrm{Y}$ & $\mathrm{n} / \mathrm{a}$ & $\mathrm{N}$ & 1 \\
\hline 36. & $\mathrm{~F}$ & $\mathrm{~L}$ & - & $\mathrm{Y}$ & $\mathrm{Y}$ & $\mathrm{Y}$ & $\mathrm{N}$ & 2,3 \\
\hline 37. & $\mathrm{~F}$ & $\mathrm{~L}$ & $\mathrm{P}$ & $\mathrm{Y}$ & $\mathrm{Y}$ & $\mathrm{n} / \mathrm{a}$ & $\mathrm{N}$ & $0,1,2$ \\
\hline 38. & $\mathrm{M}$ & $\mathrm{L}$ & $\mathrm{F}, \mathrm{T}, \mathrm{P}$ & $\mathrm{Y}$ & $\mathrm{Y}$ & $\mathrm{n} / \mathrm{a}$ & $\mathrm{N}$ & 1,3 \\
\hline 39. & $\mathrm{M}$ & $\mathrm{L}$ & $\mathrm{F}$ & $\mathrm{Y}$ & $\mathrm{Y}$ & $\mathrm{N}$ & $\mathrm{N}$ & 3 \\
\hline 40. & $\mathrm{M}$ & $\mathrm{R}$ & - & $\mathrm{Y}$ & $\mathrm{Y}$ & $\mathrm{n} / \mathrm{a}$ & $\mathrm{N}$ & 1 \\
\hline 41. & $M$ & $\mathrm{~L}$ & $\mathrm{~T}, \mathrm{P}$ & $\mathrm{Y}$ & $\mathrm{n} / \mathrm{a}$ & $\mathrm{n} / \mathrm{a}$ & $\mathrm{n} / \mathrm{a}$ & $0,1,2$ \\
\hline 42. & $\mathrm{~F}$ & $\mathrm{R}$ & $\mathrm{P}$ & $\mathrm{N}$ & $\mathrm{n} / \mathrm{a}$ & $\mathrm{n} / \mathrm{a}$ & $\mathrm{n} / \mathrm{a}$ & $0,1,2$ \\
\hline 43. & $\mathrm{M}$ & $\mathrm{L}$ & $\mathrm{P}$ & $\mathrm{Y}$ & $\mathrm{n} / \mathrm{a}$ & $\mathrm{n} / \mathrm{a}$ & $\mathrm{n} / \mathrm{a}$ & 1,2 \\
\hline 44. & $\mathrm{~F}$ & $\mathrm{~L}$ & $\mathrm{~F}, \mathrm{~T}, \mathrm{P}, \mathrm{O}$ & $\mathrm{Y}$ & $\mathrm{Y}$ & $\mathrm{N}$ & $\mathrm{N}$ & 0,3 \\
\hline 45. & $\mathrm{M}$ & $\mathrm{R}$ & $\mathrm{P}$ & $\mathrm{N}$ & $\mathrm{n} / \mathrm{a}$ & $\mathrm{n} / \mathrm{a}$ & $\mathrm{n} / \mathrm{a}$ & 1 \\
\hline 46. & $\mathrm{~F}$ & $\mathrm{~L}$ & $\mathrm{~F}$ & $\mathrm{Y}$ & $\mathrm{N}$ & $\mathrm{N}$ & $\mathrm{Y}$ & 0,3 \\
\hline 47. & $\mathrm{M}$ & $\mathrm{R}$ & $\mathrm{P}$ & $\mathrm{Y}$ & $\mathrm{N}$ & $\mathrm{n} / \mathrm{a}$ & $\mathrm{Y}$ & $1,2,3$ \\
\hline 48. & $\mathrm{~F}$ & $\mathrm{~L}$ & $\mathrm{~F}, \mathrm{~T}, \mathrm{P}, \mathrm{O}$ & $\mathrm{Y}$ & $\mathrm{Y}$ & $\mathrm{n} / \mathrm{a}$ & $\mathrm{Y}$ & 3 \\
\hline 49. & $\mathrm{~F}$ & $\mathrm{~L}$ & - & $\mathrm{Y}$ & $\mathrm{n} / \mathrm{a}$ & $\mathrm{n} / \mathrm{a}$ & $\mathrm{n} / \mathrm{a}$ & 1 \\
\hline 50. & $\mathrm{~F}$ & $\mathrm{R}$ & $\mathrm{F}, \mathrm{T}, \mathrm{P}$ & $\mathrm{Y}$ & $\mathrm{n} / \mathrm{a}$ & $\mathrm{n} / \mathrm{a}$ & $\mathrm{n} / \mathrm{a}$ & 2 \\
\hline 51. & $M$ & $\mathrm{~L}$ & $\mathrm{~T}$ & $\mathrm{~N}$ & $\mathrm{n} / \mathrm{a}$ & $\mathrm{n} / \mathrm{a}$ & $\mathrm{n} / \mathrm{a}$ & 1,2 \\
\hline 52. & $\mathrm{~F}$ & $\mathrm{~L}$ & $\mathrm{~F}$ & $\mathrm{~N}$ & $\mathrm{~N}$ & $\mathrm{n} / \mathrm{a}$ & $\mathrm{Y}$ & 2,3 \\
\hline 53. & $\mathrm{~F}$ & $\mathrm{R}$ & $\mathrm{F}, \mathrm{T}, \mathrm{P}, \mathrm{O}$ & $\mathrm{Y}$ & $\mathrm{Y}$ & $\mathrm{n} / \mathrm{a}$ & $\mathrm{Y}$ & 1,2 \\
\hline
\end{tabular}

${ }^{1} \mathrm{~F}=$ Frontal; $\mathrm{T}=$ Temporal $; \mathrm{P}=$ Parietal $; \mathrm{O}=$ Occipital

2 Study $0=$ Thal et.al., 1991. 
Table 2: Summary of Neurological Findings

\begin{tabular}{|c|c|c|c|c|c|}
\hline & $\begin{array}{l}\text { + Left } \\
\text { Lesion }\end{array}$ & $\begin{array}{l}\text { + Right } \\
\text { Lesion }\end{array}$ & $\begin{array}{l}+ \text { Left } \\
\text { Temporal } \\
\text { Lesion }\end{array}$ & $\begin{array}{l}+ \text { Left } \\
\text { Frontal } \\
\text { Lesion }\end{array}$ & $\begin{array}{l}\text { + Right } \\
\text { Frontal } \\
\text { Lesion }\end{array}$ \\
\hline \multicolumn{6}{|l|}{ Study 1: $10-17$ months } \\
\hline - Gesture & - & $\downarrow \downarrow$ & - & - & - \\
\hline - Word Comprehension & 二 & $\downarrow$ & 二 & 二 & 二 \\
\hline - Word Production & $\downarrow$ & - & - & - & - \\
\hline $\begin{array}{l}\text { - \% of Comprehended } \\
\text { Words that are Produced }\end{array}$ & - & - & $\downarrow \downarrow$ & - & - \\
\hline \multicolumn{6}{|l|}{ Study 2: 19-31 months } \\
\hline - Vocabulary & $\downarrow$ & - & $\downarrow \downarrow$ & $\downarrow \downarrow$ & $\downarrow \downarrow$ \\
\hline - Grammar & $\downarrow$ & $\downarrow$ & $\downarrow \downarrow$ & $\downarrow \downarrow$ & $\downarrow \downarrow$ \\
\hline _ "Closed Class Style" & 二 & 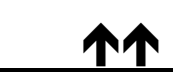 & n.a. & n.a. & n.a. \\
\hline \multicolumn{6}{|l|}{ Study 3: $19-44$ months } \\
\hline $\begin{array}{l}\text { - Mean Length of } \\
\text { Utterance in Morphemes }\end{array}$ & $\downarrow$ & - & $\downarrow \downarrow$ & - & - \\
\hline
\end{tabular}

$\uparrow$ weak advantage

$\downarrow \quad$ weak disadvantage
ヘヤ strong advantage

$\downarrow \downarrow$ strong disadvantage n.a. = not applicable 


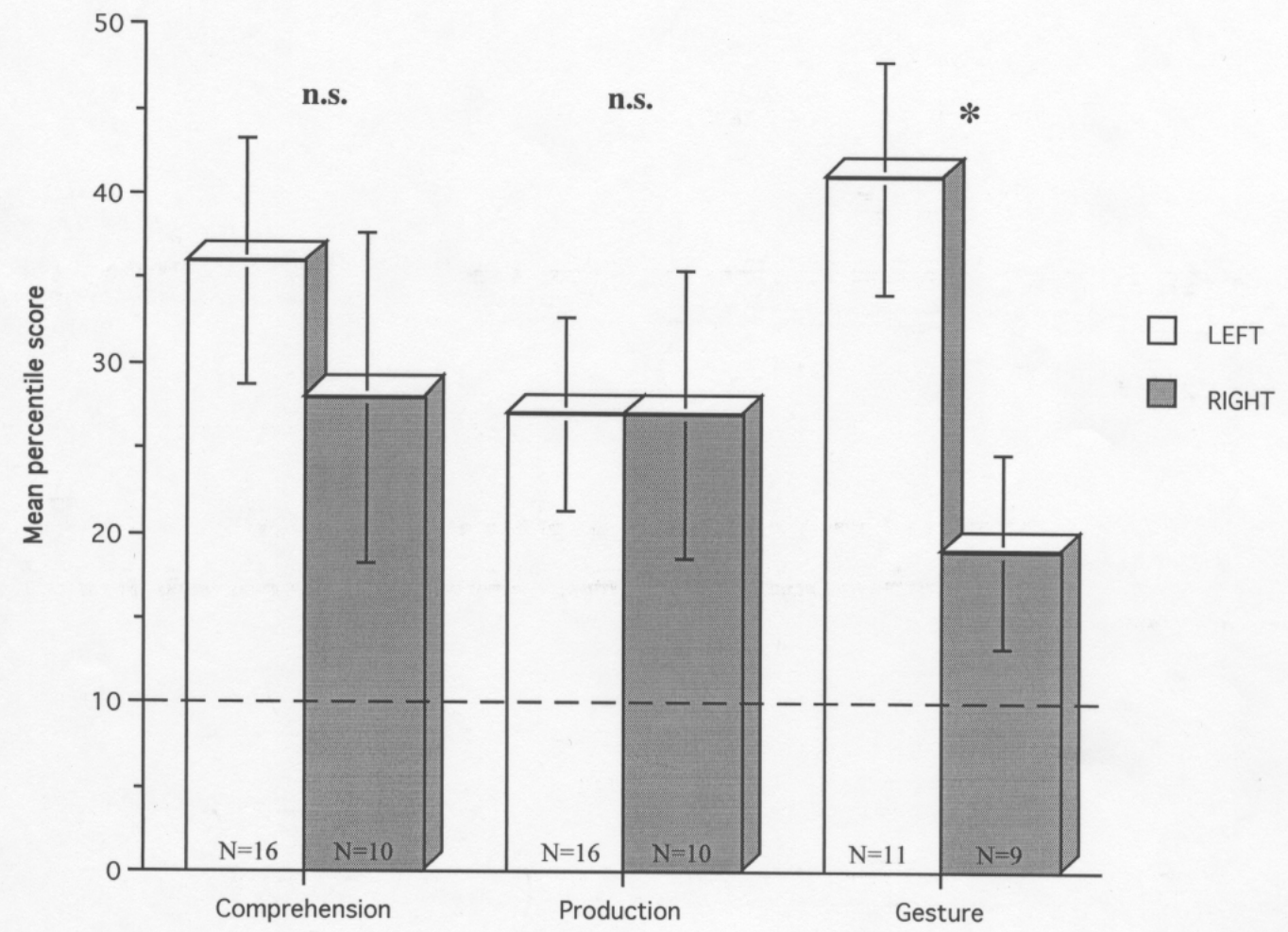

Figure 1a: Mean percentile scores for word comprehension, word production $\&$ gesture as a function of left- vs. right-hemisphere damage

$$
\begin{aligned}
*= & \text { group difference is } \\
& \text { significant at } p<.05 \\
\text { n.s. = } & \text { group difference } \\
& \text { not significant }
\end{aligned}
$$




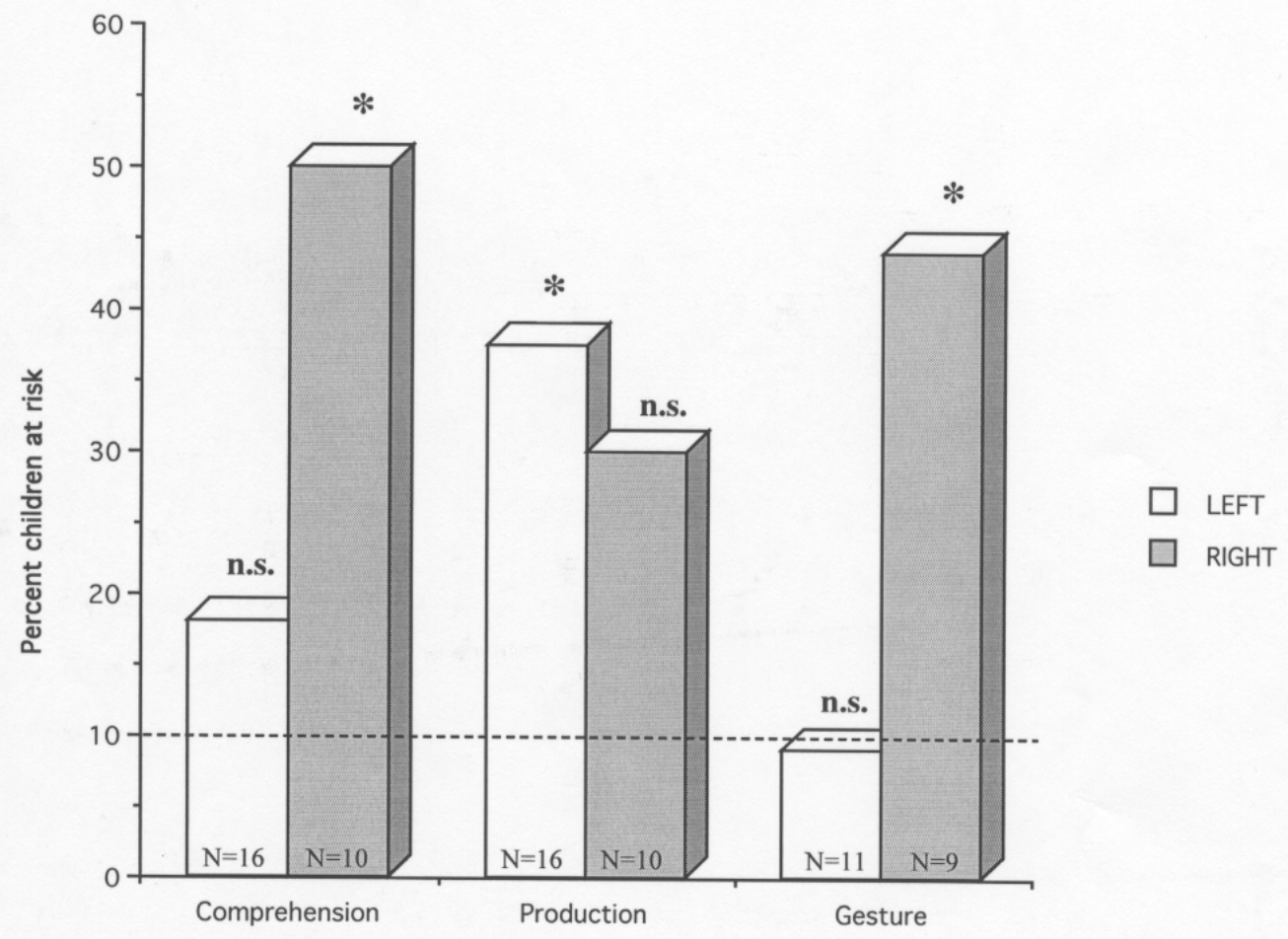

Figure 1b: Percent children in the "risk range" as a function of left vs. right hemisphere damage

$\begin{aligned} *= & \text { more children in the bottom } \\ & \text { 10th percentile than chance }(\mathrm{p}<.05)\end{aligned}$

n.s. $=$ no more children in the bottom 10th percentile than chance 


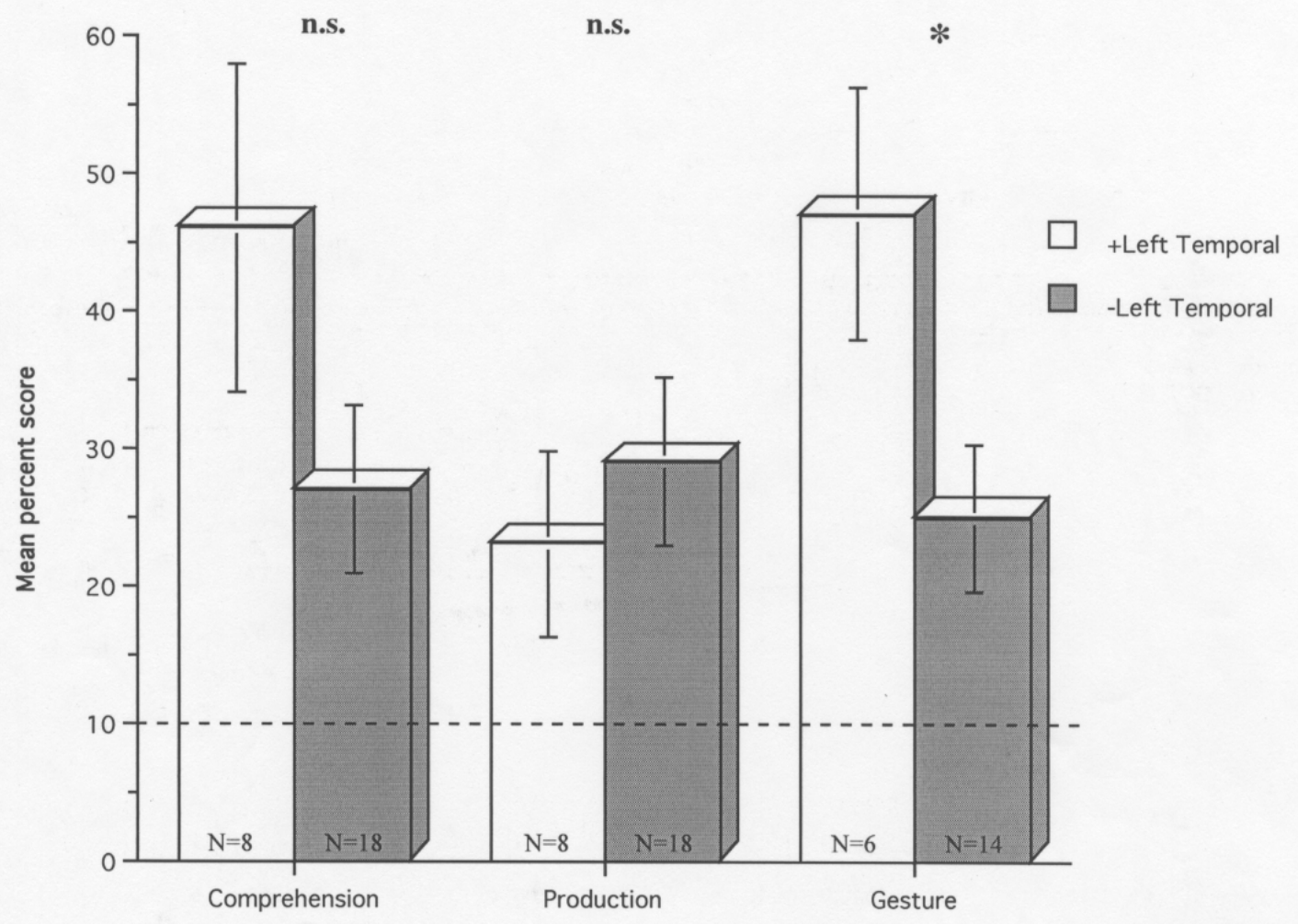

Figure 1c: Word comprehension, word production \& gesture as a function of presence/absence of left temporal damage

* = group difference is significant at $\mathrm{p}<.05$

n.s. = group difference not significant 


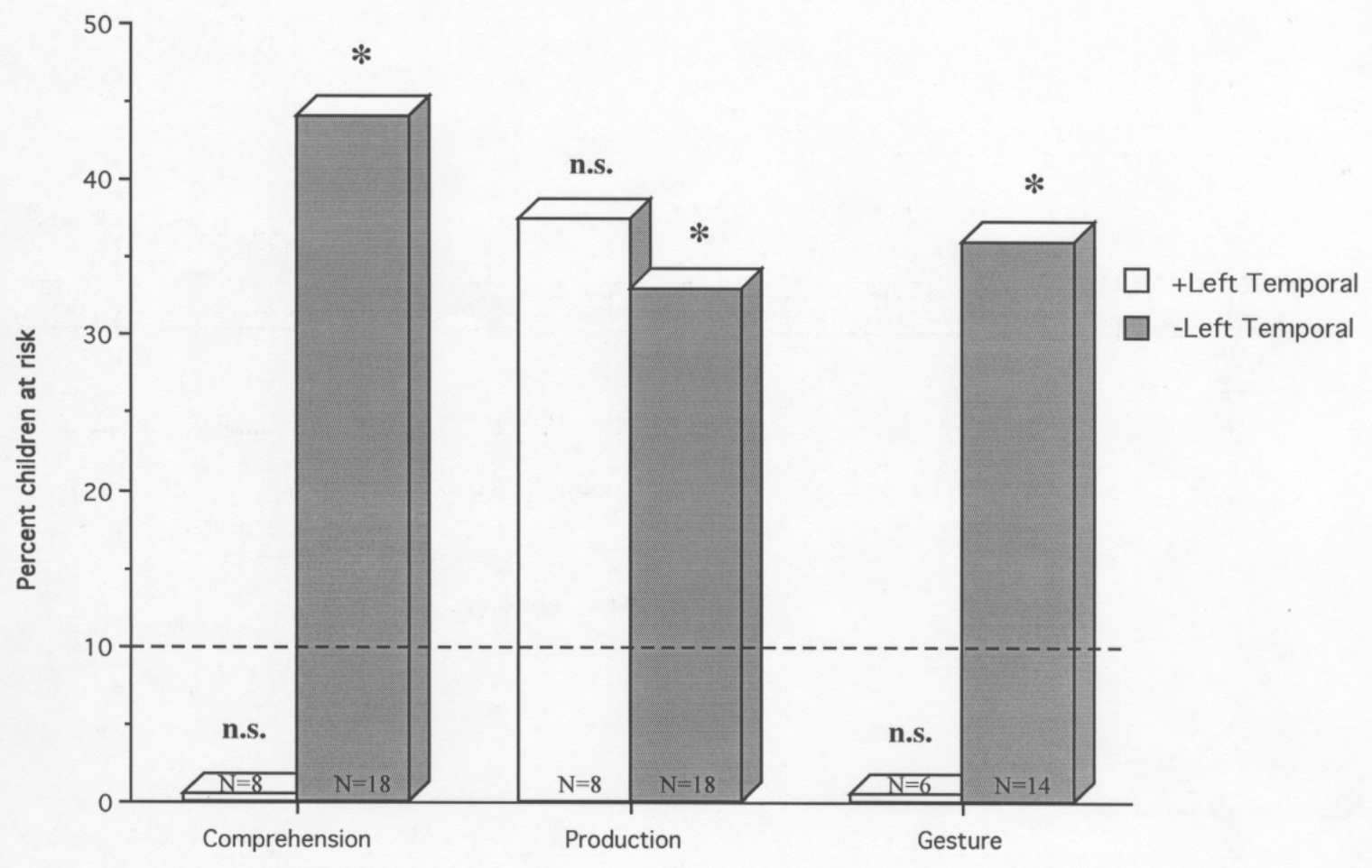

Figure 1d: Percent children in the "risk range" for word comprehension, production \& gesture

$$
\begin{aligned}
*= & \text { group difference } \\
& \text { is significant at } p<.05 \\
\text { n.s. = } & \text { group difference } \\
& \text { not significant }
\end{aligned}
$$




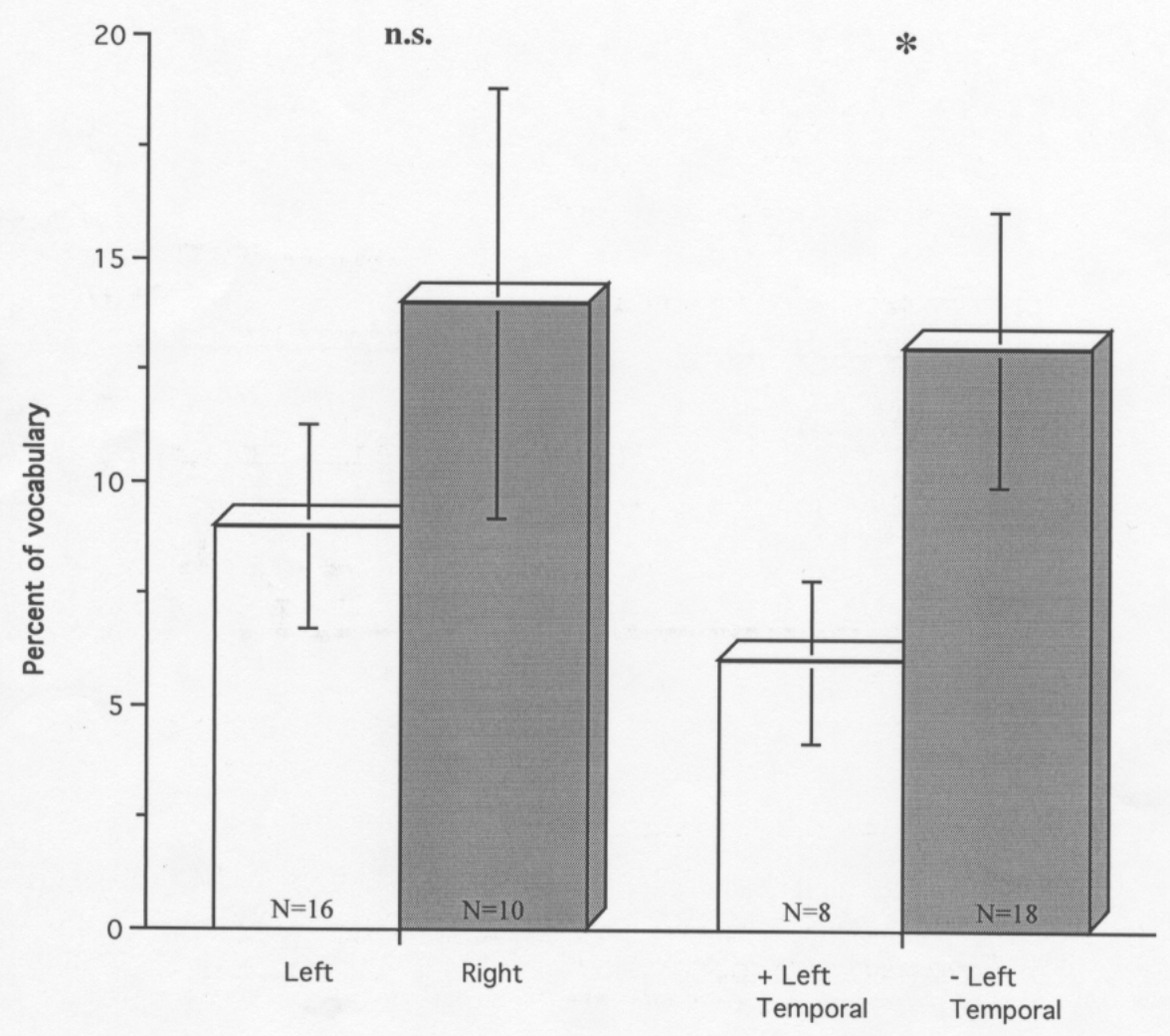

Figure 1e: Percent of receptive vocabulary that is expressed in speech

$$
\begin{aligned}
*= & \text { group difference is } \\
& \text { significant at } \mathrm{p}<.05 \\
\text { n.s. = } & \text { group difference } \\
& \text { not significant }
\end{aligned}
$$




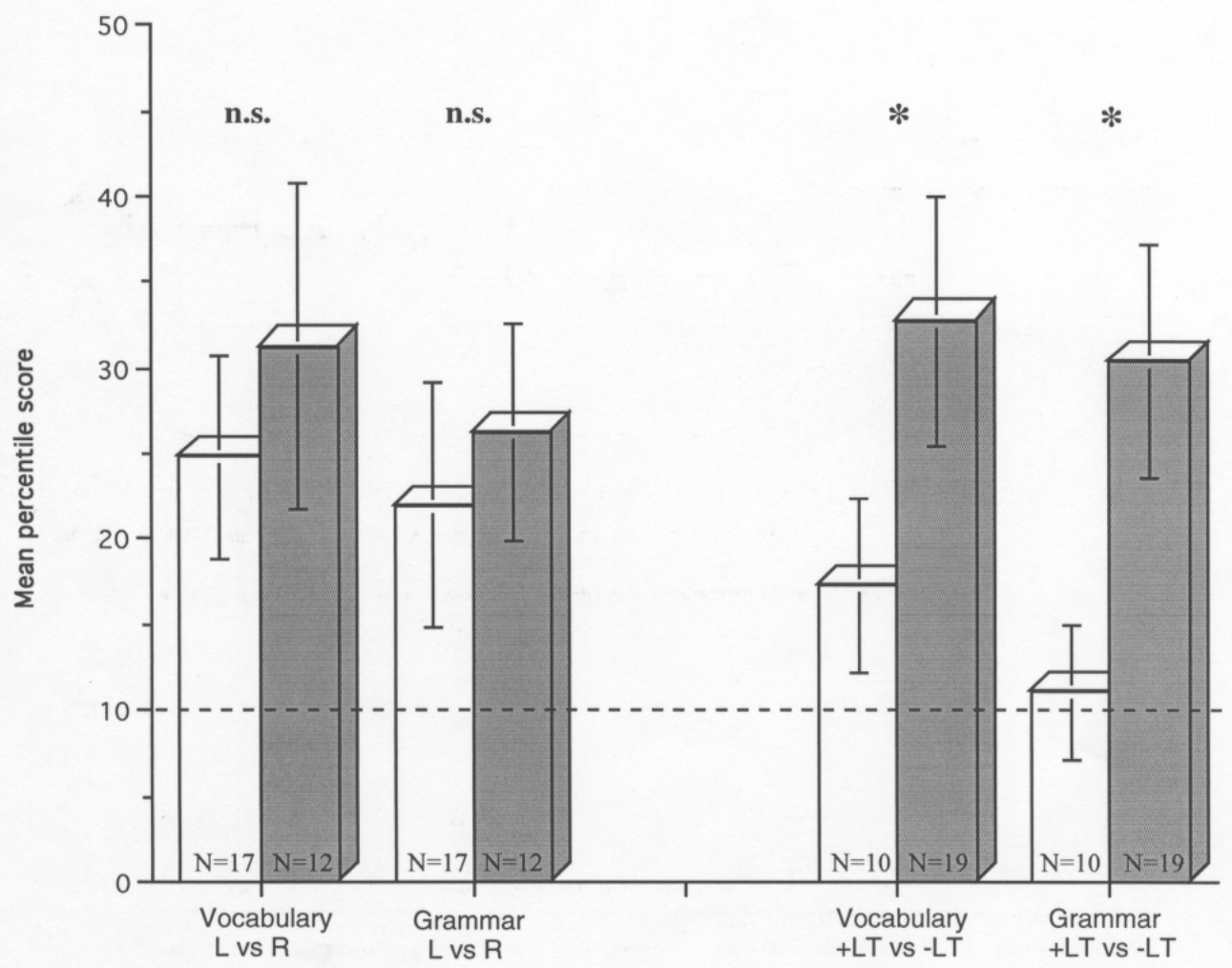

Figure 2a: Vocabulary and grammar as a function of left vs. right hemisphere and presence/absence of left temporal damage

$$
\begin{aligned}
*= & \text { group difference is } \\
& \text { significant at } p<.05 \\
\text { n.s. = } & \text { group difference } \\
& \text { not significant }
\end{aligned}
$$




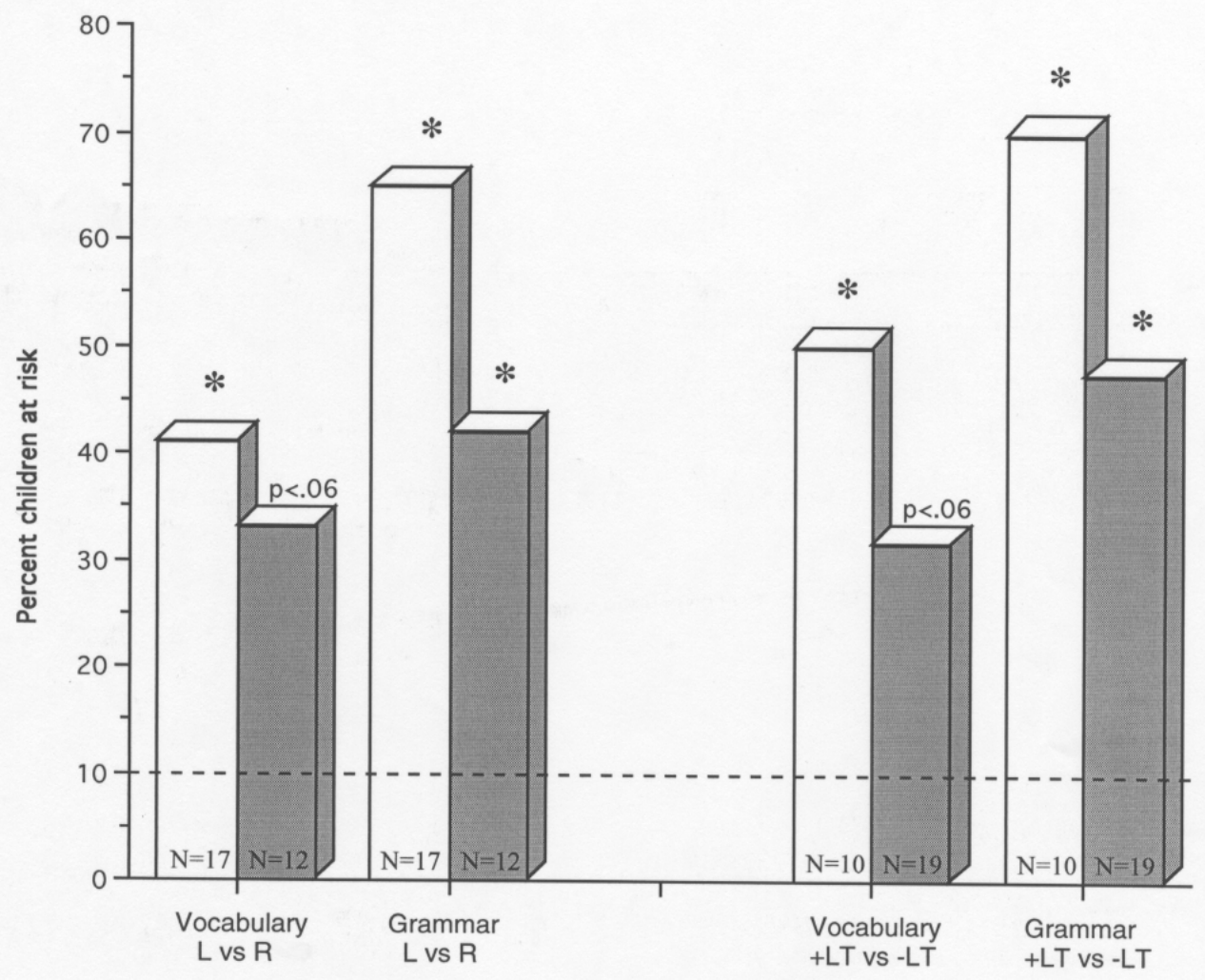

Figure 2b: Percent children in the "risk range" for vocabulary and grammar as a function of left vs. right hemisphere damage and presence/absence of left temporal damage

* = more children in the bottom 10th percentile than chance $(\mathrm{p}<.05)$

n.s. $=$ no more children in the bottom 10 th percentile than chance 


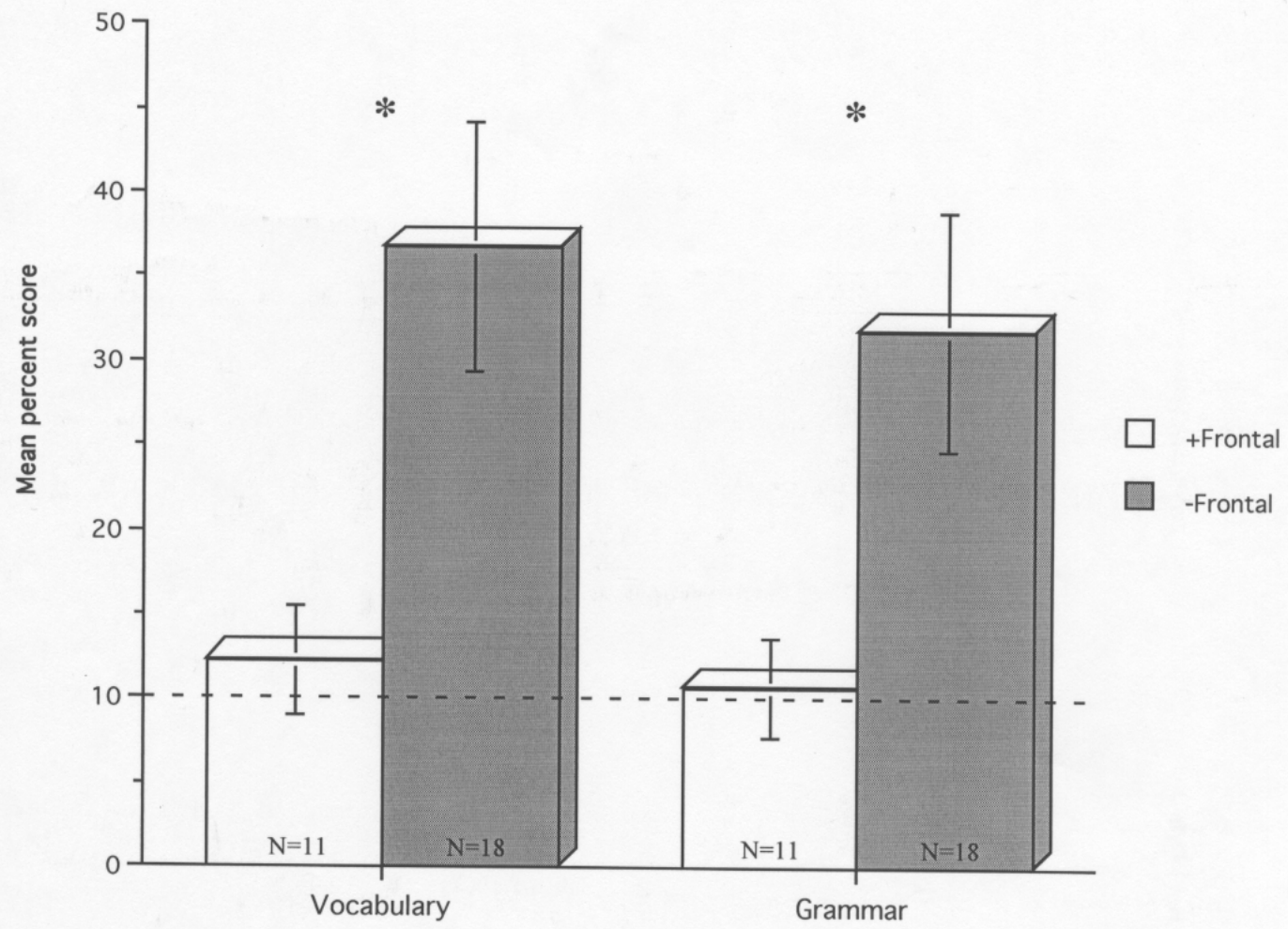

Figure 2c: Mean percentile score for vocabulary $\&$ grammar as a function of frontal damage to either hemisphere

* = difference is significant at $\mathrm{p}<.05$ 


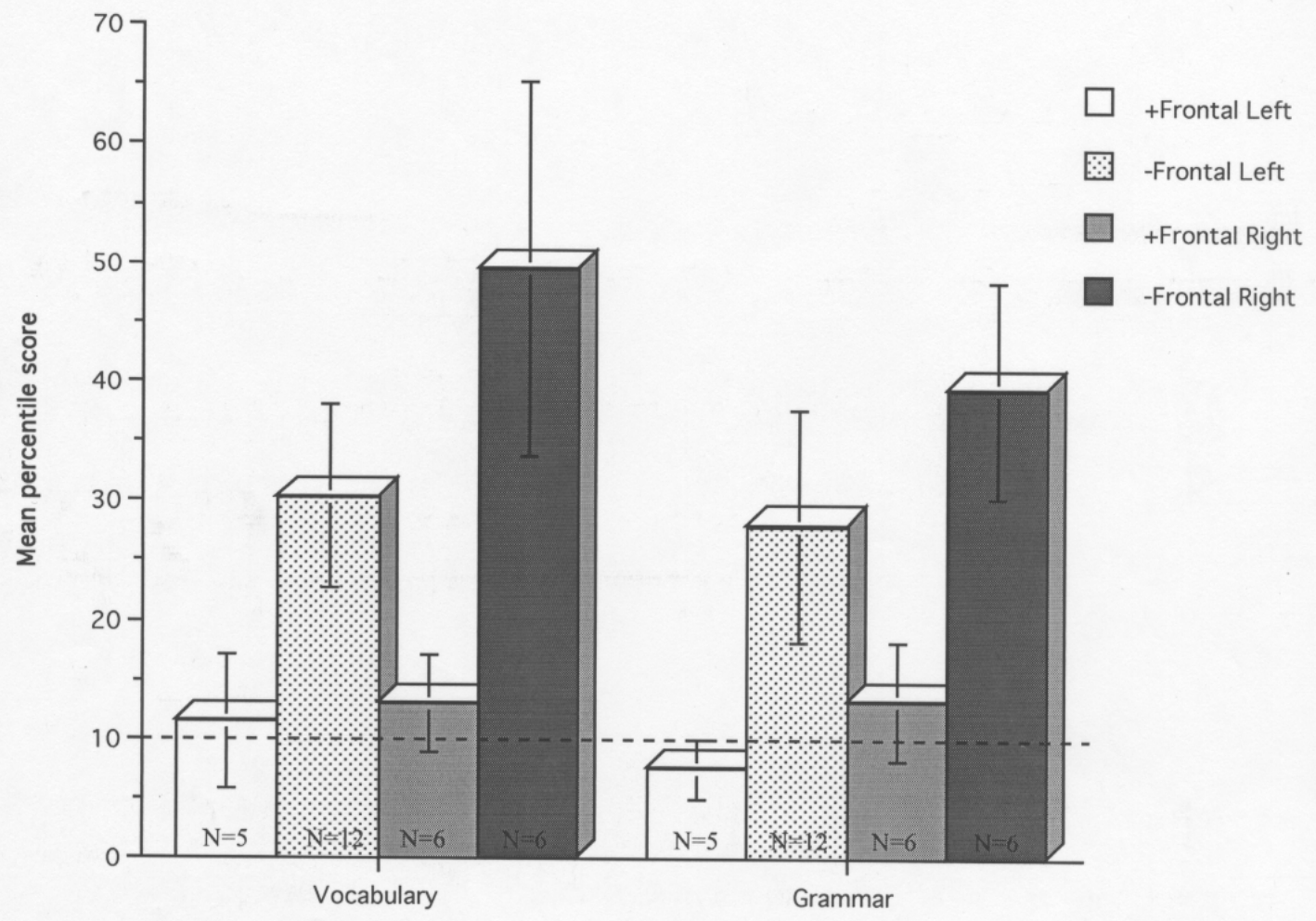

Figure 2d: Effects on frontal lesions on vocabulary and grammar with each hemisphere 


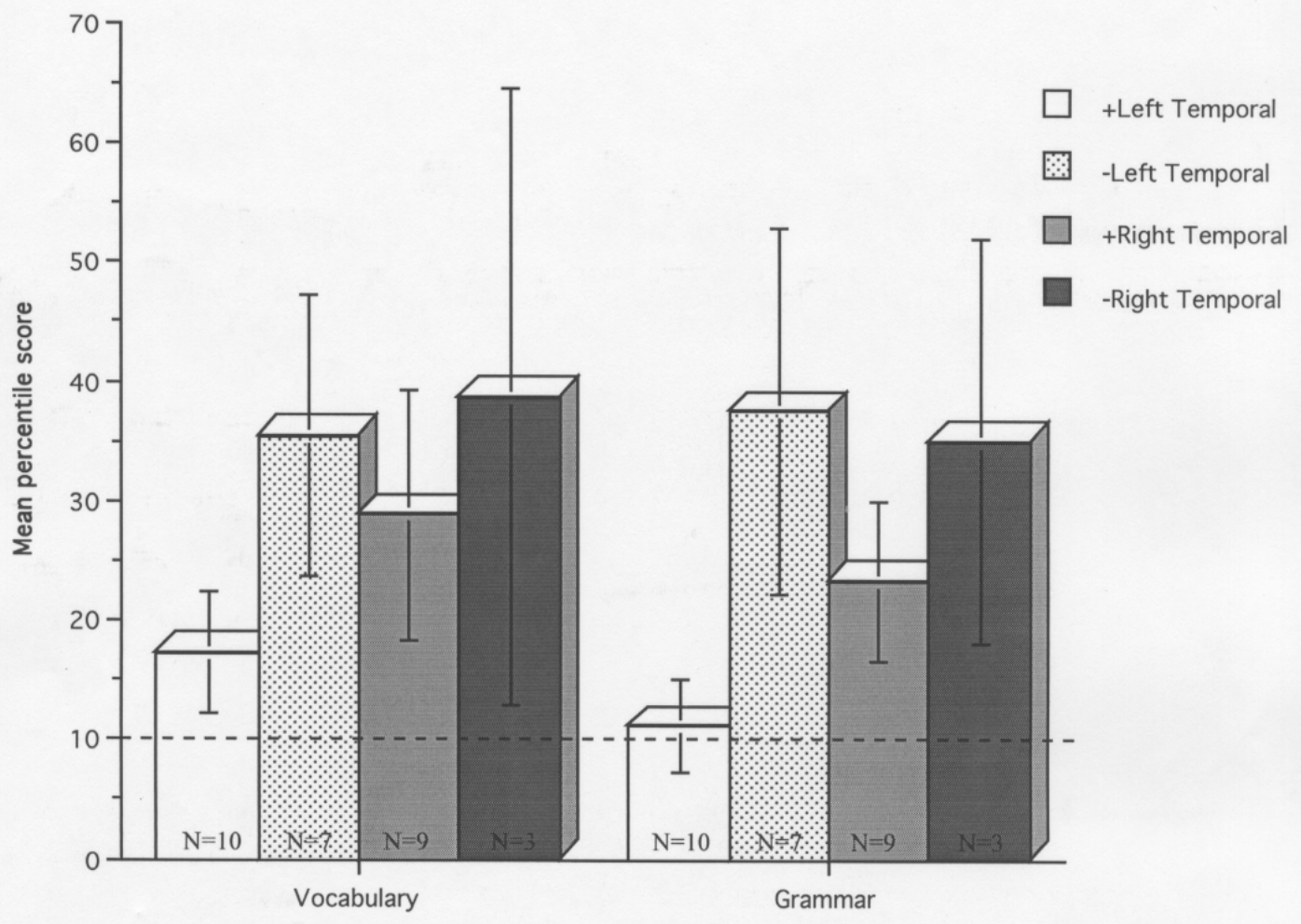

Figure 2e: Effect of temporal lesions on vocabulary and grammatical development in infants with left vs. right hemisphere lesions 


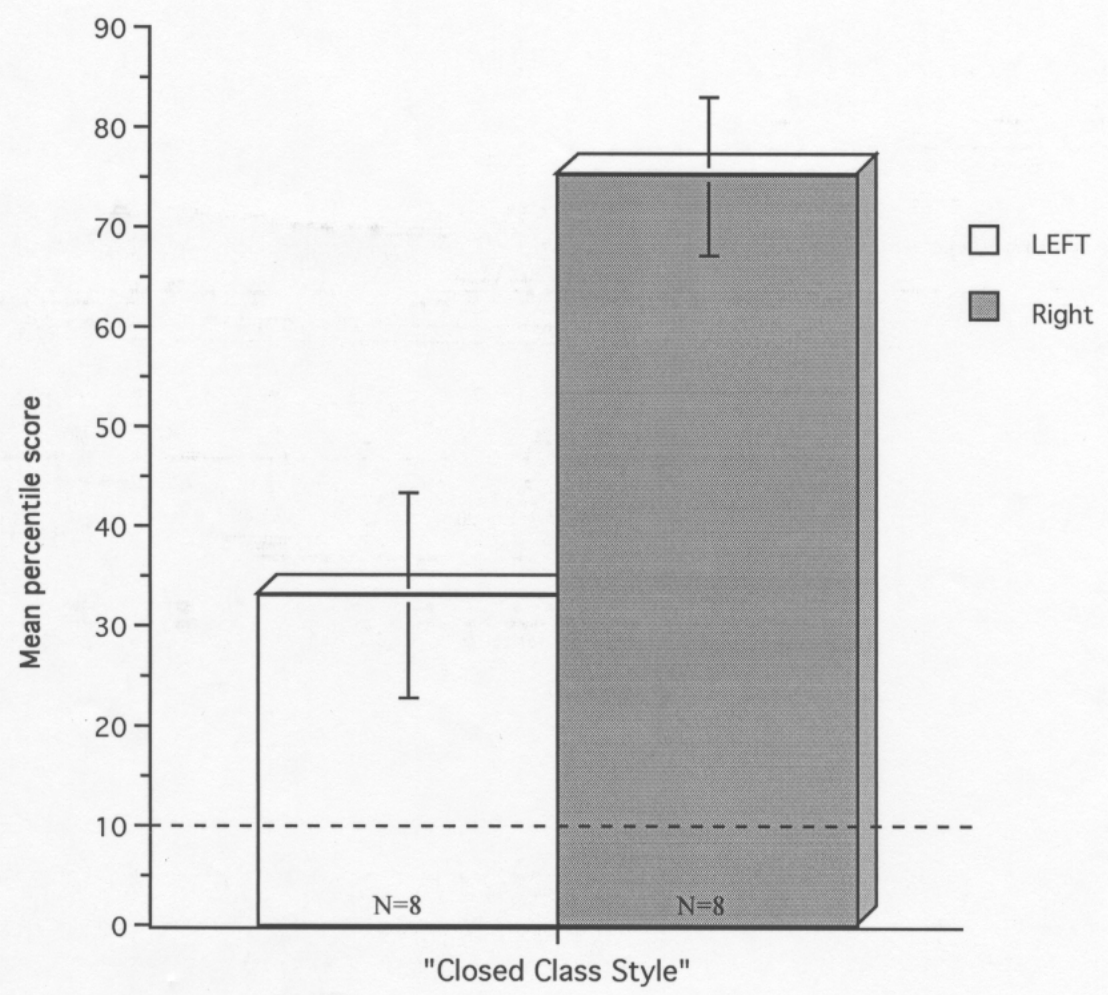

Figure 2f: "Closed-class style" as a function of left vs. right hemisphere injury

$*$ group difference is
significant at $p<.05$

n.s. $=$ group difference not significant 


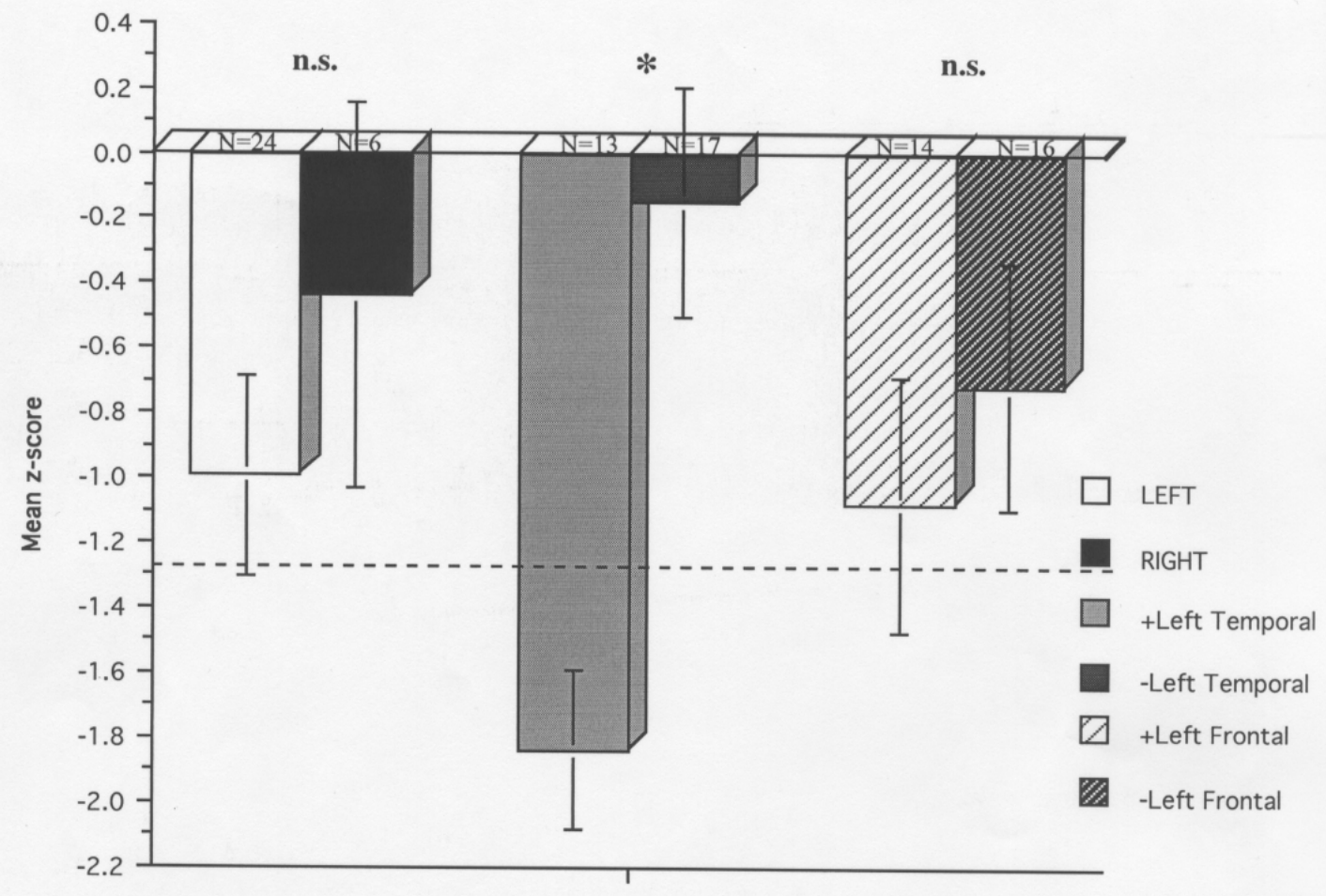

Figure 3a: MLU z-scores as a function of lesion side and lesion type

$$
\begin{aligned}
* & \text { group difference is } \\
& \text { significant at } p<.05 \\
\text { n.s. = } & \text { group difference } \\
& \text { not significant }
\end{aligned}
$$




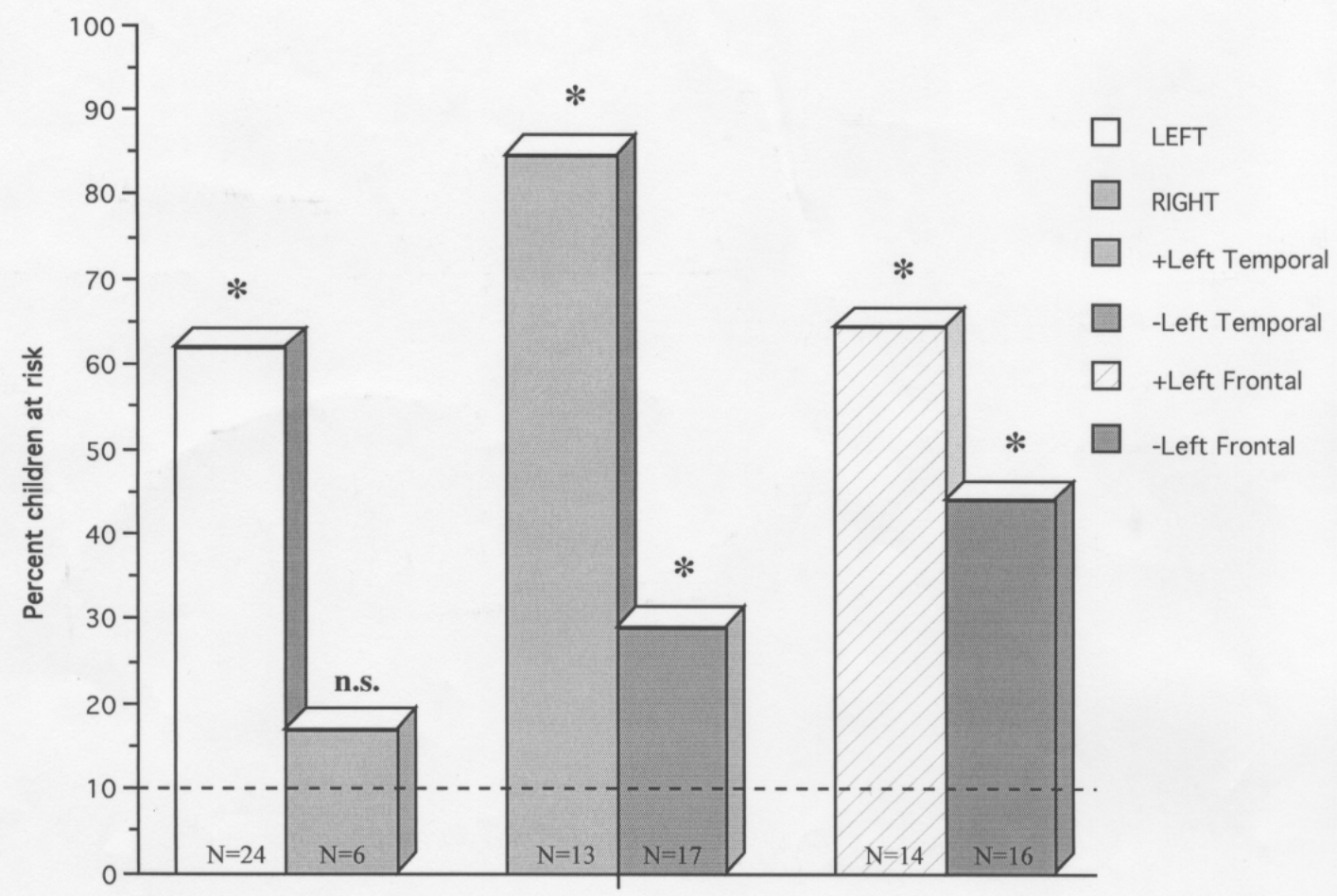

Figure 3b: Percent children in the "risk range" for MLU as a function of lesion size and lesion type

$$
\begin{aligned}
*= & \text { group difference is } \\
& \text { significant at } p<.05 \\
\text { n.s. = } & \text { group difference } \\
& \text { not significant }
\end{aligned}
$$

